\title{
PASSARELA PÊNSIL PROTENDIDA FORMADA POR ELEMENTOS PRÉ-MOLDADOS DE CONCRETO
}

LUCIANO MALDONADO FERREIRA

Dissertação apresentada à Escola de Engenharia de São Carlos da Universidade de São Paulo, como parte dos requisitos para obtenção do título de Mestre em Engenharia de Estruturas

ORIENTADOR: Prof. Roberto Luiz de Arruda Barbato

São Carlos

2001 


\section{Agradecimentos}

Ao Professor Roberto Luiz de Arruda Barbato, pela orientação, pelos ensinamentos e sobretudo pela sincera amizade.

A todos os professores do Departamento de Engenharia de Estruturas, em especial a Mounir Khalil El Debs e a Humberto Breves Coda.

Aos funcionários do Departamento de Engenharia de Estruturas, em particular à Maria Nadir Minatel.

À CAPES, pela bolsa de mestrado concedida.

A todos os amigos com quem convivi durante o mestrado.

À minha família. 
Sumário

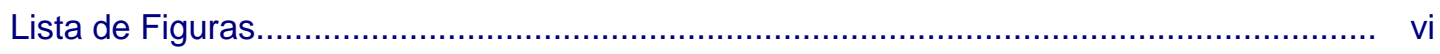

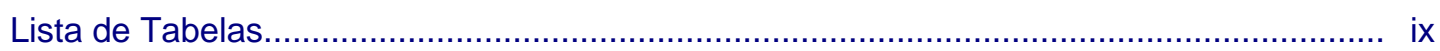

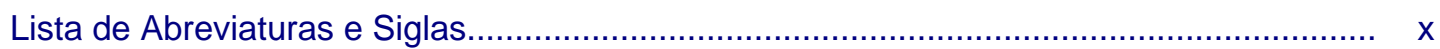

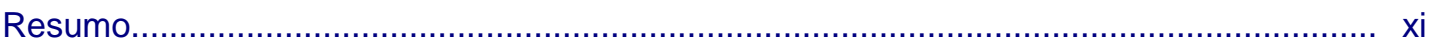

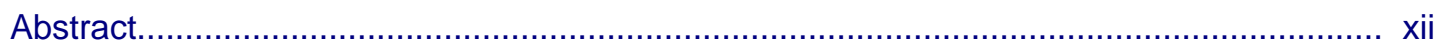

1. INTRODUÇÃO_................................................................................................

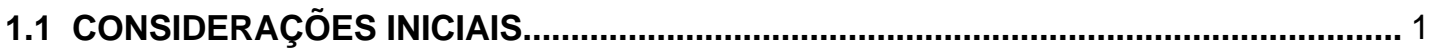

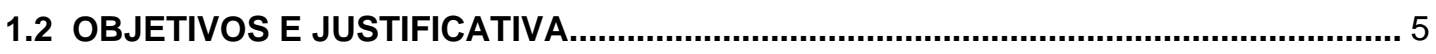

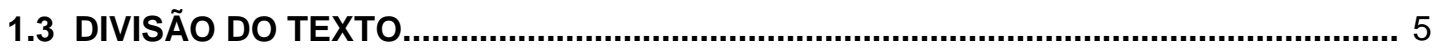

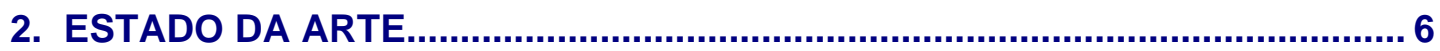

2.1 ESTRUTURA SUPORTADA POR CABOS LIVREMENTE SUSPENSOS.................... 7

2.2 ESTRUTURA SUPORTADA POR CABOS ADICIONAIS......................................... 30

2.3 ESTRUTURA SUPORTADA POR UM ARCO........................................................ 37

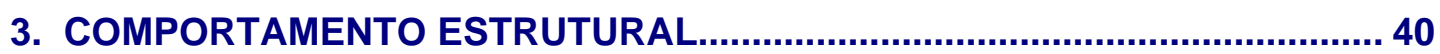

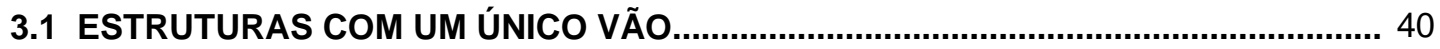

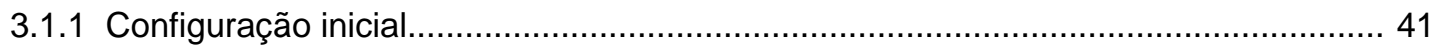

3.1.2 Equações de governo da estrutura (cabos + concreto) ........................................... 43

3.1.3 Resolução analítica das equações de governo.................................................. 46

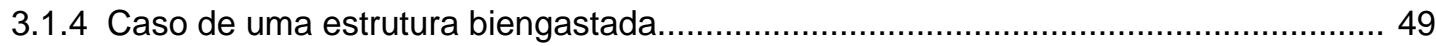

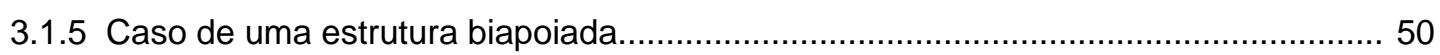

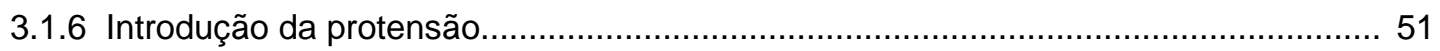

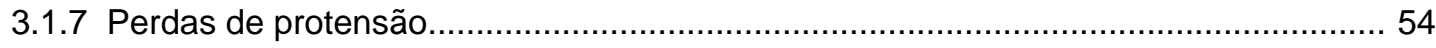

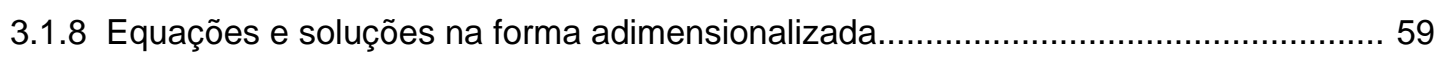

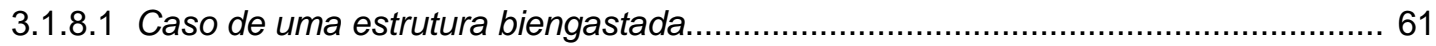

3.1.8.2 Perdas de protensão para o caso biengastado.................................................. 62

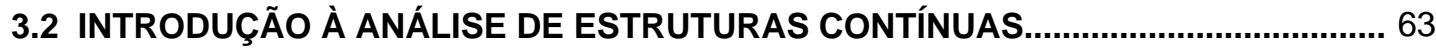


4. CONSIDERAÇOES SOBRE A ANÁLISE DINÂMICA E AS FUNDAÇÕES. 65

4.1 COMENTÁRIOS SOBRE O COMPORTAMENTO DINÂMICO......................................6 65

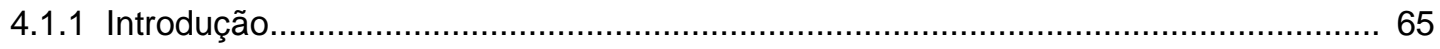

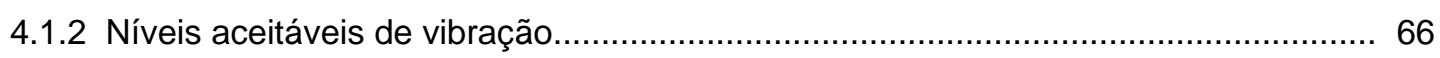

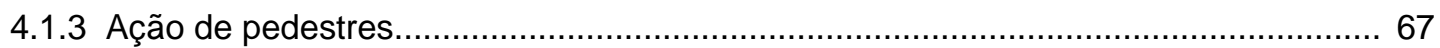

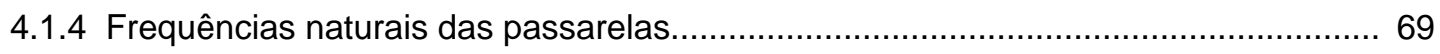

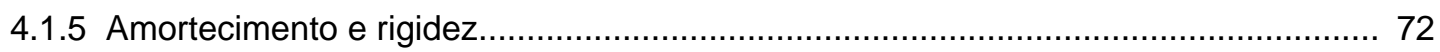

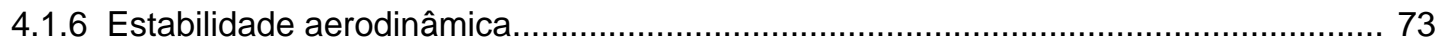

4.1.7 Dispositivos para redução das vibrações.......................................................... 74

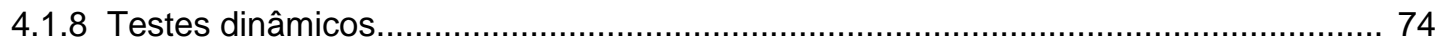

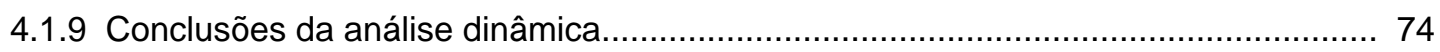

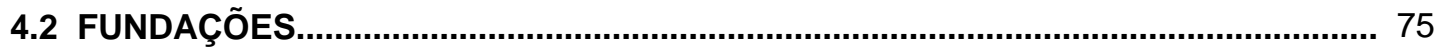

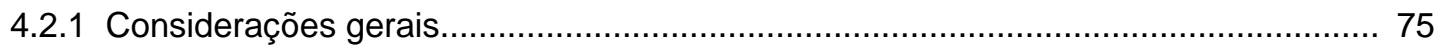

4.2.2 Alternativas para ancoragem da força horizontal.............................................. 76

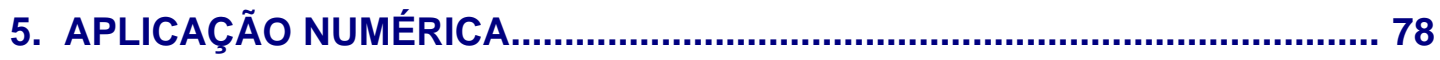

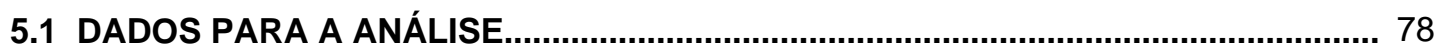

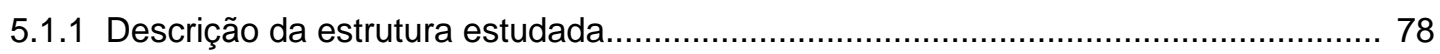

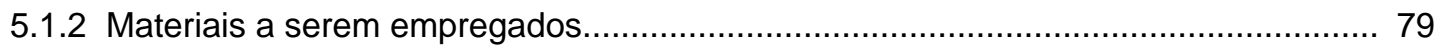

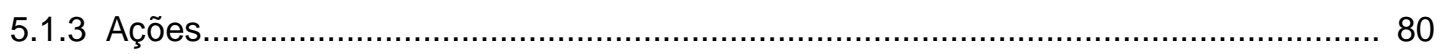

5.1.4 Determinação da flecha inicial e das áreas dos cabos de aço.................................. 80

5.1.5 Resumo dos dados para a análise ................................................................. 85

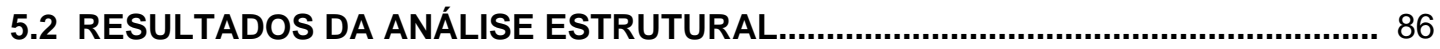

5.2.1 Estado limite de utilização, tempo zero......................................................... 86

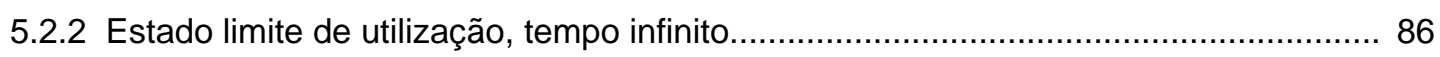

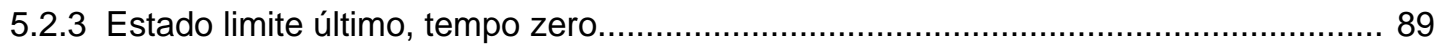

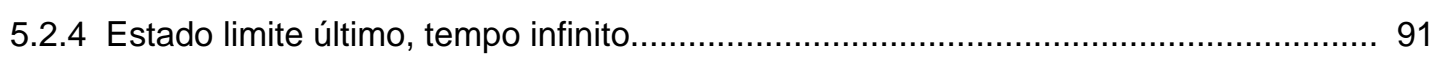

5.3 ANÁLISE DOS ESFORÇOS SOLICITANTES........................................................ 92

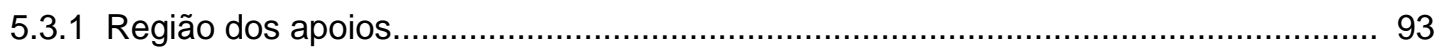

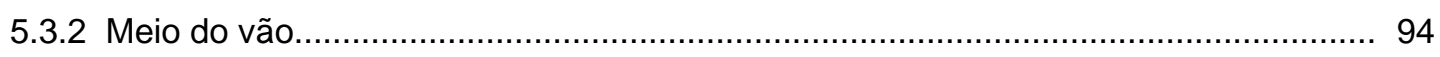

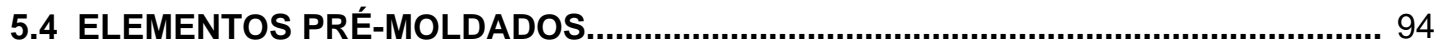

5.5 OBTENÇÃO DAS FREQUÊNCIAS DE VIBRAÇÕES VERTICAIS.............................. 97

5.6 FORÇA HORIZONTAL A SER ANCORADA NAS FUNDAÇÕES................................ 98 


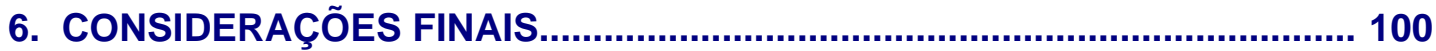

6.1 DISCUSSÃO SOBRE O COMPORTAMENTO ESTRUTURAL................................ 100

6.2 ASPECTOS A SEREM FUTURAMENTE ESTUDADOS........................................ 101

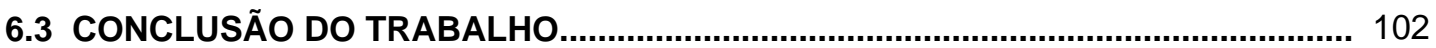

Referências bibliográficas........................................................................ 104

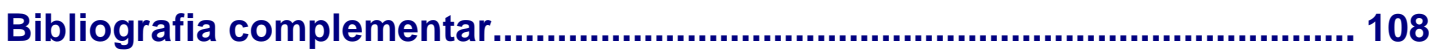




\section{Lista de Figuras}

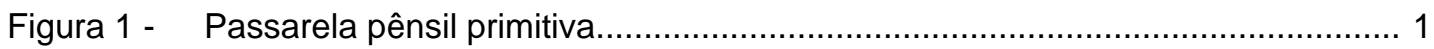

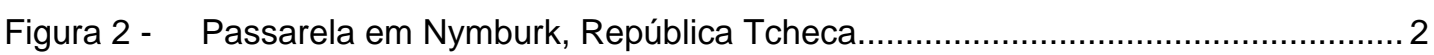

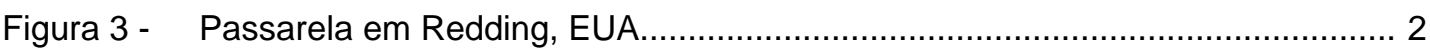

Figura 4 - Passarela em San Diego, EUA $\quad$.............................................................. 2

Figura 5 - Passarela sobre o Rio Enz, Alemanha......................................................... 3

Figura 6 - Passarela em Kromeriz, ex-Tchecoslováquia.................................................. 3

Figura 7 - Montagem de um segmento típico, Redding, EUA.......................................... 4

Figura 8 - Ponte de tubulação sustentada por cabos.................................................... 5

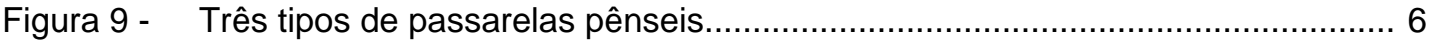

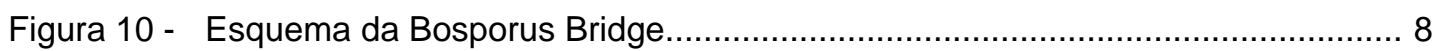

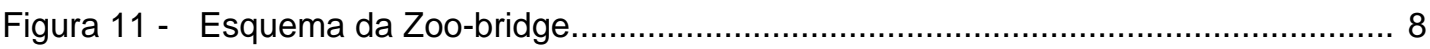

Figura 12 - Vista da ponte sobre o rio Maldonado, Uruguai................................................. 8

Figura 13 - Corte longitudinal da passarela em Bircherweid............................................. 9

Figura 14 - Passarela em Derbyshire, Reino Unido....................................................... 10

Figura 15 - Passarela em Freiburg, Alemanha................................................................ 11

Figura 16 - Configuração da mesa do pilar................................................................ 11

Figura 17 - Ancoragens para a ponte rodoviária........................................................... 12

Figura 18 - Detalhe da região de apoio da estrutura..................................................... 12

Figura 19 - Vista longitudinal da Hayahi-No-Mine Bridge............................................... 13

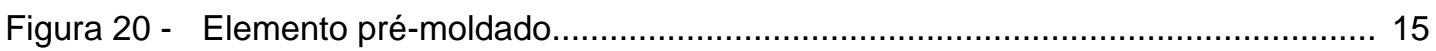

Figura 21 - Elemento pré-moldado sobre os cabos de sustentação................................... 15

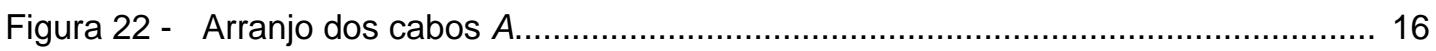

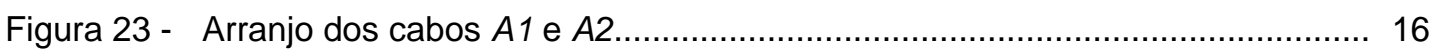

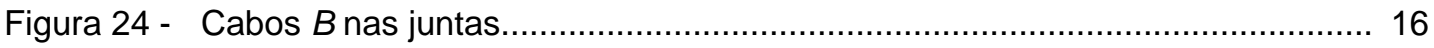

Figura 25 - Passarela em Prerov - apoio................................................................... 17

Figura 26 - Passarela em Prague-Troja - apoio........................................................ 17

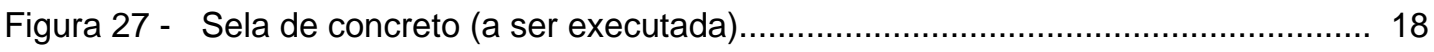

Figura 28 - Passarela em Prerov - apoio intermediário..................................................... 18

Figura 29 - Passarela em Prerov - sela de aço....................................................... 19

Figura 30 - Passarela em Prerov - sela de aço.............................................................. 19

Figura 31 - Passarela em Prague-Troja - pilar intermediário.......................................... 19

Figura 32 - Passarela em Prague-Troja - sela de aço................................................... 20

Figura 33 - Passarela em Nymburk - pilar intermediário com sela de aço........................ 20

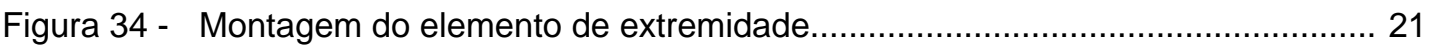

Figura 35 - Içamento de um elemento do primeiro vão.................................................... 22

Figura 36 - Inserção de dispositivos para fixação do elemento aos cabos.......................... 22 
Figura 37 - Elemento deslizando sobre os cabos de sustentação..................................... 23

Figura 38 - Colocação de tubos de aço entre os elementos.............................................. 23

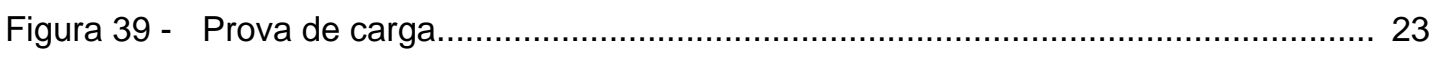

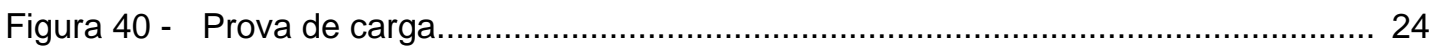

Figura 41 - Passarela formada por elementos de madeira............................................... 24

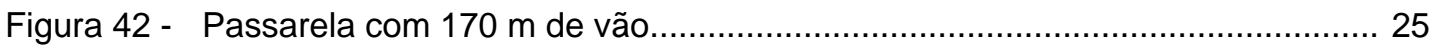

Figura 43 - Passarela em Redding - região dos apoios................................................... 25

Figura 44 - Alojamento dos cabos no elemento........................................................... 26

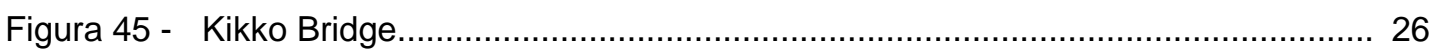

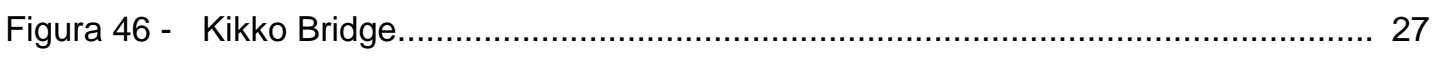

Figura 47 - Diagramas esquemáticos de momentos fletores......................................... 27

Figura 48 - Momentos fletores nos apoios devido à retração e à fluência do

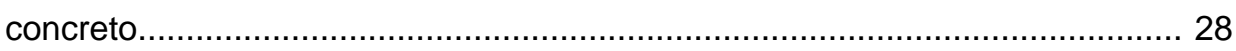

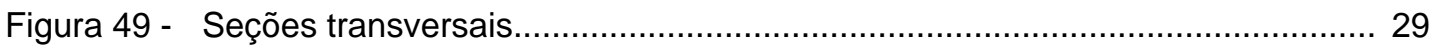

Figura 50 - Passarela formada por três trechos retos..................................................... 30

Figura 51 - Vista aérea da passarela sobre o lago Vranov, República Tcheca................... 31

Figura 52 - Passarela sobre o lago Vranov................................................................ 31

Figura 53 - Seção longitudinal da passarela.................................................................. 31

Figura 54 - Pilar, apoio e bloco de ancoragem............................................................. 32

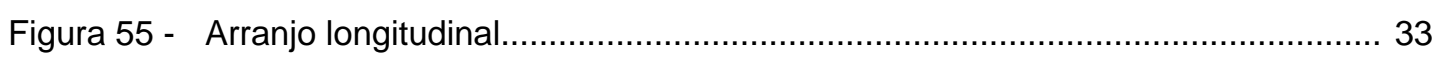

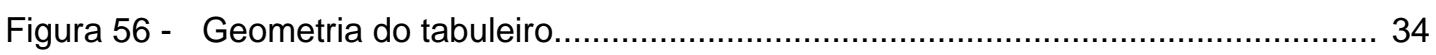

Figura 57 - Seção transversal e longitudinal do tabuleiro................................................. 34

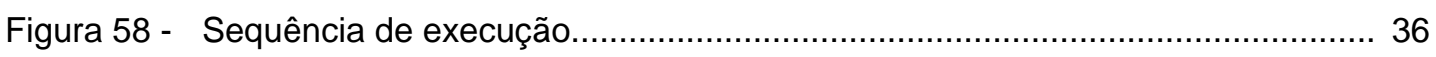

Figura 59 - Montagem do primeiro elemento do tabuleiro................................................. 37

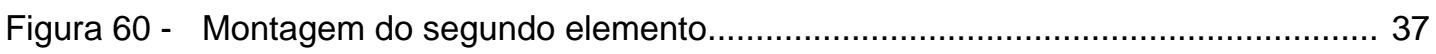

Figura 61 - Passarela em Plzen - modelo arquitetônico.................................................... 38

Figura 62 - Passarela em Plzen - modelo estático..................................................... 38

Figura 63 - Passarela em Plzen - elevação................................................................... 38

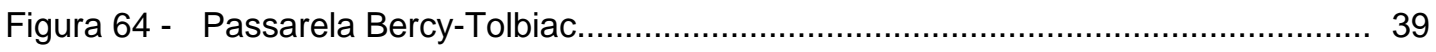

Figura 65 - Passarela Bercy-Tolbiac.................................................................... 39

Figura 66 - Efeito da protensão na estrutura............................................................. 41

Figura 67 - Cabo livremente suspenso com apoios nivelados...................................... 41

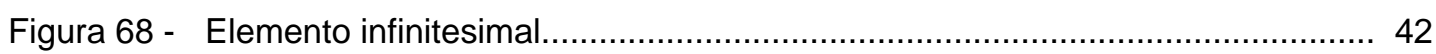

Figura 69 - Configuração de referência para continuação das deduções............................ 43

Figura 70 - Configuração deformada da estrutura..................................................... 44

Figura 71 - Introdução da protensão...................................................................... 52

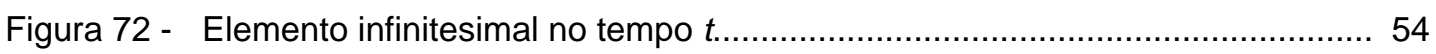

Figura 73 - Representação estática dos cabos de sustentação....................................... 63

Figura 74 - Carregamento no apoio intermediário......................................................... 64 
Figura 75 - Limites de desconforto devido à vibração.................................................... 67

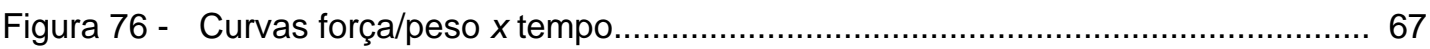

Figura 77 - Dependência da relação $\frac{\operatorname{máx}\left(F_{\text {est }}+F_{\text {din }}\right)}{F_{\text {est }}}$ em função da frequência do

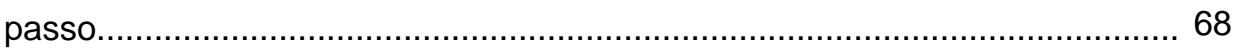

Figura 78 - Dependência de $\delta_{\mathrm{N}}$ em função do número de pessoas................................ 69

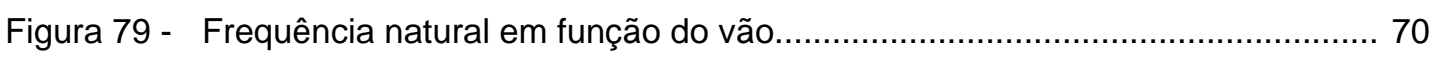

Figura 80 - Representação de uma estrutura contínua................................................... 72

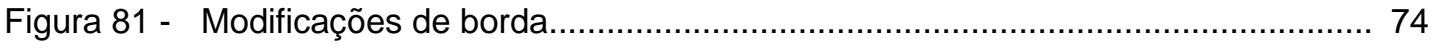

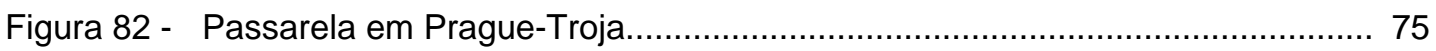

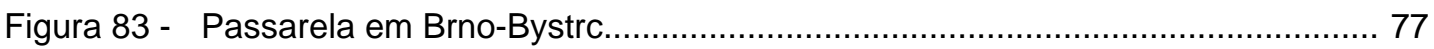

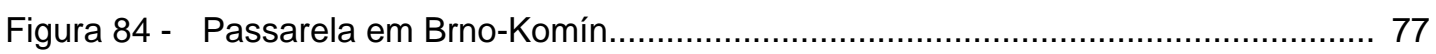

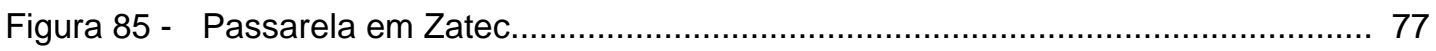

Figura 86 - Esquema longitudinal da estrutura........................................................ 79

Figura 87 - Seção transversal para pré-dimensionamento............................................ 79

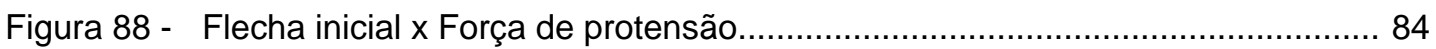

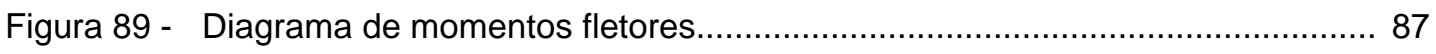

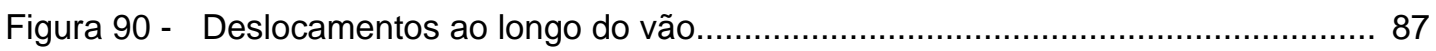

Figura 91 - Diagrama de momentos fletores............................................................. 91

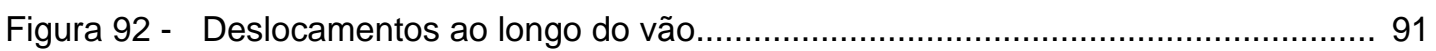

Figura 93 - Formas possíveis para o elemento pré-moldado............................................ 94

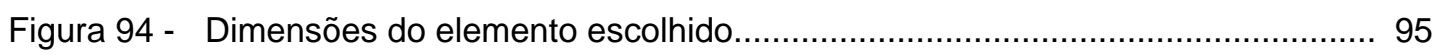

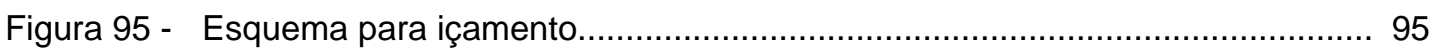

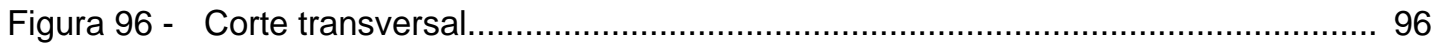

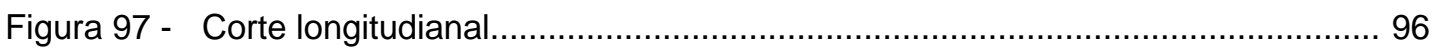

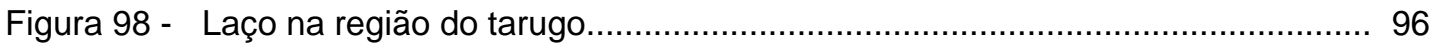

Figura 99 - Armadura nas juntas dos elementos....................................................... 97

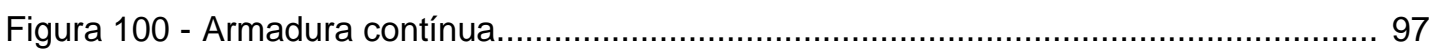

Figura 101 - Seção transversal submetida à carregamento assimétrico.......................... 101 


\section{Lista de Tabelas}

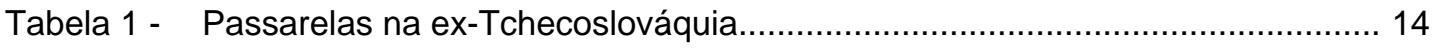

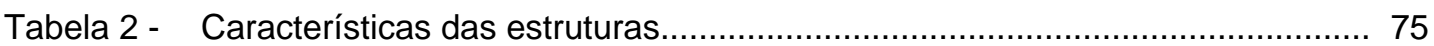

Tabela 3 - Custo da passarela em Prague-Troja, em milhões de unidade monetária da ex-Tchecoslováquia.............................................................................. 76

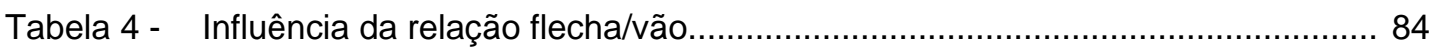

Tabela 5 - Resumo dos dados para a análise da passarela.......................................... 85

Tabela 6 - Estado limite de utilização, tempo zero......................................................... 86

Tabela 7 - Perdas de protensão para o caso 2 …........................................................ 88

Tabela 8 - Resultado do acréscimo de carregamento................................................... 89

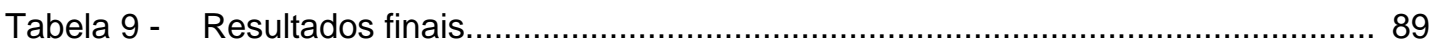

Tabela 10 - Estado limite último, tempo zero........................................................... 90

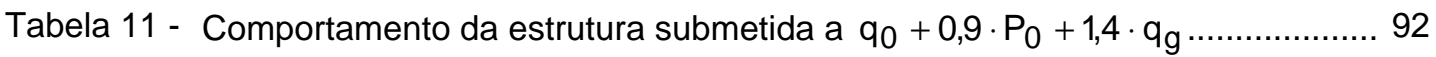

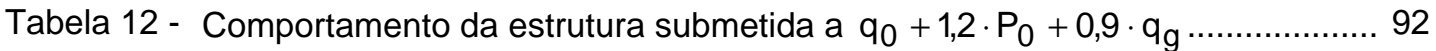

Tabela 13 - Resultado do acréscimo de carregamento.................................................... 93

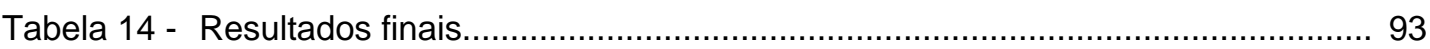

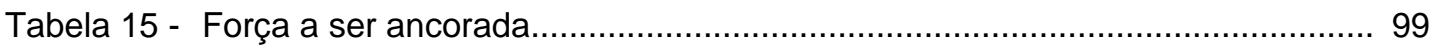




\section{Lista de Abreviaturas e Siglas}

CEB - Comite Euro-International Du Beton

CELSOC - Consulting Engineers and Land Surveyors of California 


\section{Resumo}

FERREIRA, L.M. (2001). Passarela pênsil protendida formada por elementos pré-moldados de concreto. São Carlos, 2001. 110p. Dissertação (Mestrado) - Escola de Engenharia de São Carlos, Universidade de São Paulo.

Este trabalho aborda um tipo de passarela que está ganhando bastante notoriedade internacionalmente. Inúmeras obras vêm sendo construídas em diversos países, embora no Brasil ainda seja quase desconhecida. Basicamente, a estrutura é composta por cabos livremente suspensos, sobre os quais se apóia o tabuleiro formado por elementos prémoldados de concreto. A protensão é utilizada como forma de enrijecer o conjunto. Dentre suas principais características, estão a rapidez e a facilidade de execução, a estética bastante agradável e o custo competitivo. Inicialmente, apresenta-se uma conceituação básica e um estado da arte. Em seguida, é estudado o comportamento estrutural da passarela. Alguns tópicos relativos à análise dinâmica e às fundações são brevemente comentados. Finalizando a dissertação, é feita uma aplicação numérica, enfatizando os aspectos que a diferenciam das estruturas convencionais.

Palavras-chave: passarelas, pontes pênseis, concreto pré-moldado, concreto protendido. 


\begin{abstract}
FERREIRA, L.M. (2001). Precast stress-ribbon pedestrian bridges. São Carlos, 2001. 110p. Dissertação (Mestrado) - Escola de Engenharia de São Carlos, Universidade de São Paulo.
\end{abstract}

This work treats a kind of pedestrian bridge that is standing out internationally. Several structures have been built in different countries, although they are almost unknown in Brazil. Basically, the deck is formed by precast concrete elements over free suspended cables. Prestressing is applied behind the abutments to provide rigidity to the structure. Quick and easy to assemble, aesthetically beautiful and the competitive cost are some of their main features. First, the basic concepts and a state of art are presented. Then, the structural behavior is studied. Some questions related to dynamic analysis and foundations are briefly commented. Ending the dissertation, an example is done, with emphasis to the aspects that make the stress-ribbon a non-conventional structure.

Keywords: stress-ribbon, pedestrian bridges, suspension bridges, precast concrete, prestressed concrete. 


\subsection{CONSIDERAÇÕES INICIAIS}

Dentre os diversos sistemas estruturais possíveis de serem adotados no projeto de uma ponte, uma alternativa relativamente nova vem se destacando. Trata-se de um aperfeiçoamento das antigas passarelas pênseis (v. figura 1), agora utilizando materiais de alta resistência e técnicas de protensão.

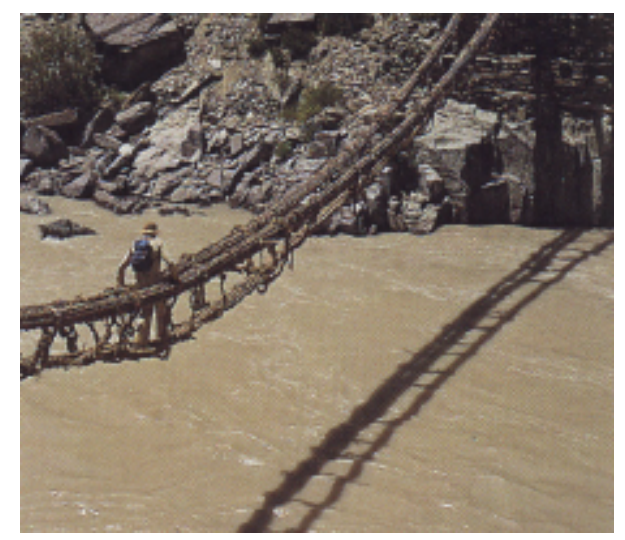

Figura 1 - Passarela pênsil primitiva. (DETAIL, 1999a)

Conhecido internacionalmente como "stress-ribbon", as primeiras divulgações desse sistema estrutural foram feitas por volta de 1965 pelo engenheiro alemão Ulrich Finsterwalder, sofrendo desde então diversas adaptações para se adequar às mais diferentes obras. No Brasil, PFEIL (1980) chama essas estruturas de "lâminas protendidas".

Basicamente, a estrutura é composta por cabos livremente suspensos sobre os quais se apóia o tabuleiro. A protensão é utilizada como forma de enrijecer o conjunto. As figuras de 2 a 6 são exemplos de passarelas construídas utilizando o sistema "stressribbon". 


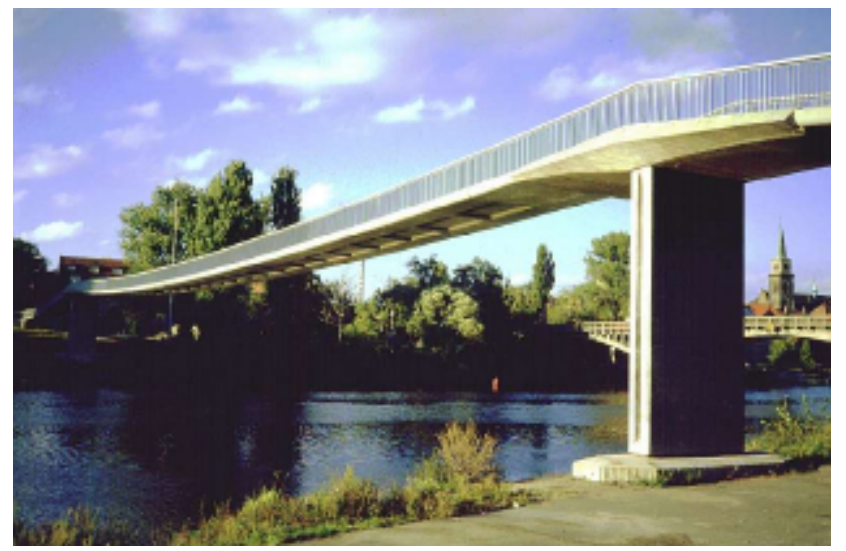

Figura 2 - Passarela em Nymburk, República Tcheca. (STRASKY, 1999)

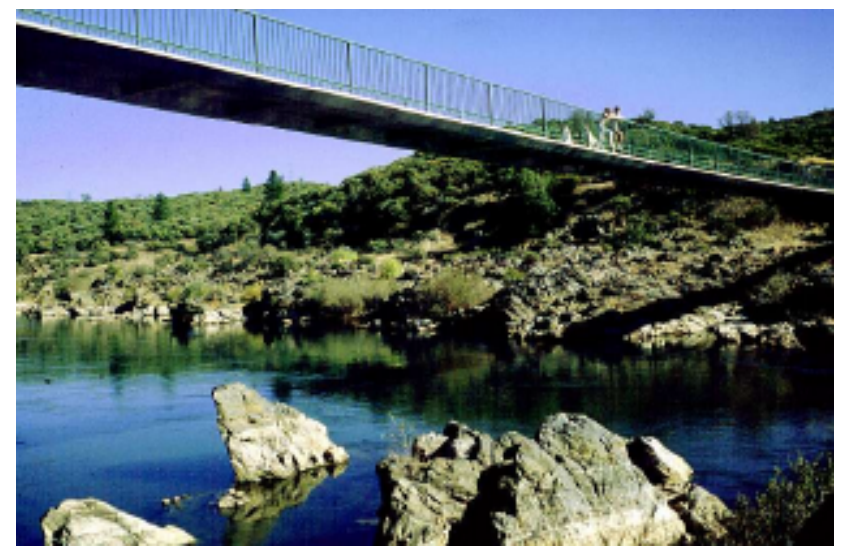

Figura 3 - Passarela em Redding, EUA. (STRASKY, 1999)

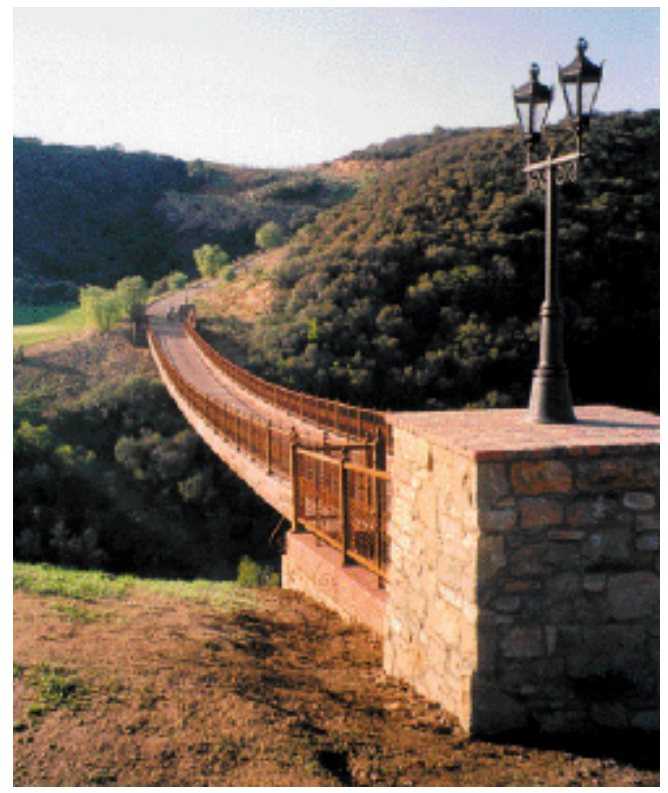

Figura 4 - Passarela em San Diego, EUA. ${ }^{1}$

\footnotetext{
${ }^{1}$ CELSOC, http://www.celsoc.org/images/EE\%202000\%20Photos/TYLinGolf1.jpeg
} 


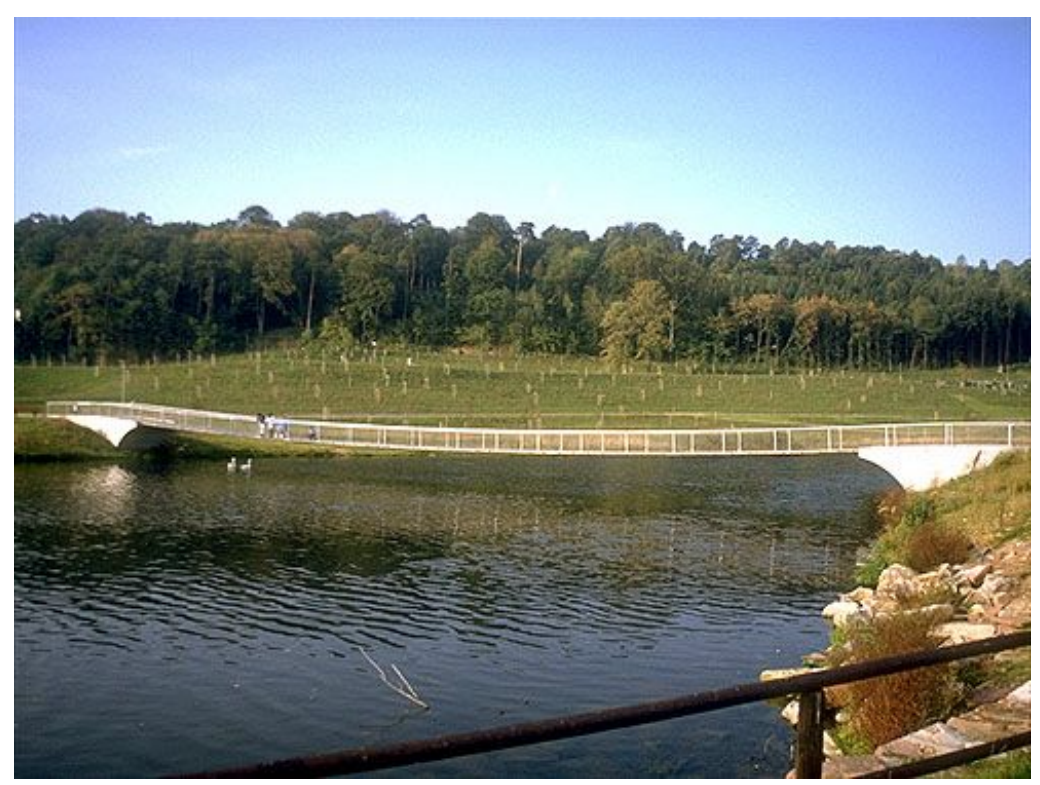

Figura 5 - Passarela sobre o Rio Enz, Alemanha. ${ }^{2}$

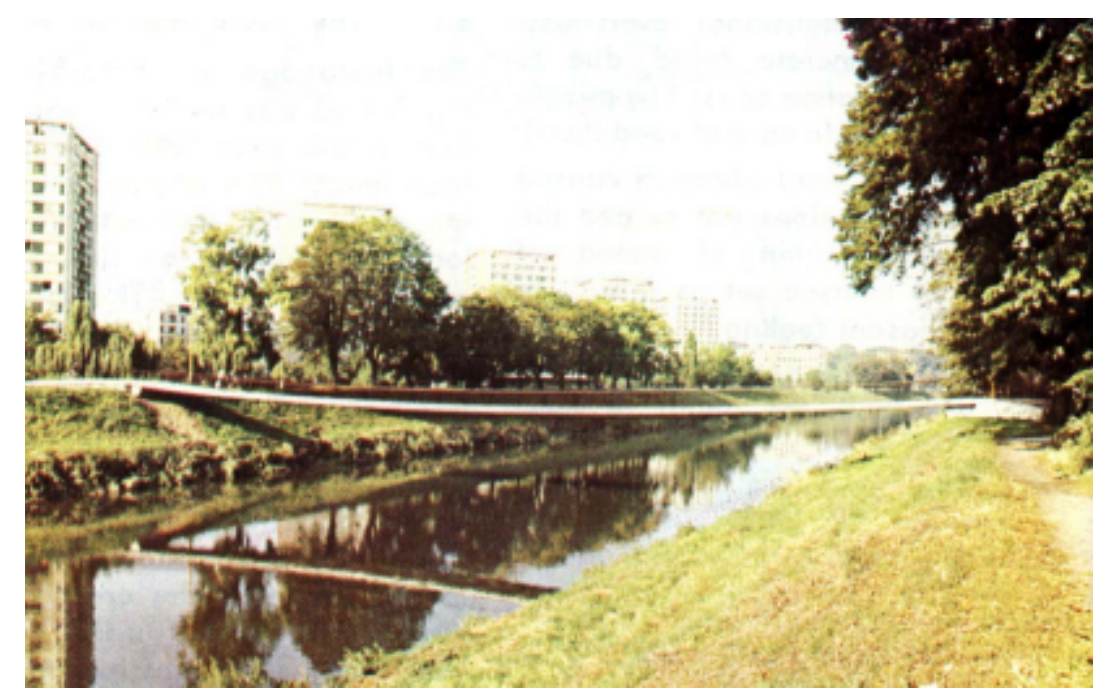

Figura 6 - Passarela em Kromeriz, ex-Tchecoslováquia. (STRASKY \& PIRNER, 1986)

O tabuleiro pode ser formado por elementos pré-moldados de concreto de seção completa ou parcial, elementos de aço ou madeira, ou ainda moldado totalmente no local com as fôrmas suspensas nos próprios cabos. Embora em qualquer caso a execução da estrutura não exija cimbramentos e praticamente não ocorra interferência na circulação de veículos ou embarcações, é no uso da pré-fabricação que se nota algumas das principais vantagens desse sistema estrutural. Nesse caso, para a montagem da estrutura, os elementos deslizam um a um sobre os cabos de sustentação até chegar a sua posição de projeto (v. figura 7), caracterizando assim uma execução fácil e rápida.

\footnotetext{
${ }^{2}$ SCHLAICH, BERGERMANN AND PARTNERS, http://www.sbp.de/proj-img/56/56.hi.jpeg
} 


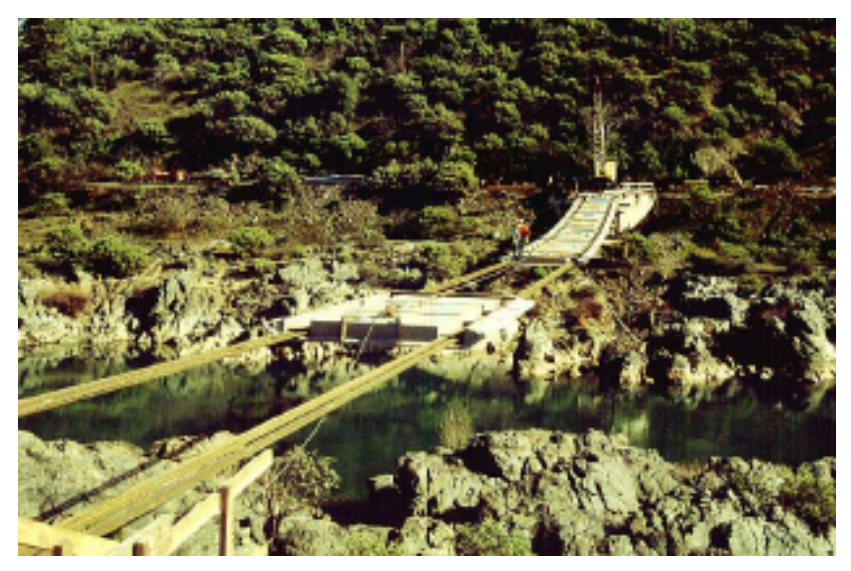

Figura 7 - Montagem de um segmento típico, Redding, EUA. (STRASKY, 1999)

A protensão pode ser introduzida de duas formas. A primeira, mais comumente usada, é através de cabos adicionais aos de sustentação, ancorados na parte detrás dos blocos de fundação, de modo que seu único efeito são forças distribuídas verticais atuando num esquema de arco invertido. A segunda forma de protensão produz o mesmo efeito, mas é conseguido com a colocação de uma sobrecarga (sacos de água, por exemplo) antes da concretagem das juntas. Após o concreto dessas juntas adquirir resistência suficiente, a sobrecarga é retirada e a estrutura tende a se deslocar para cima, ocorrendo o efeito de protensão desejado.

Embora, em princípio, sua utilização seja possível para qualquer natureza de tráfego, a elevada magnitude das ações horizontais geradas torna seu uso mais conveniente para passarelas, onde a sobrecarga nos cabos é menor e permite-se maiores declividades. De qualquer forma, sua viabilidade técnica e econômica está condicionada a condições favoráveis do subsolo.

Apesar do custo relativamente elevado das fundações e blocos de ancoragem, esse sistema estrutural é bastante competitivo economicamente, em particular para vãos acima dos 40 metros, onde o custo da infra-estrutura passa a representar uma parcela menos significativa no custo total, e para estruturas de vãos múltiplos, onde considerando-se vãos, flechas e carregamentos iguais, a força horizontal corresponde apenas à de um vão, ou seja, o número de vãos pode ser aumentado tanto quanto se queira e a força horizontal continua a mesma. Além disso, a forma curva e a notável esbeltez, sem no entanto comprometer a segurança e o conforto dos usuários, tornam a estrutura esteticamente agradável. Existem inúmeros exemplos de passarelas construídas em diversos países, como por exemplo ex-Tchecoslováquia, Alemanha, Reino Unido, Suíça, Espanha, Uruguai, Estados Unidos e Japão.

Outro campo de aplicação viável do sistema estrutural aqui discutido é no caso de pontes de tubulação (v. figura 8), pontes de correia transportadora e coberturas. 


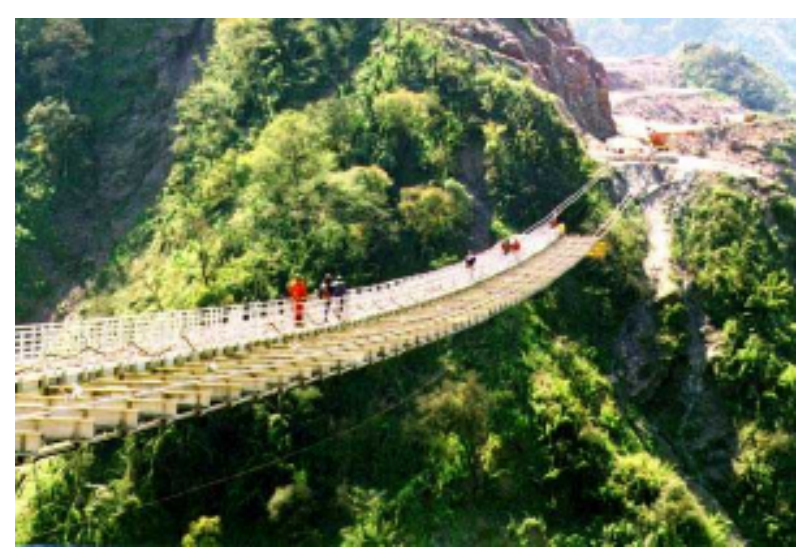

Figura 8 - Ponte de tubulação sustentada por cabos. (KETCHUM et al, 1999)

\subsection{OBJETIVOS E JUSTIFICATIVA}

O objetivo principal deste trabalho é difundir no meio técnico e científico brasileiro a potencialidade do sistema estrutural em questão e fornecer subsídios para o cálculo de passarelas pênseis protendidas formadas por elementos pré-moldados de concreto.

A combinação entre cabos e elementos pré-moldados de concreto tira vantagem de ambos os materiais, resultando numa estrutura leve, econômica, de fácil montagem e sobretudo reconhecida como um marco na arquitetura local. Espera-se, portanto, um crescente uso deste tipo de estrutura.

\subsection{DIVISÃO DO TEXTO}

O segundo capítulo compreende um estado da arte do sistema estrutural em questão. Várias aplicações são descritas sucintamente, desde o início de sua utilização até recentemente. Algumas variações que surgiram com 0 decorrer dos anos são caracterizadas.

O comportamento estrutural é estudado no capítulo 3. São tratadas estruturas com um único vão e apoios nivelados. Algumas particularidades das estruturas contínuas são rapidamente comentadas.

O capítulo 4 trata de alguns aspectos relativos à análise dinâmica e alternativas de fundações para a ancoragem da força horizontal.

No capítulo 5 é desenvolvida uma aplicação numérica, que visa exemplificar e esclarecer assuntos que constam nos capítulos 3 e 4.

Finalizando a dissertação, o capítulo 6 aborda as considerações finais, onde são discutidos alguns tópicos, sugerem-se outros estudos e são tiradas algumas conclusões relacionadas ao projeto e execução das passarelas pênseis protendidas formadas por elementos pré-moldados de concreto. 
Com o decorrer do tempo, a idéia inicial descrita sucintamente no capítulo anterior foi sendo desenvolvida visando o alcance de maiores vãos e para se adequar a situações particulares. Assim, duas variações surgiram derivadas da concepção original.

$\mathrm{Na}$ figura 9 estão mostrados simplificadamente os três arranjos estruturais possíveis.

a)

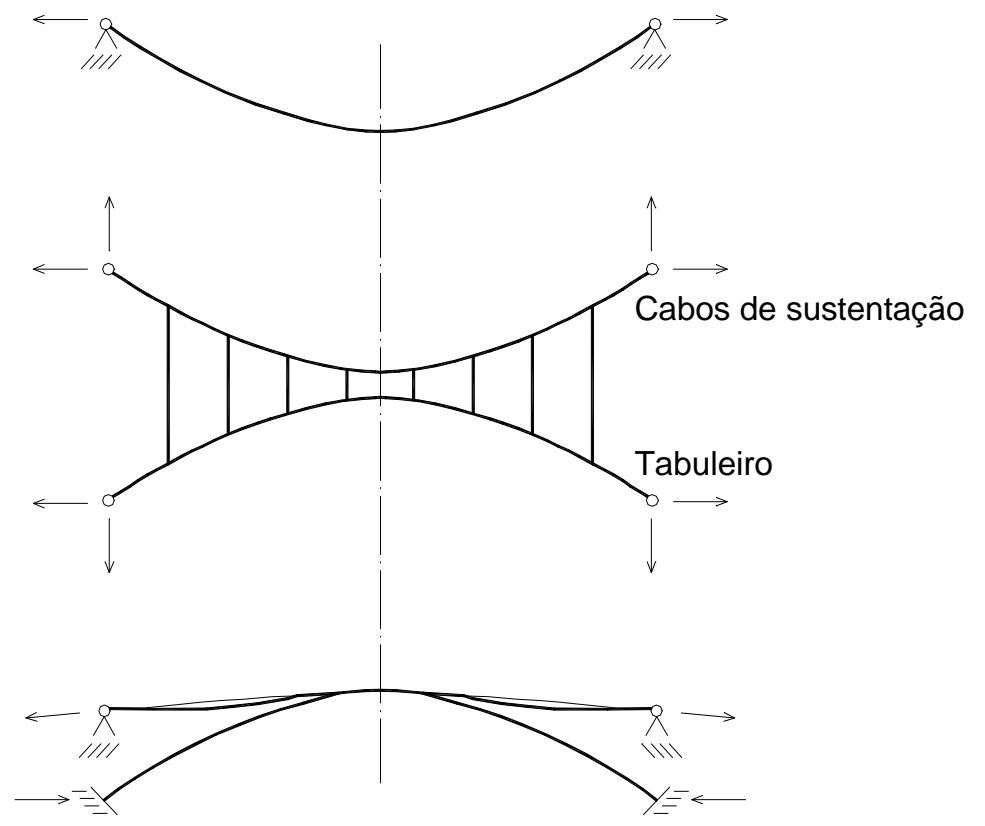

Figura 9 - Três tipos de passarelas pênseis.

(PIRNER \& FISCHER, 1998)

O item $\boldsymbol{a}$ da figura 9 corresponde à concepção original, onde a estrutura é suportada por cabos livremente suspensos. Os itens $\boldsymbol{b}$ e $\boldsymbol{c}$ referem-se às variações do sistema estrutural. 
No item $\boldsymbol{b}$, cabos localizados acima do tabuleiro (v. figura 9b) sustentam a estrutura, que toma a forma de um cabo-treliça. Essa alternativa é conveniente para vãos relativamente grandes, onde os efeitos dinâmicos são mais notados e as forças horizontais são bastante elevadas para se conseguir flechas aceitáveis. Se o tabuleiro não fosse curvo e protendido, o comportamento seria o de uma ponte pênsil clássica. A protensão do tabuleiro, apesar de aumentar os esforços de tração no cabo superior, enrijece a estrutura.

Um arco funcionando como apoio intermediário para a estrutura é a inovação inserida no item $\boldsymbol{c}$ da figura 9 , caracterizando assim uma estrutura híbrida.

Embora o objetivo principal deste trabalho seja o estudo das estruturas inicialmente desenvolvidas, ou seja, sustentadas por cabos livremente suspensos, tomar conhecimento das variantes é imprescindível para a perfeita noção da versatilidade oferecida pelo sistema estrutural.

A seguir, serão fornecidas maiores informações a respeito de cada um dos três arranjos estruturais.

\subsection{ESTRUTURA SUPORTADA POR CABOS LIVREMENTE SUSPENSOS}

As primeiras estruturas propostas e as primeiras descrições do sistema estrutural foram feitas pelo engenheiro alemão Ulrich Finsterwalder, chamado por ele de "spannband" (ou ainda, em outros idiomas, "cinta pretensada", "banda tesa" e "stress-ribbon"). Em FINSTERWALDER (1965a) a proposta de uma ponte sobre o lago Genebra é descrita sucintamente. A parte central de $305 \mathrm{~m}$ do vão principal de $457 \mathrm{~m}$ seria pênsil, com apenas $250 \mathrm{~mm}$ de espessura de concreto armado e taxa de armadura de $25 \%$. O tabuleiro seria moldado no local e seria utilizada uma protensão limitada. Embora essa ponte e outras, como a Bosporus Bridge (v. figura 10) na Turquia, a Naruto Bridge no Japão e a Zoo-bridge (v. figura 11) na Alemanha, com vãos pênseis de 190 m, 336 m e 166 m respectivamente, não tenham sido executadas, elas marcam o início desse sistema estrutural como uma alternativa para os projetistas.

Talvez a primeira aplicação do sistema estrutural efetivamente construída seja a ponte sobre o rio Maldonado, no Uruguai, embora pouco noticiada internacionalmente. $\mathrm{O}$ comprimento total da estrutura é de $150 \mathrm{~m}$, sendo que o vão principal mede cerca de $90 \mathrm{~m}$. O tabuleiro é formado por aduelas de seção caixão com quatro células de 1,4 $\mathrm{m}$ de altura, que repousam sobre os cabos responsáveis pela sustentação. A largura total é de 9,6 m. A protensão da estrutura foi conseguida através da colocação de uma sobrecarga uniforme sobre as aduelas pré-moldadas e posterior concretagem das juntas. Após esse concreto adquirir resistência suficiente, a sobrecarga é retirada e o tabuleiro fica comprimido. Processo idêntico de protensão foi usado na cobertura pênsil do Estádio de Montevidéu, também no Uruguai. No Brasil, existem pelo menos duas obras que exibem esse tipo de protensão: a cobertura da Igreja Nossa Senhora das Graças, em Araraquara, e do ginásio 
esportivo de Rolândia. Maiores detalhes sobre essas coberturas podem ser encontrados em BARBATO (1975). A ponte sobre o rio Maldonado é mostrada na figura 12.

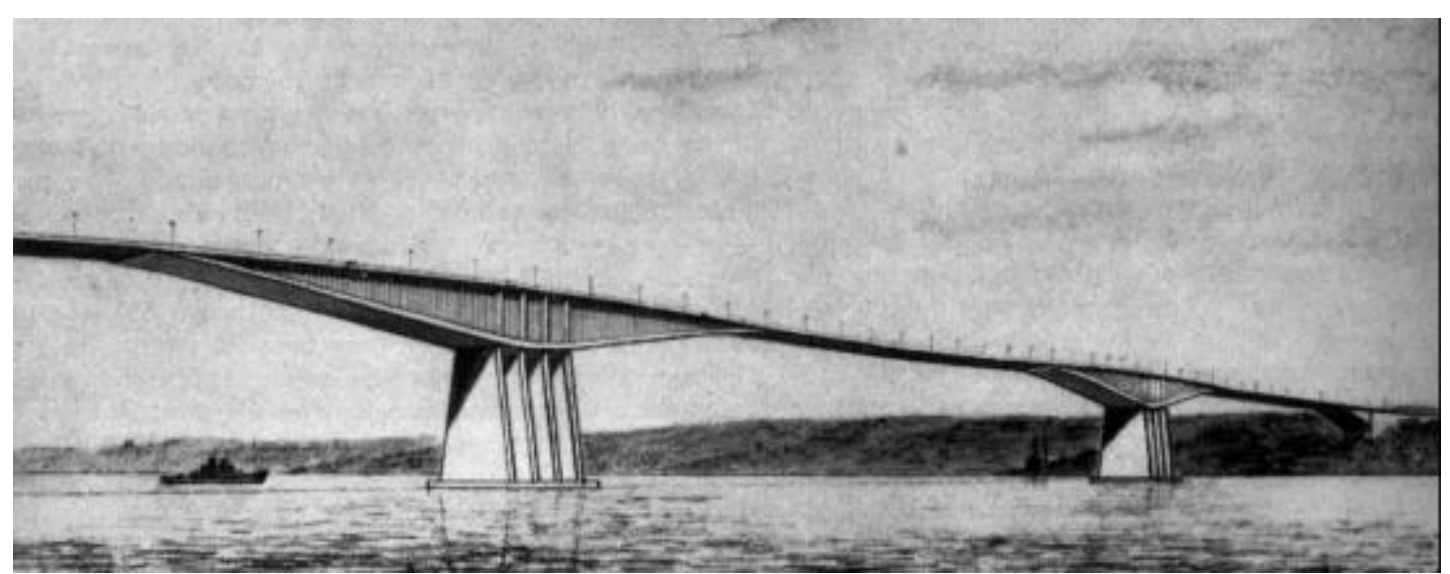

Figura 10 - Esquema da Bosporus Bridge. (WITTFOHT, 1975)

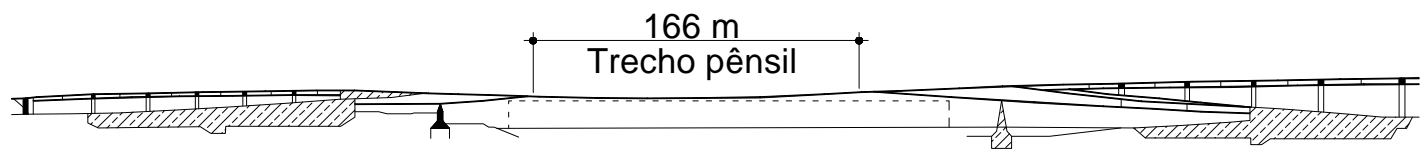

Figura 11 - Esquema da Zoo-bridge. (WALTHER, 1971)

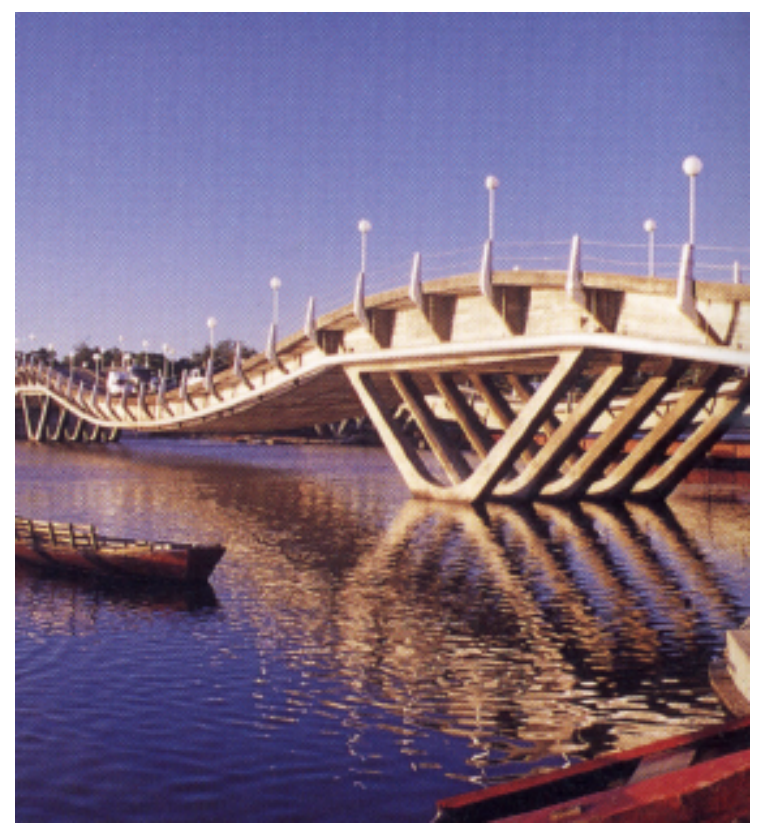

Figura 12 - Vista da ponte sobre o rio Maldonado, Uruguai. 
WALTHER (1971) descreveu a Holderbank Bridge, uma ponte de correia transportadora construída em 1963/1964, com um vão único de 216 m e o tabuleiro sendo formado por elementos pré-moldados de concreto. Quando todos os elementos foram colocados e solidarizados, a estrutura foi protendida. Graças à finalidade da ponte, foi possível a adoção de uma flecha relativamente grande ( $f \cong L / 15)$, resultando em esforços horizontais menores e assim tornando a estrutura bastante econômica.

Conceitualmente, WALTHER (1971) define a estrutura como "um tipo de ponte pênsil em que os cabos estão tão esticados que o tráfego pode ser disposto diretamente na laje de concreto que envolve esses cabos". Ainda em WALTHER (1971), é sugerido o uso de concreto leve com o objetivo de reduzir os empuxos horizontais e portanto economizar na quantidade de aço e nas fundações.

De acordo com WHEEN \& WILSON (1977) outras obras de menores proporções foram construídas na sequência. É citada a passarela em Bircherweid (v. figura 13), Suíça, com um vão de $40 \mathrm{~m}$ e uma máxima espessura de tabuleiro de $180 \mathrm{~mm}$, descrita em WALTHER (1971). A flecha varia de $290 \mathrm{~mm}$ no inverno sem atuação da sobrecarga para $550 \mathrm{~mm}$ no verão sob toda a ação variável. A estrutura é protendida pelos próprios cabos de sustentação.

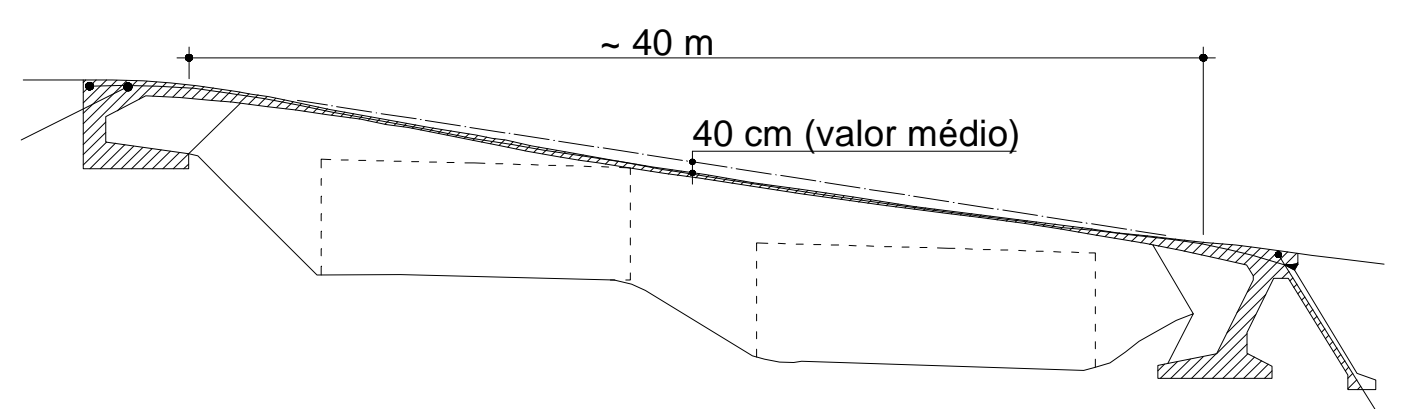

Figura 13 - Corte longitudinal da passarela em Bircherweid. (WALTHER, 1971)

BUTLER (1974) (1977) descreve a primeira passarela desse tipo construída no Reino Unido. O vão é de $34 \mathrm{~m}$ e as condições de subsolo bastante favoráveis. Originalmente, a idéia era que a força horizontal fosse absorvida por 4 tirantes agindo em conjunto com os blocos de fundação. Entretanto, devido à dificuldade de instalação desses tirantes com o comprimento e a inclinação previstos, foi executado um reforço utilizando-se escoras de concreto armado (v. figura 14). Além disso, o número e a inclinação dos tirantes foram alterados, e a largura dos blocos de fundação foi aumentada, de modo que toda a reação devido ao peso próprio da estrutura fosse absorvida por esses blocos em conjunto com as escoras, sem a ajuda dos tirantes. A superestrutura é considerada agindo em 2 partes: o tabuleiro com $160 \mathrm{~mm}$ de espessura, e as regiões de espessura variável nas extremidades com a função de proporcionar uma transição suave entre o tabuleiro flexível e os apoios rígidos. A passarela é protendida de maneira que sob toda a carga variável e a 
pior combinação de retração, fluência e variação de temperatura ainda persiste uma pequena tensão de compressão em todo o vão. O corrimão foi usado de forma a colaborar no amortecimento de vibrações advindas da circulação de pessoas, embora sua interação com a estrutura não tenha sido calculada. $O$ tabuleiro foi moldado no local.

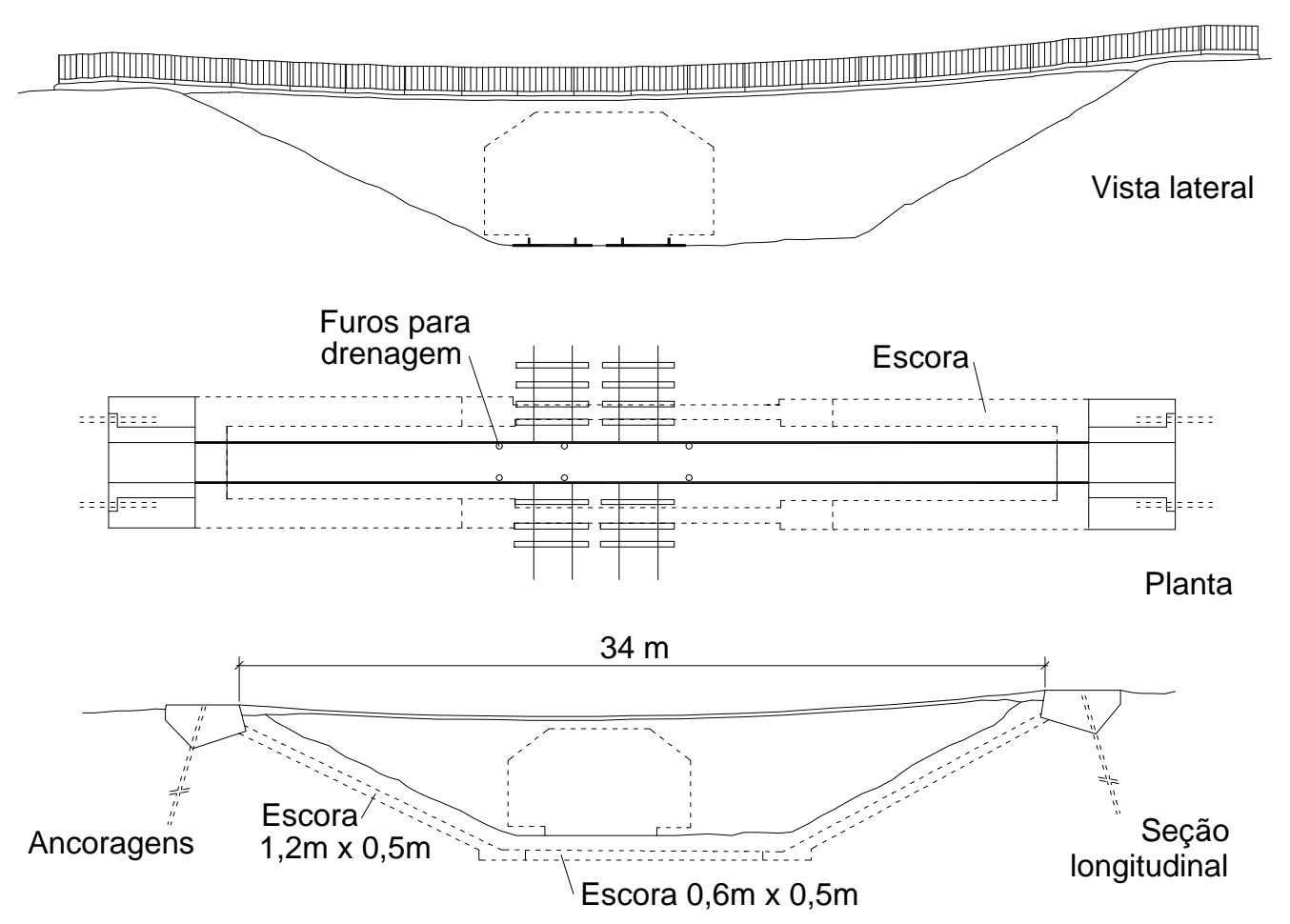

Figura 14 - Passarela em Derbyshire, Reino Unido. (BUTLER, 1977)

Uma passarela pênsil contínua com três vãos em Freiburg, Alemanha (v. figura 15), é comentada por TANG (1976). Os vãos medem $23 \mathrm{~m}, 39,5 \mathrm{~m}$ e $42 \mathrm{~m}$, com um comprimento total incluindo as regiões de ancoragem de 136,5 m. A largura do tabuleiro é de 4,4 m com espessura de $254 \mathrm{~mm}$ e máxima inclinação de $14 \%$ nos apoios intermediários. A drenagem está localizada no centro da passarela. O tabuleiro é protendido longitudinalmente a fim de enrijecer a estrutura, melhorando tanto seu comportamento estático quanto dinâmico. Os efeitos da retração e da fluência resultam em elevada perda de protensão: causam uma redução da tensão de compressão no concreto de $31 \mathrm{MPa}$ para 6,2 MPa. A variação de temperatura é a ação mais significativa. Devido a uma variação de 20 ○C, a flecha no meio do vão varia $160 \mathrm{~mm}$, enquanto devido à carga variável, a variação é de apenas $51 \mathrm{~mm}$. Os pilares intermediários são articulados na base, de maneira a balancear a componente horizontal em vãos adjacentes através de sua rotação. Para permitir essa rotação e permitir também mudanças de declividade nas extremidades sob diferentes condições de carregamento, as mesas dos pilares são estendidas em ambas as direções ( $\mathrm{v}$. figura 16). Visando a uma variação de rigidez mais gradual e assim reduzir o máximo 
momento fletor no tabuleiro nas regiões de apoio em mais de $50 \%$, as mesas dos pilares diminuem de espessura à medida que se afastam do pilar. A força horizontal de aproximadamente $11,1 \mathrm{MN}$ é resistida pelo empuxo passivo que age no bloco de fundação. O deslocamento horizontal desses blocos é apenas de $2 \mathrm{~mm}$ a $4 \mathrm{~mm}$, sendo considerado insignificante.

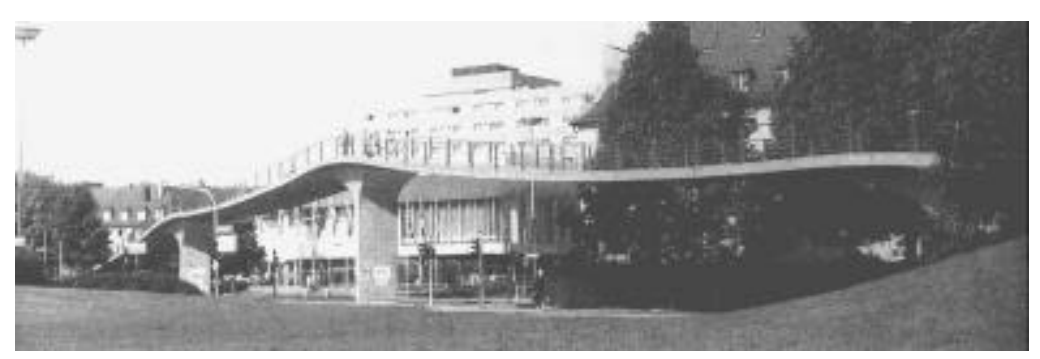

Figura 15 - Passarela em Freiburg, Alemanha. (STRASKY, 1990)

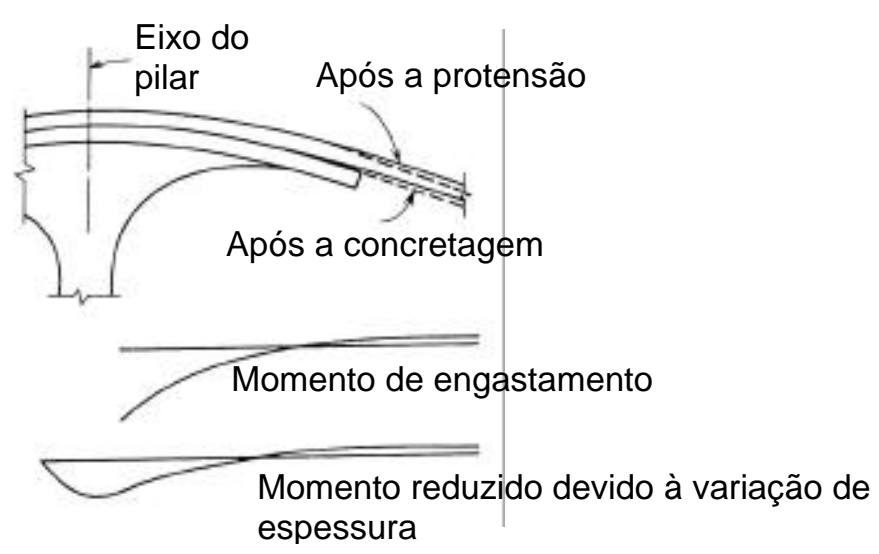

Figura 16 - Configuração da mesa do pilar. (TANG, 1976)

O uso de elementos de aço para formar o tabuleiro e sua comparação com o uso do concreto é discutido por WHEEN \& WILSON (1977). A respeito do uso de concreto moldado no local, é citada a possibilidade do tabuleiro ser fortemente armado de maneira que as fissuras de tração sejam bem distribuídas. Entretanto, salienta-se que o uso da protensão longitudinal, além de comprimir o tabuleiro e evitar tensões de tração, o enrijece. Como principal desvantagem do uso do concreto, argumenta-se que esse material não tem condições de colaborar na sustentação da estrutura sob carga última, sendo necessários cabos e ancoragens adicionais para suportar o peso próprio do concreto. Enquanto isso, sendo o tabuleiro formado por elementos de aço unidos, tanto os cabos quanto o próprio tabuleiro trabalham na função de transmitir esforços em direção às fundações. 
Na sequência, WHEEN \& WILSON (1977), idealizam como exemplo uma ponte rodoviária de $490 \mathrm{~m}$ de vão sem apoios intermediários, com uma flecha de 5,8 $\mathrm{m}$ sob peso próprio. A largura total é de $25 \mathrm{~m}$ e o tabuleiro é formado por elementos de aço de seção caixão enrijecido, dentro dos quais se localizam os cabos de sustentação. Tanto o tabuleiro quanto os cabos são independentemente ligados aos apoios e tracionados a níveis prédeterminados. $\mathrm{O}$ tracionamento do tabuleiro é conseguido fixando cabos nos elementos e os ancorando em trincheiras juntamente com os cabos principais (v. figura 17). A fim de evitar tensões de flexão elevadas no tabuleiro junto às extremidades da passarela, uma série de pontos dispostos longitudinalmente ao eixo da ponte segundo uma curva vertical de grande raio formam o apoio da estrutura (v. figura 18). O raio é escolhido de acordo com a curvatura que a estrutura adota sob condições aceitáveis de tensões de flexão.

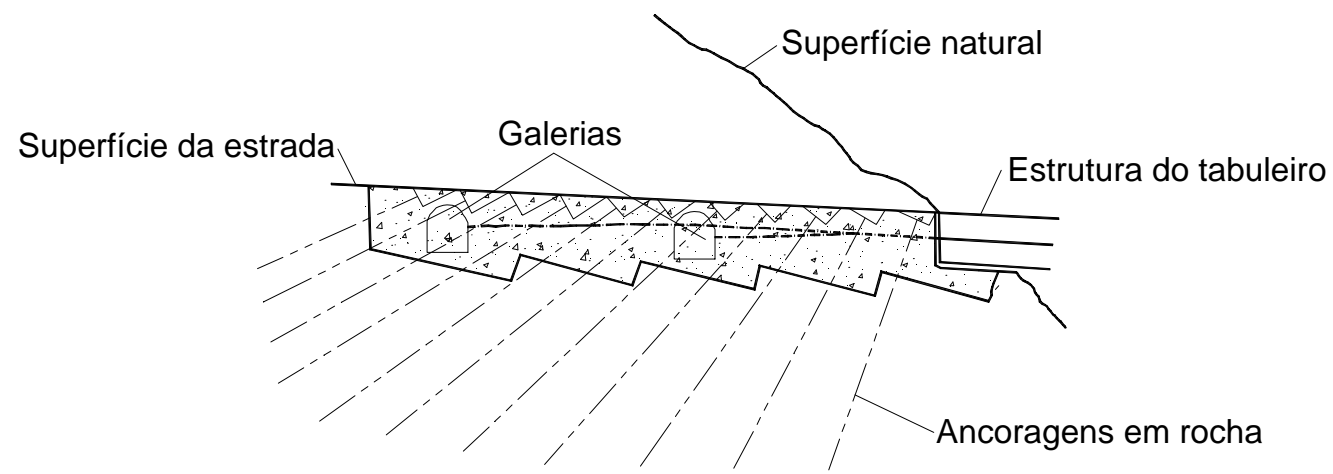

Figura 17 - Ancoragens para a ponte rodoviária. (WHEEN \& WILSON, 1977)

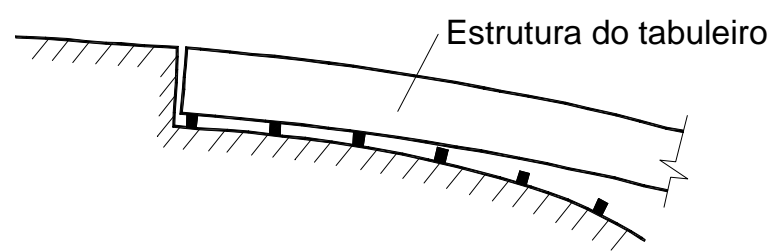

Figura 18 - Detalhe da região de apoio da estrutura. (WHEEN \& WILSON, 1977)

A montagem da estrutura é feita por deslizamento dos elementos, que são unidos posteriormente por solda ou parafusos. A ligação das extremidades do tabuleiro aos apoios se dá através de fios de aço de alta resistência. Por fim, as forças de tração no tabuleiro e nos cabos são ajustadas a níveis ideais.

Do ponto de vista de cargas variáveis, WHEEN \& WILSON (1977) alertam para os dois efeitos gerados. O primeiro é um aumento da flecha. $O$ segundo efeito é devido à excentricidade do carregamento na estrutura, causando torção. Essa torção é resistida por tensões de cisalhamento na seção transversal e variações de tensões axiais nos diversos 
cabos e ao longo da largura dos elementos.

Quanto aos efeitos da relaxação dos cabos de aço, WHEEN \& WILSON (1977) citam o aumento da flecha e a transferência indesejável de tensões para o tabuleiro. Como solução, deve-se escolher cabos com mínima relaxação, tracionar o tabuleiro com tensões menores prevendo essa transferência de tensões ou ainda prever retracionamento dos cabos.

Em estruturas compostas por cabos, quanto maior a flecha, menor a força horizontal gerada, para a mesma sobrecarga atuante. Assim, seria interessante a utilização de flechas maiores, a fim de reduzir os custos das fundações. No entanto, essa possibilidade esbarra em limites máximos de declividade impostos pelo tráfego e na altura disponível abaixo da estrutura. Em passarelas, por exemplo, rampas muito íngremes podem inviabilizar o acesso de deficientes físicos. Esse inconveniente foi superado por MATSUSHITA \& SATO (1979) através de um tabuleiro superior na Hayahi-No-Mine Bridge (v. figura 19), localizada na ilha de Kyushu, Japão. As dificuldades impostas pelas condições topográficas locais determinaram a escolha do sistema estrutural. $O$ tabuleiro inferior é composto por cabos sobre os quais se apoiam elementos pré-moldados. As juntas entre esses elementos são concretadas para se obter continuidade e protensão axial é introduzida por cordoalhas adicionais. $O$ tabuleiro superior consiste de sete vãos vencidos por elementos pré-moldados cuja continuidade é conseguida pela protensão. Os membros verticais trabalham à compressão, com neoprene instalado nas suas extremidades. As forças horizontais geradas são absorvidas por tirantes ancorados em rocha. Se associarmos essa estrutura a uma ponte pênsil convencional, porém invertida, o tabuleiro inferior seriam os cabos principais, os membros verticais seriam os pendurais e o tabuleiro superior seria a viga de rigidez.

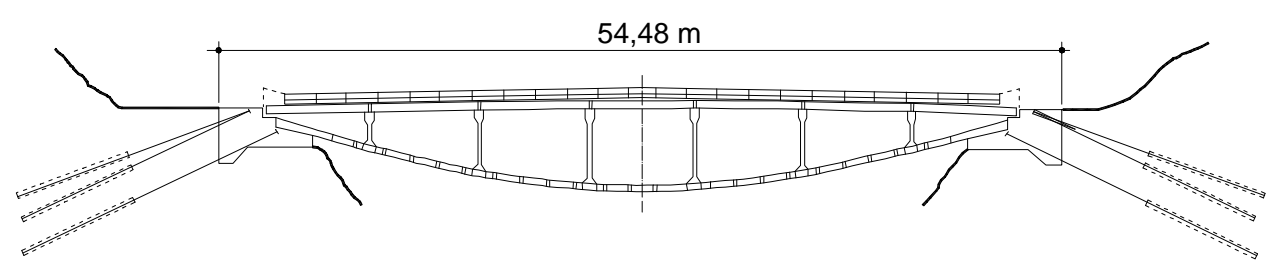

Figura 19 - Vista longitudinal da Hayahi-No-Mine Bridge.

(MATSUHITA \& SATO, 1979)

Uma série de passarelas pênseis protendidas utilizando elementos prémoldados de concreto na ex-Tchecoslováquia são abordadas por STRASKY \& PIRNER (1986) e STRASKY (1987). Um resumo das passarelas é mostrado na tabela 1. 
Tabela 1 - Passarelas na ex-Tchecoslováquia. (STRASKY \& PIRNER, 1986)

\begin{tabular}{|c|c|c|c|c|c|}
\hline Passarela & $\begin{array}{c}\text { Número de } \\
\text { vãos }\end{array}$ & $\begin{array}{c}\text { Maior vão } \\
\left(\mathrm{L}_{\text {máx }}-\text { metro }\right)\end{array}$ & $\begin{array}{c}\text { Flecha } \\
(\mathrm{f}-\text { metro })\end{array}$ & $\begin{array}{c}\mathrm{L}^{2}{ }_{\text {máx }} / \mathrm{f} \\
(\text { metro })\end{array}$ & $\begin{array}{c}\text { Ano de } \\
\text { construção }\end{array}$ \\
\hline Brno-Bystrc & 1 & 63,0 & 1,20 & 3308 & 1979 \\
\hline Kromeriz & 1 & 63,0 & 1,20 & 3308 & 1983 \\
\hline Radonice & 1 & 63,0 & 1,20 & 3308 & 1984 \\
\hline Brno-Komin & 1 & 78,0 & 1,35 & 4507 & 1985 \\
\hline Prerov & 2 & 67,5 & 1,43 & 3186 & 1983 \\
\hline Zatec & 2 & 75,5 & 1,60 & 3563 & projeto \\
\hline Prague-Troja & 3 & 96,0 & 1,69 & 5453 & 1984 \\
\hline Nymburk & 3 & 102,0 & 1,98 & 5255 & 1985 \\
\hline Velke Brezno & 4 & 126,0 & 2,22 & 7151 & projeto \\
\hline
\end{tabular}

Todas essas passarelas são formadas por elementos pré-moldados de concreto de 3,80 m de largura, 3,00 m de comprimento e $0,30 \mathrm{~m}$ de espessura. Com exceção dos elementos que estão sobre os apoios, que são maciços, a forma dos elementos é indicada na figura 20. Possuem duas aberturas de $12 \mathrm{~cm}$ para a passagem de encanamentos e cabos elétricos, além de orifícios de menor diâmetro para a passagem dos cabos que irão protender a estrutura após a concretagem das juntas. A resistência à compressão do concreto obtida a partir de corpos de prova prismáticos é de $50 \mathrm{MPa}$.

Durante a montagem da estrutura os elementos se apóiam em cabos de sustentação dispostos em duas fileiras (v. figura 21) cuja forma é a de uma catenária. No entanto, devido à pequena relação flecha/vão, essa curva é bem aproximada por uma parábola. Tanto os cabos de sustentação (por convenção, cabos $A$ ) quanto os cabos de protensão (por convenção, cabos $B$ ) são formados por seis cordoalhas de 15,5 mm.

Dependendo do número de cabos e portanto da magnitude das forças horizontais, o arranjo dos cabos de sustentação se dá de duas maneiras:

a) Se em cada fileira forem usados no máximo seis cabos, a disposição se dá em uma única linha, de acordo com a figura 22;

b) Se em cada fileira forem usados no máximo doze cabos, a disposição se dá em duas linhas, conforme a figura 23. Durante a montagem da estrutura, os elementos são sustentados por apenas metade dos cabos (cabos A1). Após a colocação de todos os elementos, a outra metade dos cabos (cabos A2) é colocada e tracionada, atingindo-se a forma final da estrutura.

Em qualquer das situações acima especificadas, os cabos de sustentação são protegidos com cobrimento de $5,5 \mathrm{~cm}$ de concreto com resistência à compressão obtida em corpos de prova prismáticos igual a $40 \mathrm{MPa}$. 

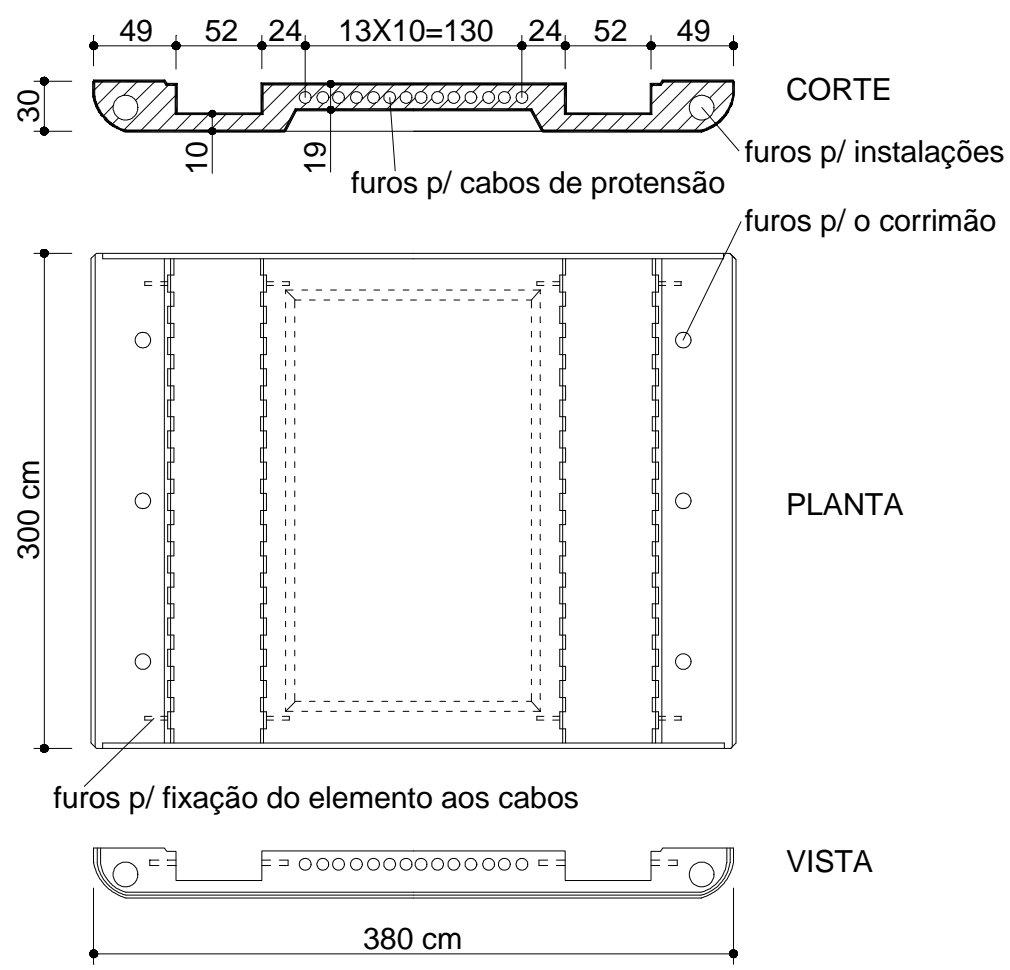

Figura 20 - Elemento pré-moldado. (STRASKY \& PIRNER, 1986)

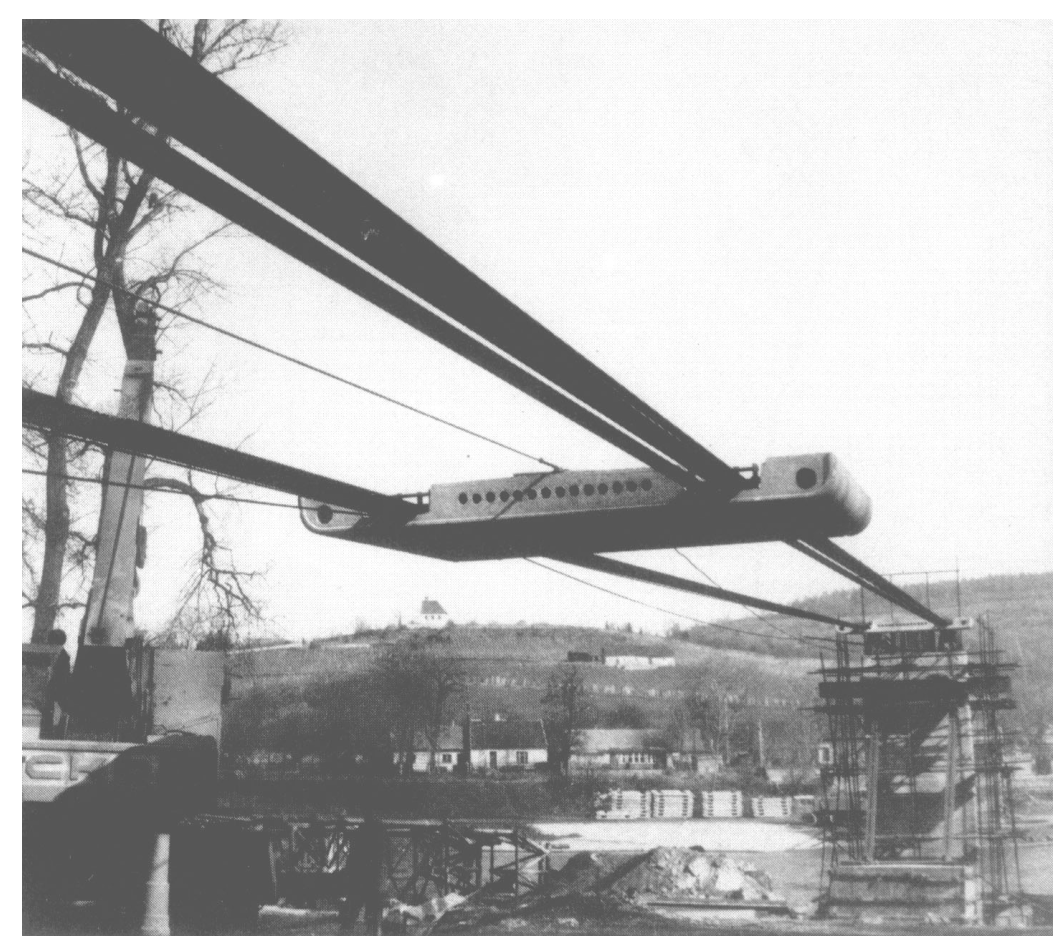

Figura 21 - Elemento pré-moldado sobre os cabos de sustentação. (STRASKY \& PIRNER, 1986) 


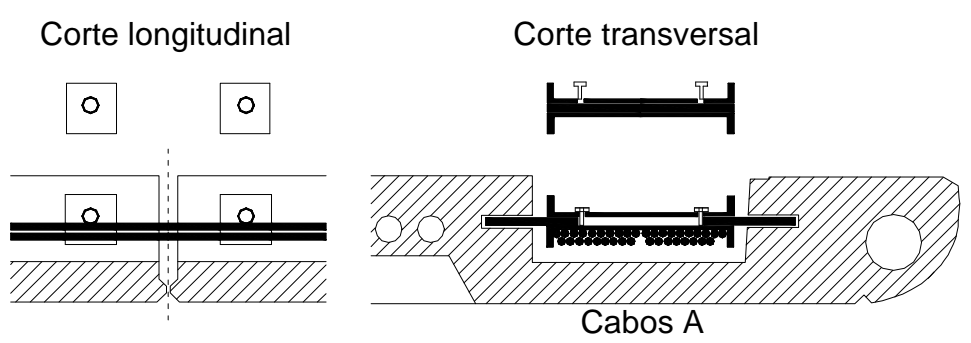

Figura 22 - Arranjo dos cabos A. (STRASKY \& PIRNER, 1986)

Corte longitudinal
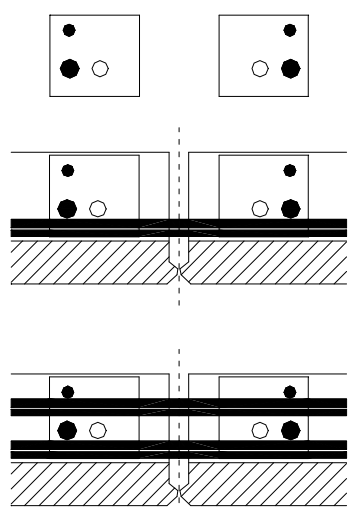

Corte transversal
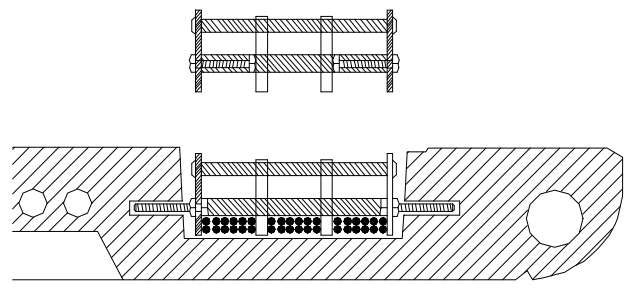

Cabos A1

Cabos A2

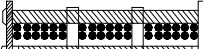

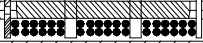

Cabos A1

Figura 23 - Arranjo dos cabos A1 e A2. (STRASKY \& PIRNER, 1986)

Os cabos de protensão (cabos $B$ ) ficam localizados nos elementos em dutos formados pelo próprio concreto. Entretanto, nas juntas, selas e blocos de ancoragens são usados dutos de aço (figura 24).

Cabos B

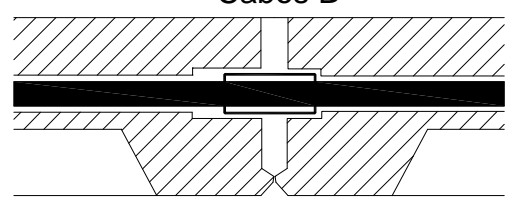

Figura 24 - Cabos $B$ nas juntas. (STRASKY \& PIRNER, 1986)

Nessas passarelas, STRASKY \& PIRNER (1986) apóiam os últimos elementos sobre almofadas de elastômero, permitindo assim que o tabuleiro possa se movimentar para cima com o abaixamento da temperatura e depois retornar à sua posição, ou seja, permitindo certa rotação nos apoios.

Quanto às fundações, nas primeiras estruturas o bloco de ancoragem e a laje de fundação eram duas partes distintas (v. figura 25). Posteriormente, passou-se a fazer com 
que o bloco de ancoragem também assumisse a função de laje (v. figura 26).
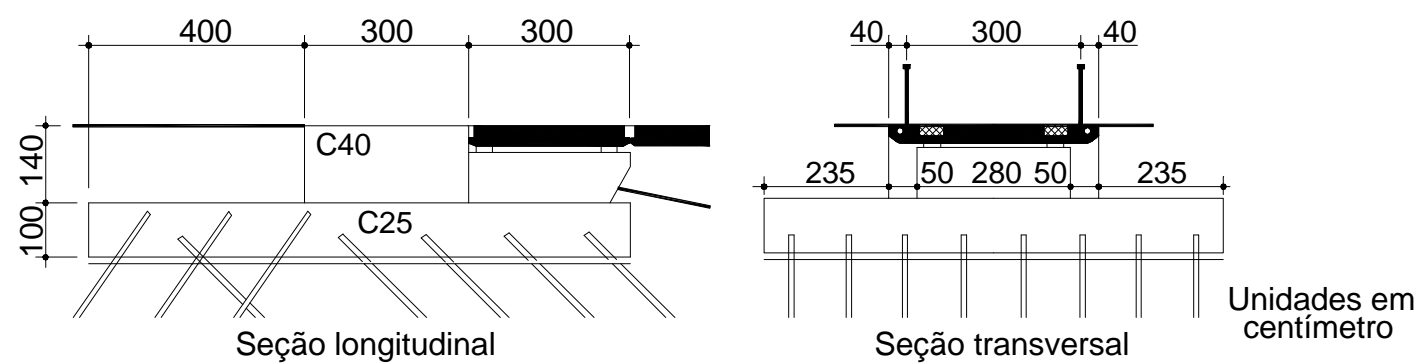

Figura 25 - Passarela em Prerov - apoio. (STRASKY \& PIRNER, 1986)

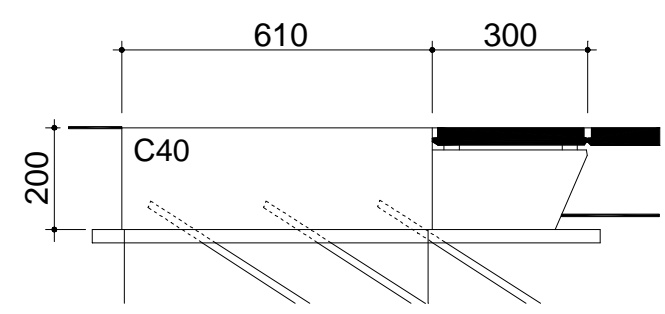

Seção longitudinal

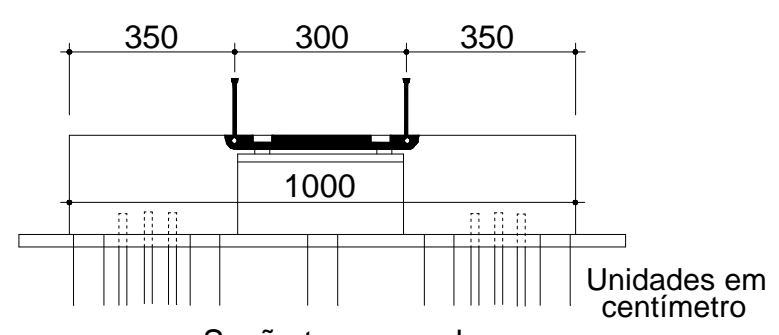

Seção transversal

Figura 26 - Passarela em Prague-Troja - apoio. (STRASKY \& PIRNER, 1986)

A força horizontal a ser absorvida pode atingir $30 \mathrm{MN}$. Os meios usados para sua ancoragem são:

a) Estacas ocas rígidas à flexão;

b) Estacas inclinadas;

c) Uma combinação de paredes diafragma e micro-estacas;

d) Ancoragens em solo ou rocha.

Em estruturas contínuas, a configuração dos pilares intermediários utilizada por STRASKY \& PIRNER (1986) difere das utilizadas em outras estruturas construídas anteriormente. Enquanto se adotava pilares pendulares com mesas de espessura variável, de onde o tabuleiro poderia se elevar de acordo com a variação de carregamento e temperatura, nessa série de passarelas é usada a chamada sela de concreto (v. figura 27). Essa sela é concretada utilizando fôrmas suspensas nos elementos vizinhos.

Embora a concepção dos pilares intermediários seja a mesma em todas as estruturas de STRASKY \& PIRNER (1986), dois tipos de detalhes são usados: 


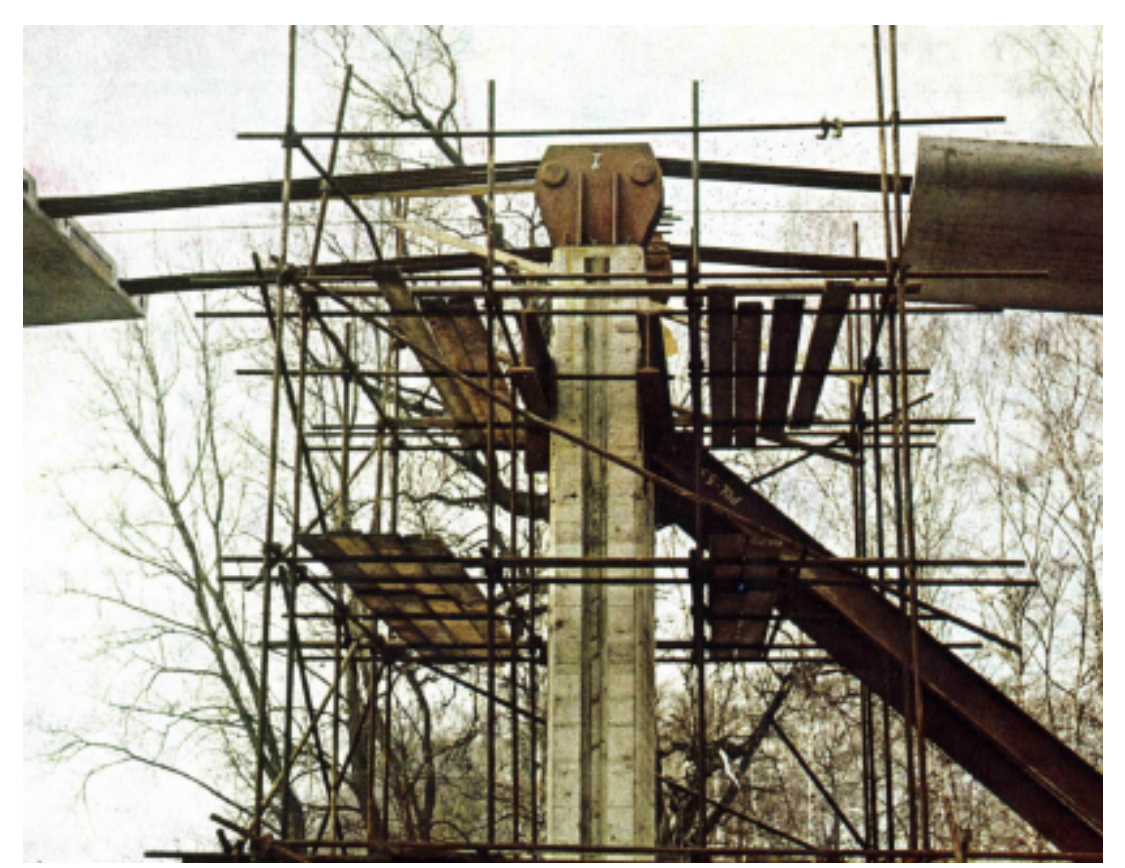

Figura 27 - Sela de concreto (a ser executada). (STRASKY \& PIRNER, 1986)

a) Em estruturas com comprimento aproximado de $100 \mathrm{~m}$, os apoios intermediários são formados por pilares estreitos (v. figura 28). Assim, uma parte considerável da torção devido à carga assimétrica é absorvida somente nos blocos de ancoragem. Os cabos $A$ repousam sobre selas de aço soldadas a travessas de aço ligadas ao pilar (v. figura 29 e 30).
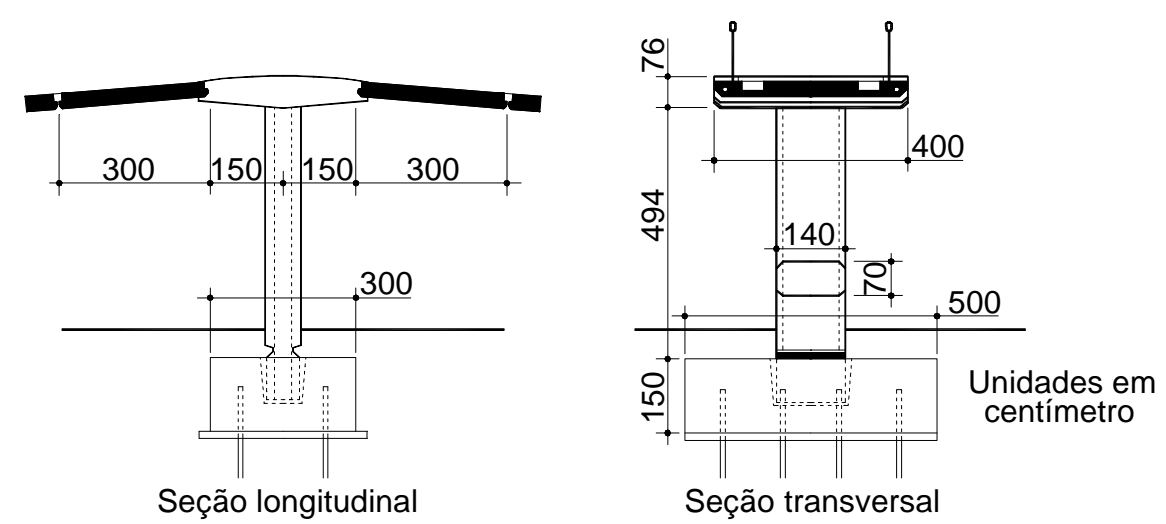

Figura 28 - Passarela em Prerov - apoio intermediário. (STRASKY \& PIRNER, 1986)

b) Em estruturas mais longas, com vãos de aproximadamente $100 \mathrm{~m}$, a torção é absorvida em cada vão por pilares relativamente largos (v. figura 31). Os cabos de sustentação repousam em selas de aço formadas por dois cilindros circulares de 20 cm de diâmetro (v. figuras 32 e 33). 


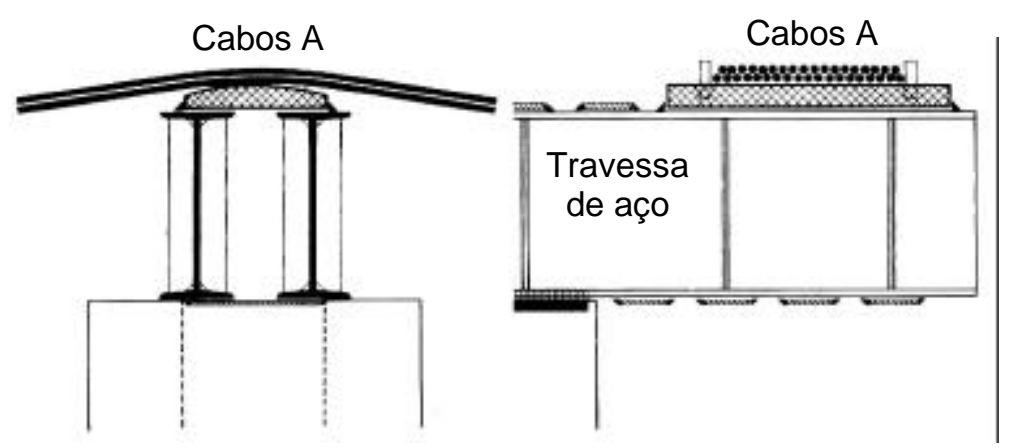

Figura 29 - Passarela em Prerov - sela de aço. (STRASKY \& PIRNER, 1986)

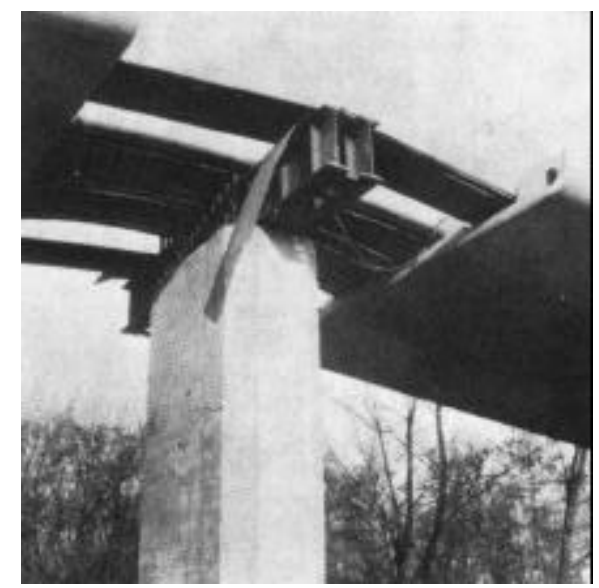

Figura 30 - Passarela em Prerov - sela de aço. (STRASKY \& PIRNER, 1986).
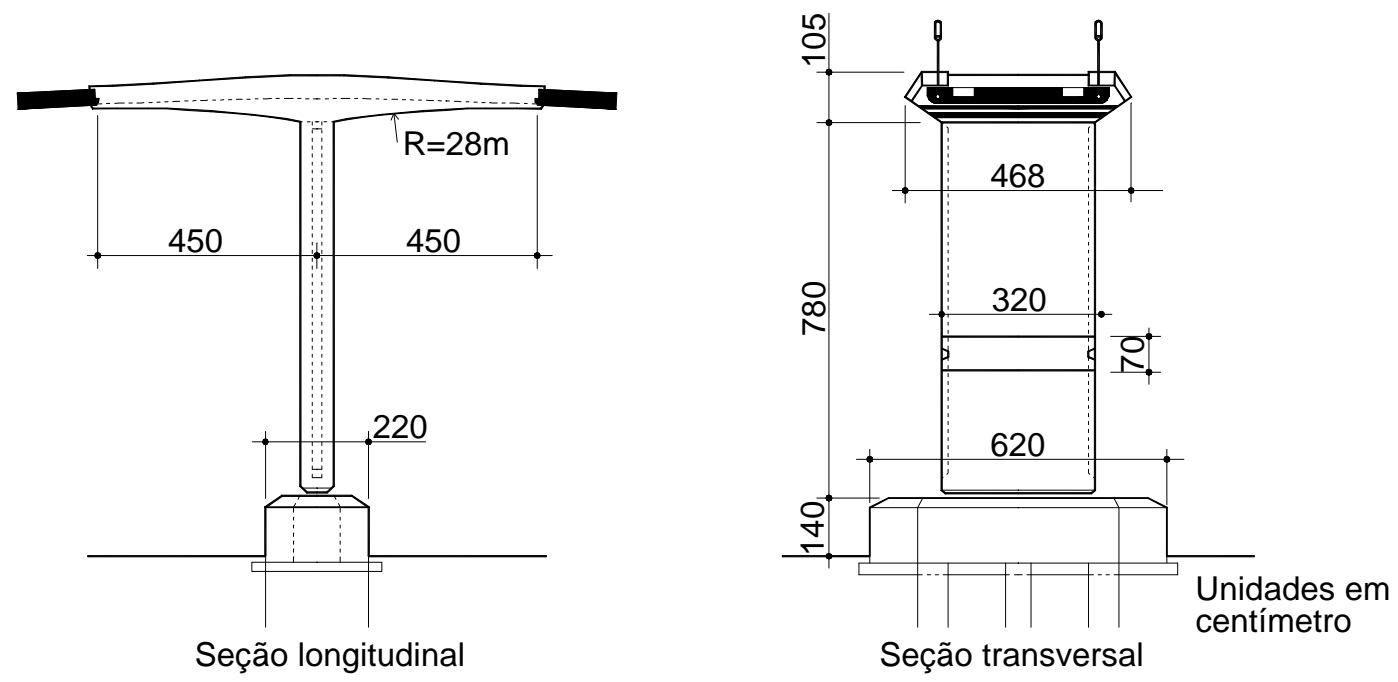

Figura 31 - Passarela em Prague-Troja - pilar intermediário.(STRASKY \& PIRNER, 1986) 


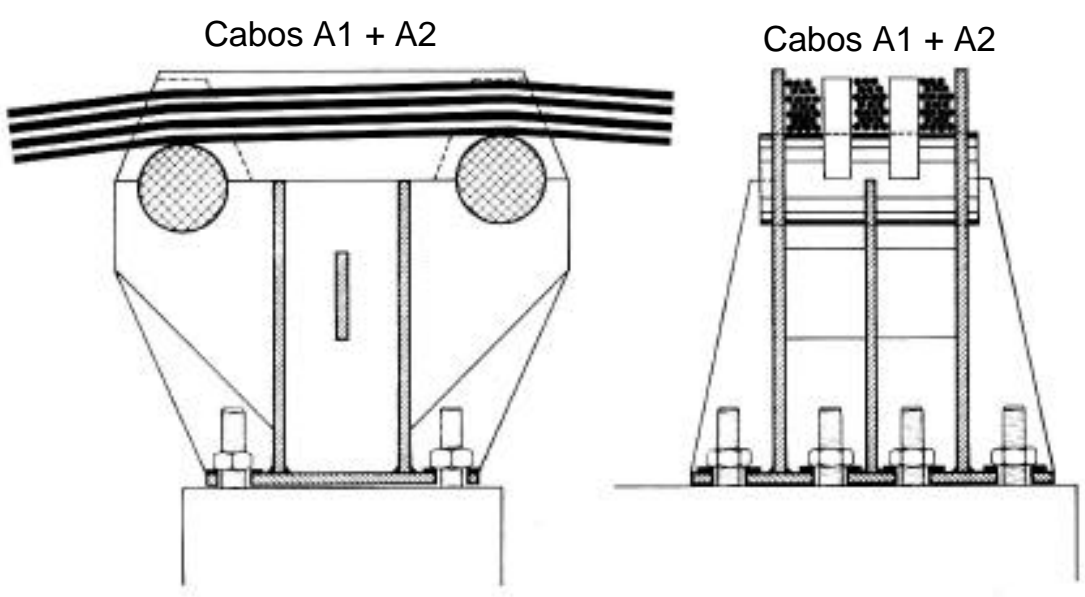

Figura 32 - Passarela em Prague-Troja - sela de aço.

(STRASKY \& PIRNER, 1986)

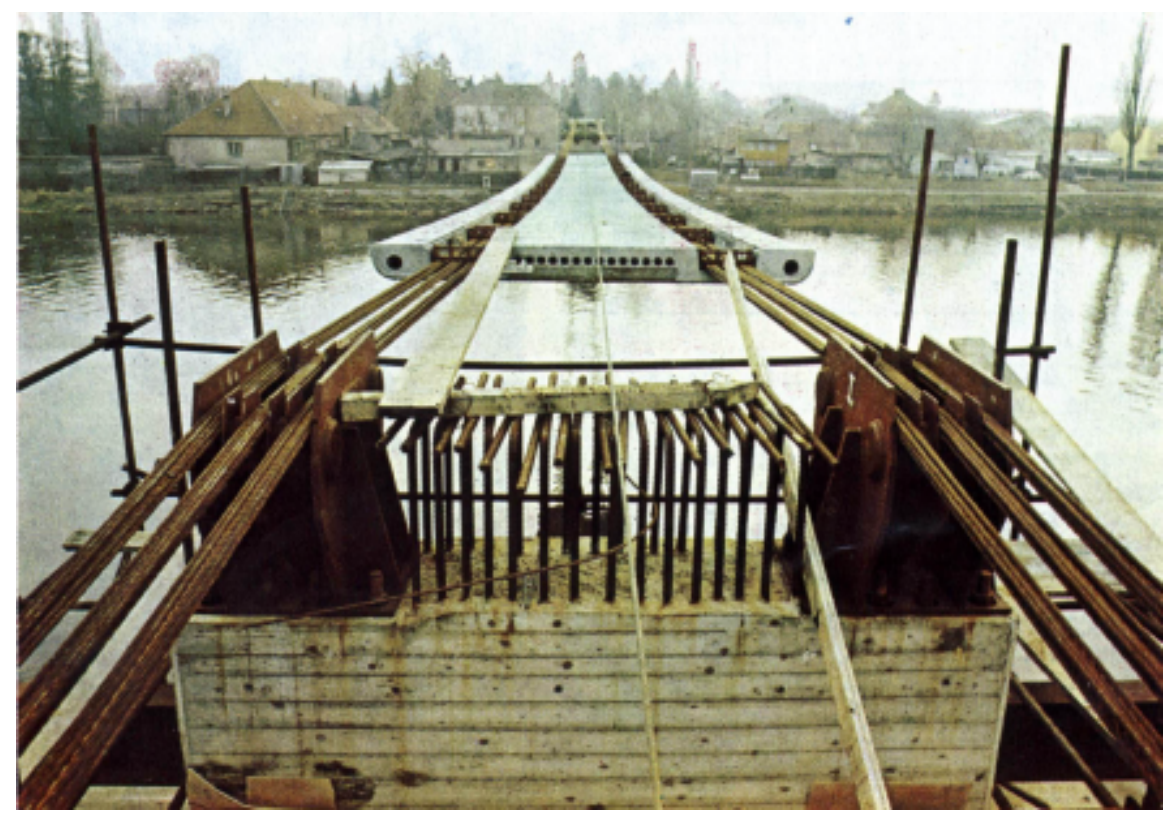

Figura 33 - Passarela em Nymburk - pilar intermediário com sela de aço.

(STRASKY \& PIRNER, 1986)

O pavimento é formado por concreto de $1 \mathrm{~cm}$ de espessura que impermeabiliza o tabuleiro.

Os elementos que formarão o tabuleiro foram moldados em fôrmas de aço em ciclo de 1 dia. Foram usados vibradores de superfície. A fim de reduzir os efeitos da retração e fluência do concreto, a moldagem se deu 6 meses antes da montagem da estrutura.

A construção das passarelas pode ser dividida em 6 etapas básicas:

a) Execução das fundações, blocos de ancoragem e pilares intermediários; 
b) Os elementos de extremidades são colocados sobre almofadas de elastômero (v. figura 34), as selas de aço são colocadas nos apoios intermediários e são colocadas escoras temporárias nos pilares (v. figura 27);

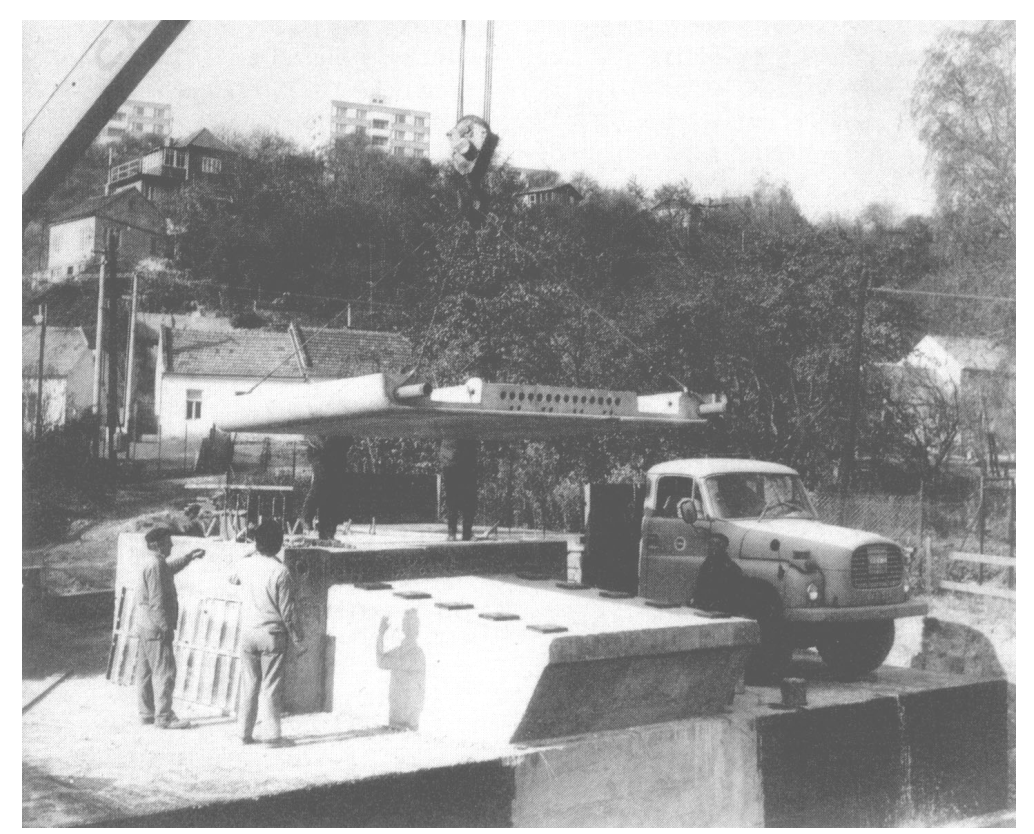

Figura 34 - Montagem do elemento de extremidade. (STRASKY \& PIRNER, 1986)

c) Os cabos $A$ são desenrolados das bobinas, cortados todos com o mesmo comprimento e dispostos no vão com o auxílio de cabos auxiliares. Em seguida, os cabos são tracionados de acordo com o projeto. Em estruturas com apenas uma linha de cabos, todos são dispostos. Se existirem duas linhas, apenas a inferior (cabos A1) é disposta nesse momento;

d) Os segmentos são erguidos com o auxílio de guinchos (v. figura 35) e presos aos cabos com o auxílio de dispositivos que se instalam em furos previamente deixados nos elementos (v. figura 36). Em seguida, os elementos são ligados aos cabos auxiliares e deslizam até sua posição de projeto (v. figura 37). Nas juntas são colocados tubos de aço (v. figura 38). Esse processo se repete até que toda a passarela seja montada;

e) Em estruturas com duas linhas de cabos, a linha superior (cabos A2) é colocada e tracionada. A fôrma das selas é segura nos elementos vizinhos, os cabos de protensão (cabos $B$ ) são colocados e a armação da região dos cabos de sustentação e da sela são dispostas. As juntas, a região onde estão alojados os cabos de sustentação e as selas são concretadas ao mesmo tempo. Assim que possível, o tabuleiro é parcialmente protendido (cabos $B$ ). Após ser atingida a resistência requerida, todos os cabos de protensão são tracionados; 


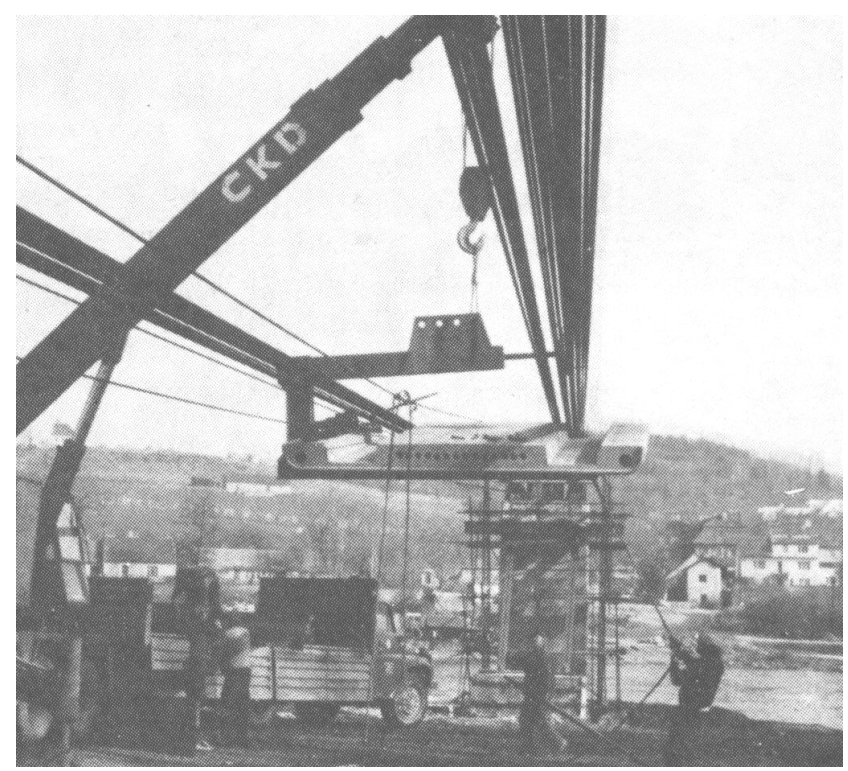

Figura 35 - Içamento de um elemento do primeiro vão. (STRASKY \& PIRNER, 1986)

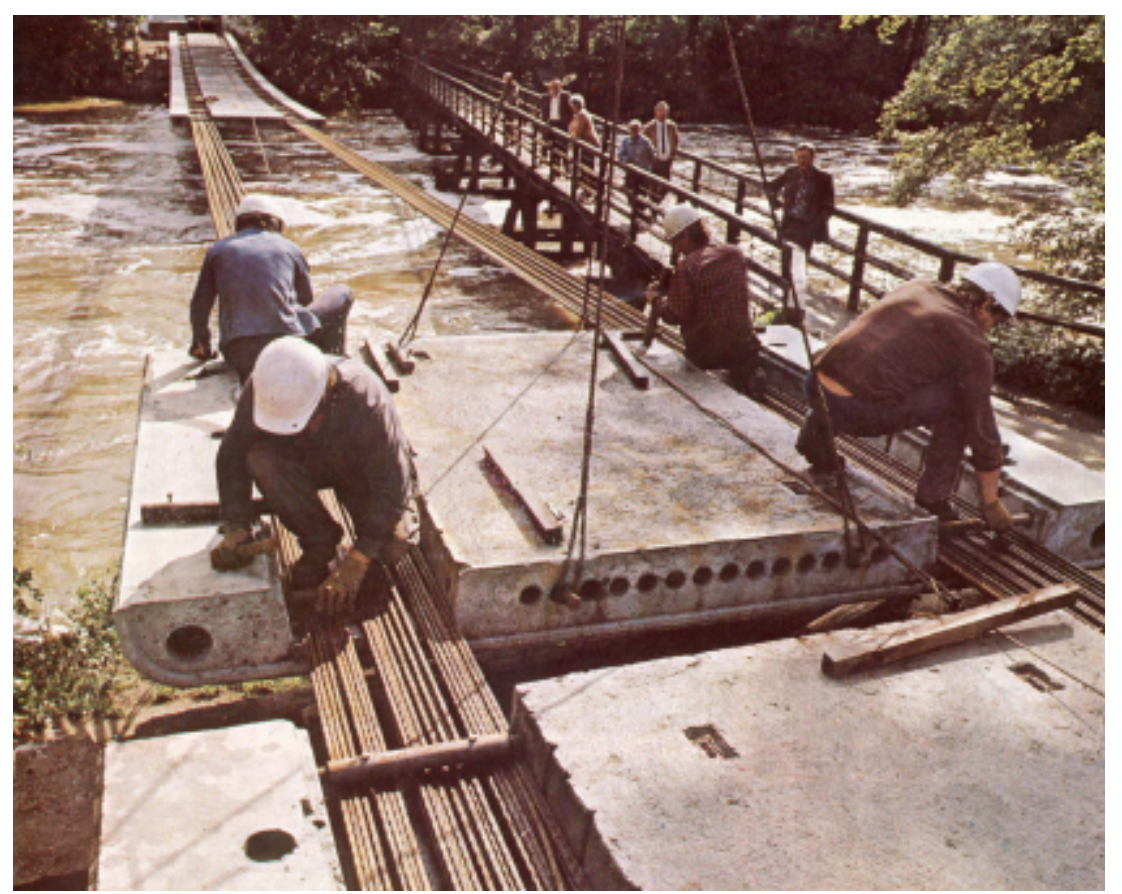

Figura 36 - Inserção de dispositivos para fixação do elemento aos cabos.

(STRASKY \& PIRNER,1986)

f) Os furos onde estão instalados os cabos de protensão (cabos $B$ ) são concretados, é montado o corrimão e concretado o pavimento. Em seguida, tem-se início a prova-decarga, que é exemplificada nas figuras 39 e 40 (nesse caso, foram utilizados caminhões pesando de 2,8 a $8,4 \mathrm{tf})$. 


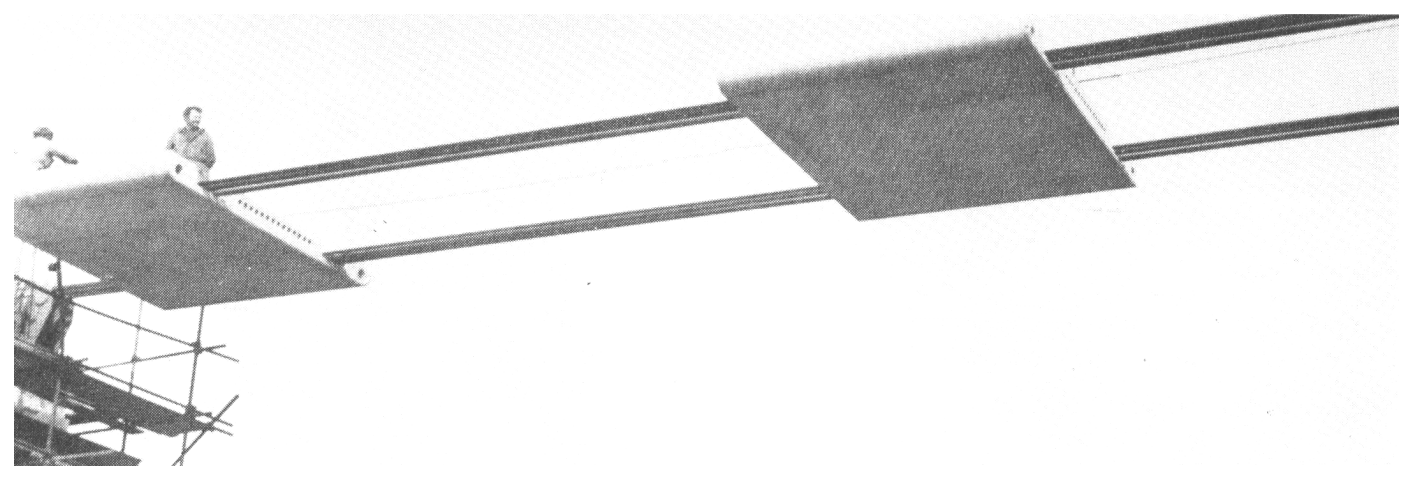

Figura 37 - Elemento deslizando sobre os cabos de sustentação.

(STRASKY \& PIRNER, 1986)
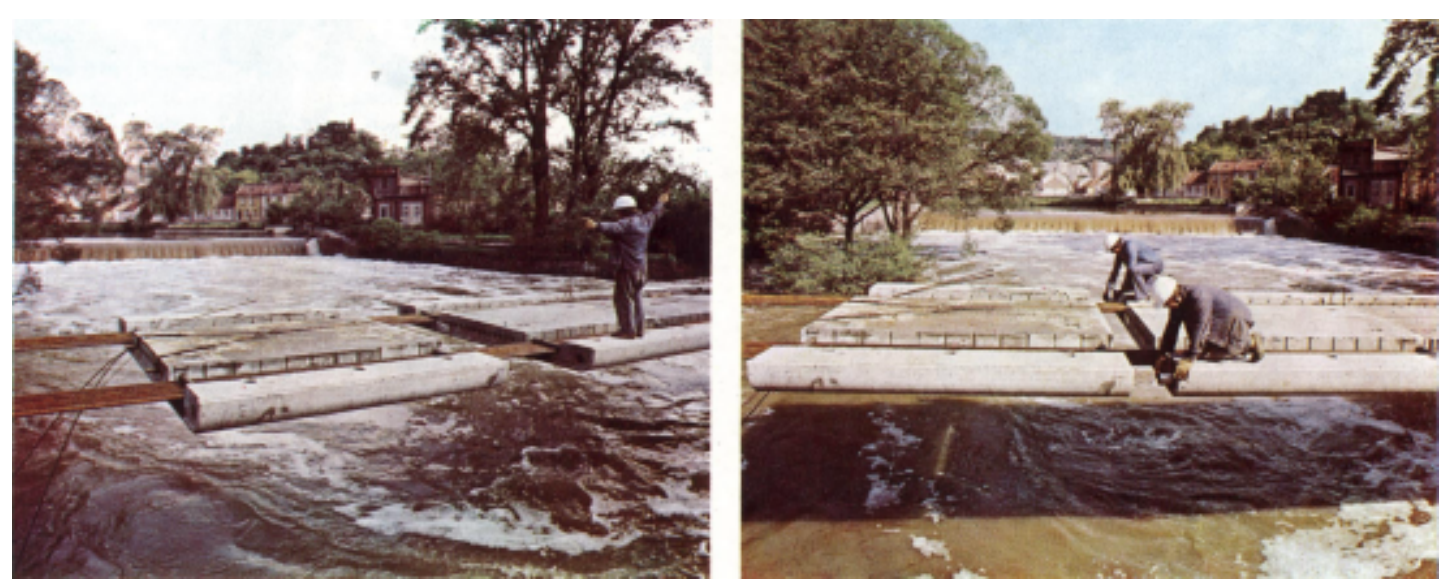

Figura 38 - Colocação de tubos de aço entre os elementos. (STRASKY \& PIRNER, 1986)

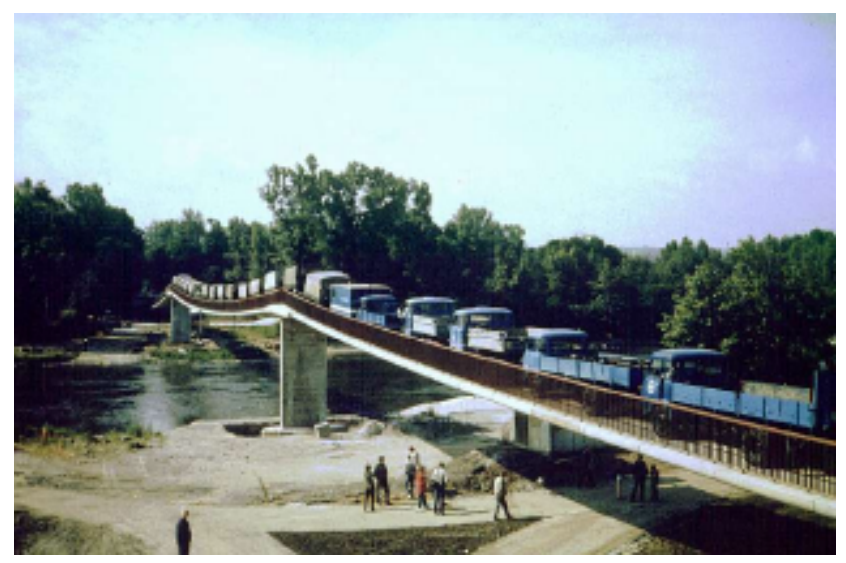

Figura 39 - Prova de carga. (STRASKY, 1999) 


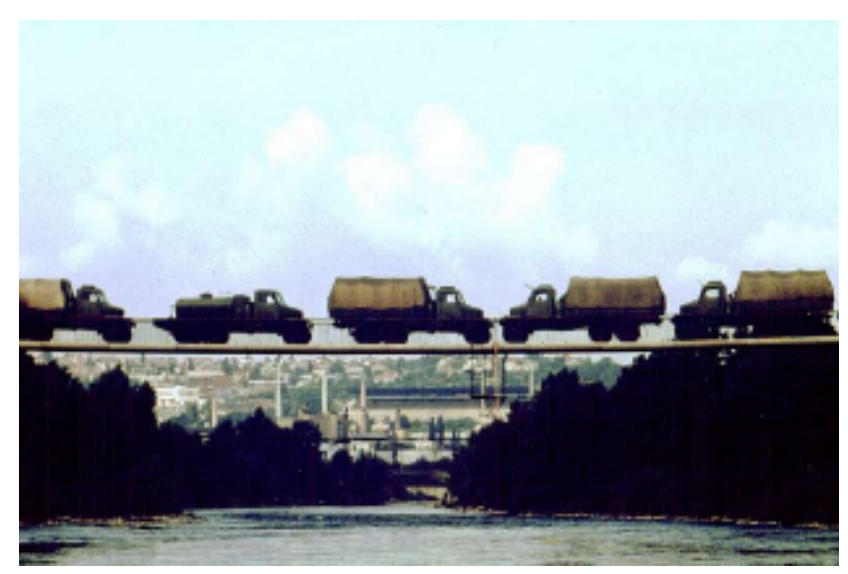

Figura 40 - Prova de carga. (STRASKY, 1999)

STRASKY (1990) comenta sucintamente duas passarelas idênticas cujo tabuleiro é formado por painéis de madeira ( $v$. figura 41). As estruturas possuem três vãos com comprimento de $15 \mathrm{~m}, 40 \mathrm{~m}$ e 15m. Os cabos são formados por cordoalhas dentro de tubos de polietileno grauteados e a montagem da estrutura é similar à executada com elementos pré-moldados de concreto. Os painéis de madeira são conectados a vigas longitudinais nas bordas laterais, tornando o comportamento dinâmico satisfatório.

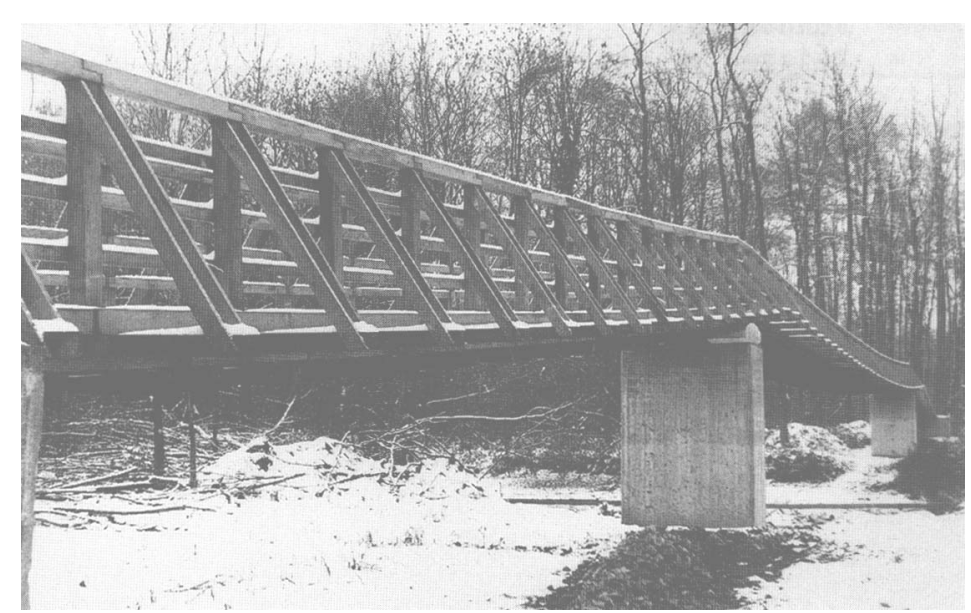

Figura 41 - Passarela formada por elementos de madeira. (STRASKY, 1990)

Ainda em STRASKY (1990) é descrita uma alternativa usada para o enrijecimento de uma estrutura com $170 \mathrm{~m}$ de vão (v. figura 42). A montagem do tabuleiro se dá igualmente às demais passarelas pênseis. Em seguida, esse tabuleiro é usado como plataforma de trabalho para a fixação dos cabos adicionais. 

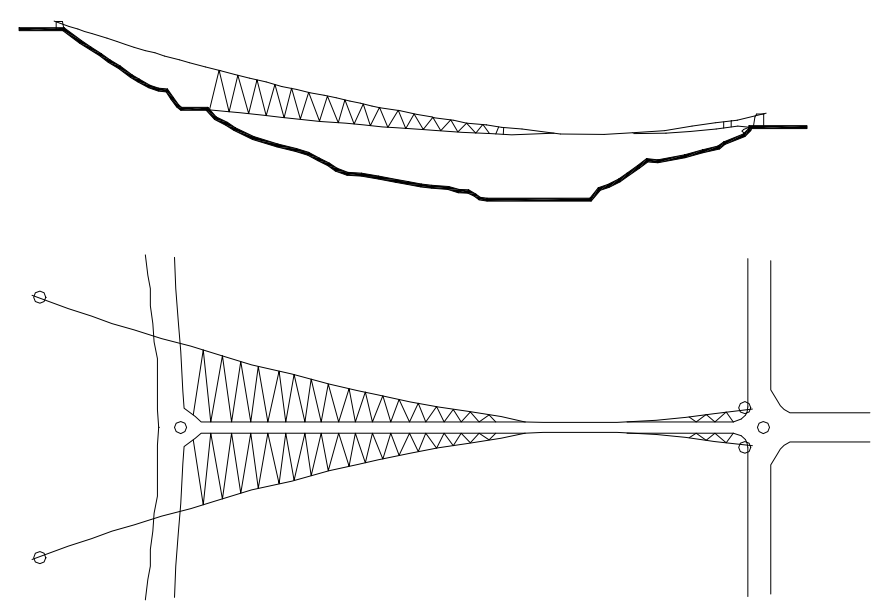

Figura 42 - Passarela com 170 m de vão. (STRASKY, 1990)

Uma passarela (v. figura 3) sobre o rio Sacramento em Redding, California, é descrita por REDFIELD et al (1992). O vão livre é de 127,41 m e a largura total é de 3,96 m. A flecha varia de 3,35 m (logo após a construção, máxima temperatura e máxima carga variável) para 2,44 m (tempo infinito e mínima temperatura). O tabuleiro tem uma espessura constante de $38,1 \mathrm{~cm}$, com exceção dos trechos distantes $5,79 \mathrm{~m}$ dos apoios, que possuem altura variável (v. figura 43). A variação de altura próxima aos apoios foi a solução encontrada para resistir às tensões devidas aos elevados momentos fletores que surgem nessa região devido à protensão, queda de temperatura e retração do concreto. Outras alternativas, como o projeto de uma articulação junto aos apoios ou a construção de uma sela flexível de concreto foram descartadas, a primeira devido à fadiga a que os cabos estariam sujeitos e a segunda por ser considerada "desnecessariamente sofisticada" pelos autores.
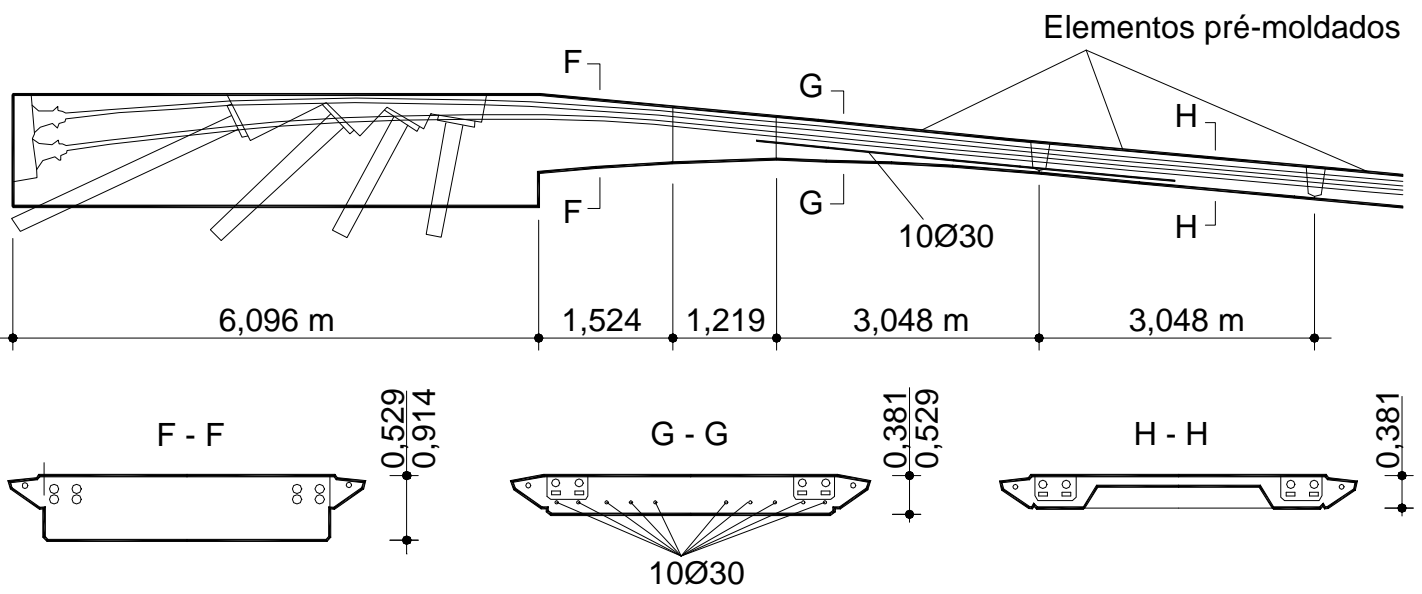

Figura 43 - Passarela em Redding - região dos apoios.

(REDFIELD et al, 1992) 
Como em outros projetos de Strasky, a protensão é introduzida por um segundo grupo de cabos instalados em dutos. Tanto os cabos de protensão quanto os cabos de sustentação estão alojados no próprio elemento pré-moldado (v. figura 44) e estão ancorados na parte traseira dos blocos de fundação. Os elementos pré-moldados são armados nas faces expostas com uma malha de ferros de $12 \mathrm{~mm}$ espaçados de $15 \mathrm{~cm}$, de maneira a reduzir a fissuração por retração do concreto. As juntas entre os elementos foram concretadas sob a menor temperatura possível, durante a noite, no inverno. Com o aumento da temperatura no dia seguinte, obtém-se um certo efeito de compressão.

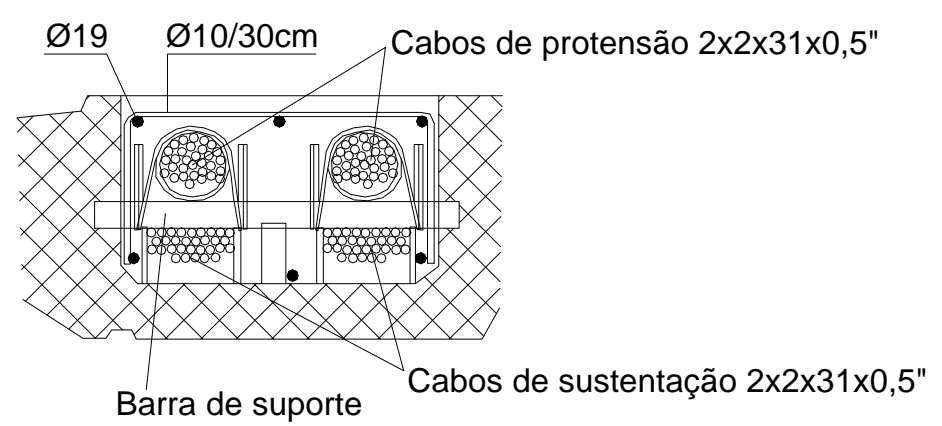

Figura 44 - Alojamento dos cabos no elemento. (REDFIELD et al, 1992)

Quanto à análise estática, para as cargas de montagem a estrutura considerada foi um cabo perfeitamente flexível. Para as cargas de serviço, a estrutura consiste de elementos de viga com comportamento não-linear, tanto geométrico quanto físico. A estrutura foi projetada com protensão completa, com exceção do pequeno arco de altura variável moldado no local nas proximidades dos apoios. A força de protensão aplicada em ambas as extremidades da passarela foi de 14,8 MN.

Uma obra que merece destaque é a Kikko Bridge (v. figuras 45 e 46) localizada em um clube de golfe no Japão. Os três trechos pênseis estão separados por ângulos de $120^{\circ}$. O tabuleiro é formado por elementos pré-moldados de concreto.

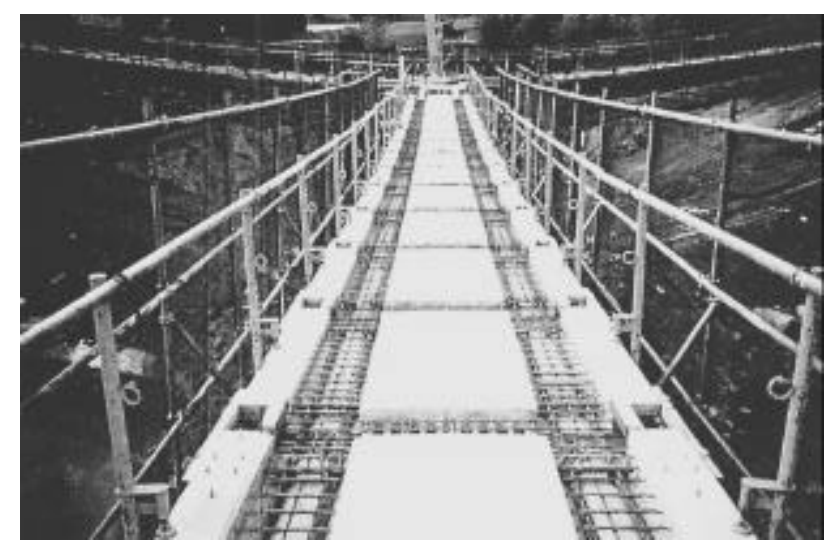

Figura 45 - Kikko Bridge. (ARAI \& OTA, 1997) 


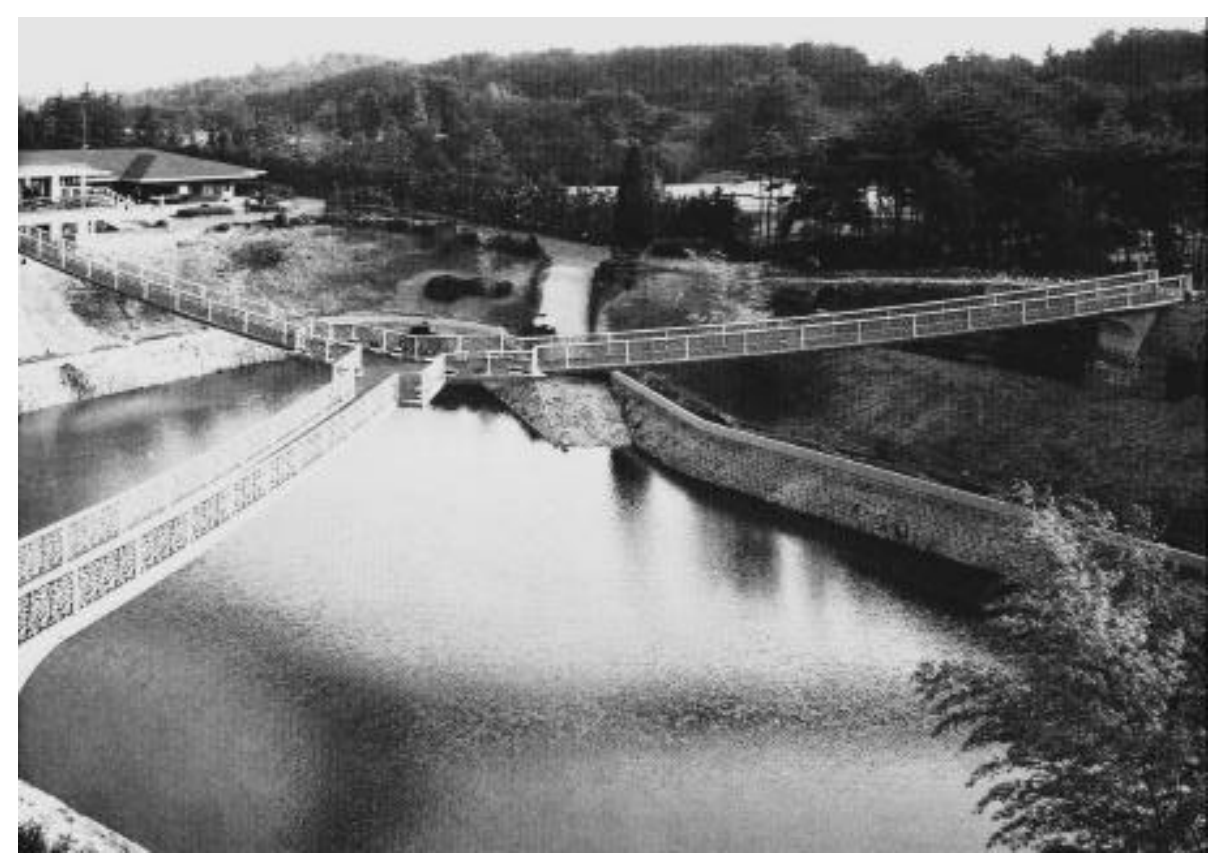

Figura 46 - Kikko Bridge. (ARAI \& OTA, 1997)

STRASKY (1999) apresenta os diagramas de momentos fletores (v. figura 47) para uma estrutura típica. A situação $\boldsymbol{b}$ da figura corresponde à estrutura sem protensão e na situação $\boldsymbol{c}$ a protensão atua. Como a protensão deve estar sempre presente, o caso $\boldsymbol{b}$ tem caráter apenas conceitual.

a)

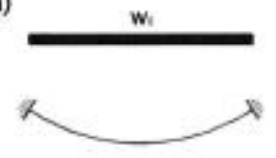

b)

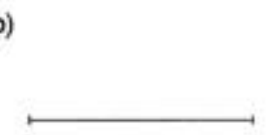

c)

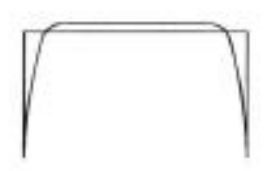

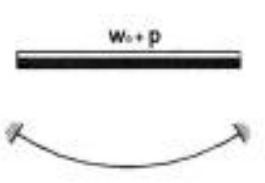
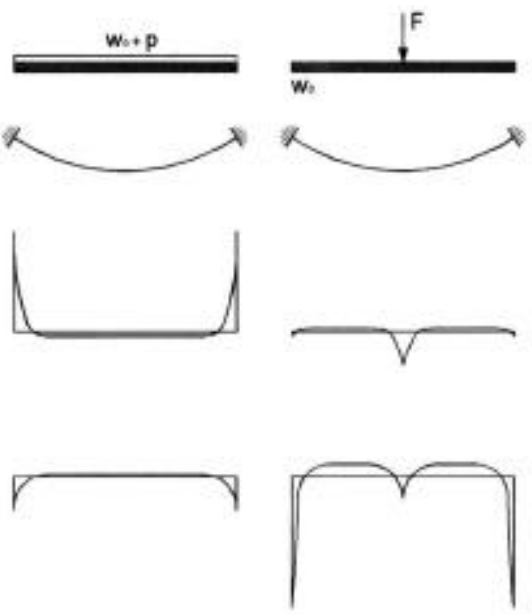
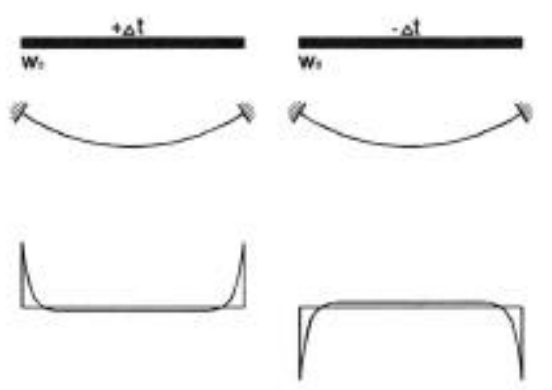
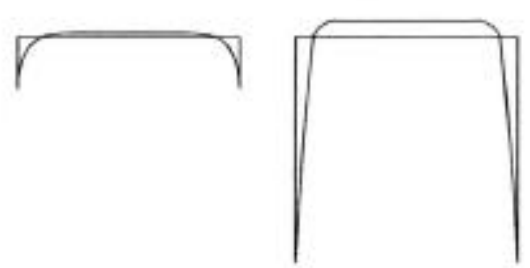

Figura 47 - Diagramas esquemáticos de momentos fletores. (STRASKY, 1999)

Como pode ser observado da figura, momentos fletores elevados só ocorrem nos apoios. De acordo com STRASKY (1999), uma seção transversal típica não tem condições de suportar esses momentos. Como alternativas para solucionar o problema são apresentadas duas opções, de acordo com a figura 48. A primeira maneira é fazer com que 
o tabuleiro possa se elevar após a protensão ou quando a temperatura cai (v. figura 48b). A segunda alternativa é incorporar à estrutura pequenos arcos moldados no local (v. figura 48c). Nesse caso, embora os momentos fletores sejam maiores em comparação com tabuleiros de espessuras constantes ( $v$. figura 48a), as tensões resultantes são menores. Segundo STRASKY (1999), esses arcos são projetados como peças parcialmente protendidas e devem ser suficientemente armados com barras situadas nas suas fibras inferiores.

\section{a)}

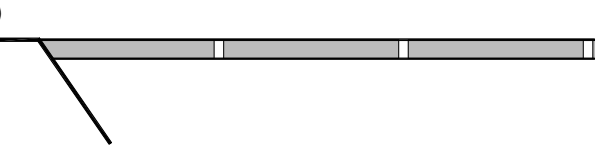

b)

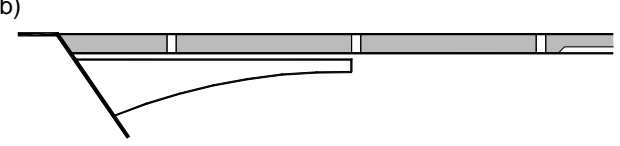

c)
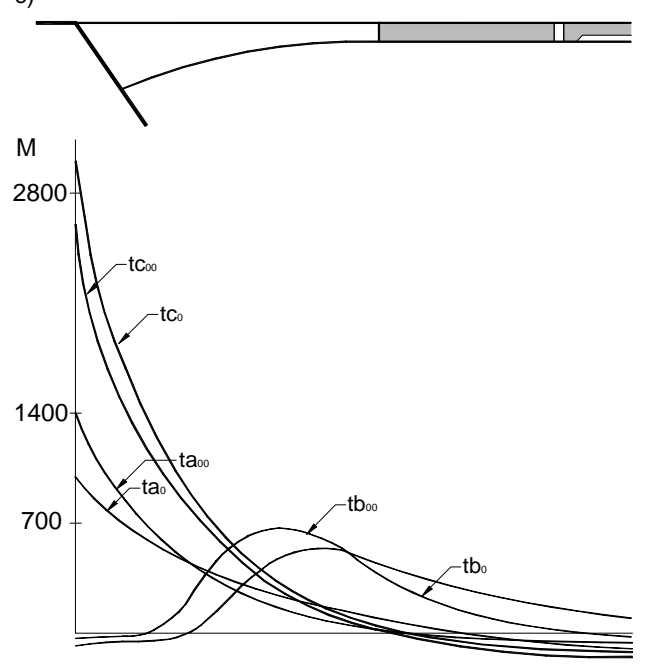

Figura 48 - Momentos fletores nos apoios devido à retração e à fluência do concreto.

(STRASKY, 1999)

Ainda em STRASKY (1999) são fornecidas algumas formas possíveis para a seção transversal das passarelas ( $\mathrm{v}$. figura 49):

$\checkmark$ a alternativa a corresponde a um elemento moldado "in situ", com as fôrmas suspensas nos próprios cabos. Nesse caso, uma das principais vantagens do sistema estrutural aqui discutido, a rapidez na execução, é de certa forma perdida;

$\checkmark$ nas situações $\boldsymbol{b}$ e $\boldsymbol{c}$ são mostradas as seções utilizadas nas primeiras estruturas construídas por Strasky. Os cabos de sustentação passam sobre os elementos e depois da montagem o tabuleiro é protendido por um segundo grupo de cabos. Os cabos de sustentação são protegidos com concreto moldado no local simultaneamente com a 
concretagem das juntas entre os elementos. A junta longitudinal entre os elementos prémoldados e o concreto moldado no local deve ser coberta com camada impermeabilizante, já que podem ocorrer fissuras nessa interface;

$\checkmark \quad$ os elementos também podem ser montados sobre cabos que serão removidos após a protensão do tabuleiro, conforme item $\boldsymbol{d}$;

$\checkmark$ no item $\boldsymbol{f}$ os elementos são sustentados e protendidos por cabos externos;

$\checkmark$ em aplicações recentes, estão sendo usadas seções compostas ( $v$. item e). Os elementos de concreto pré-moldado são suspensos e servem de fôrma para o concreto moldado no local. A concretagem é feita simultaneamente com a moldagem das juntas entre os elementos e a estrutura é protendida por cabos situados dentro do concreto moldado no local. O tabuleiro contínuo proporciona ótima proteção para os cabos e requer mínimos trabalhos de manutenção.

a)

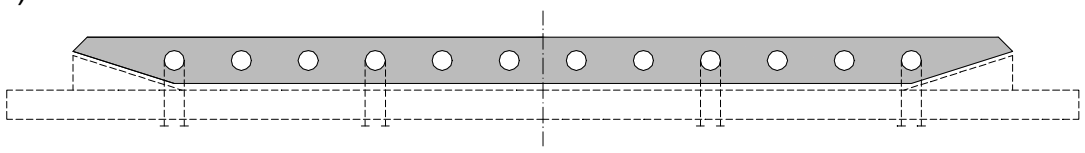

b)

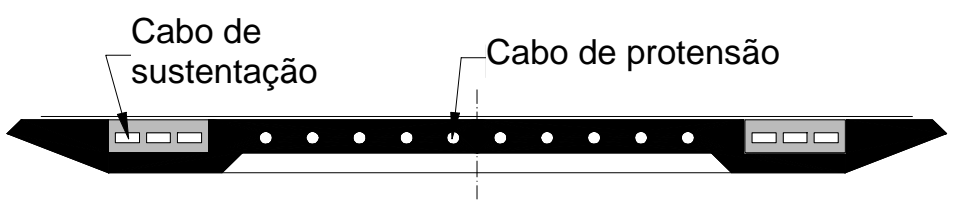

c)

d)
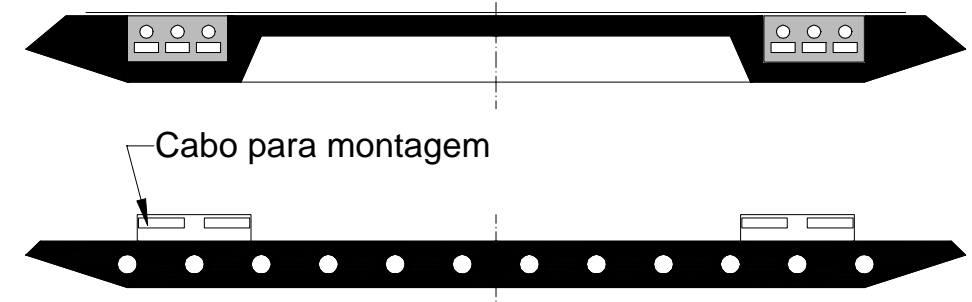

e)

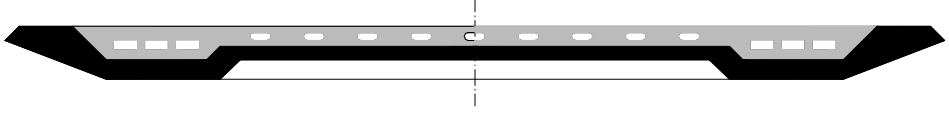

f)

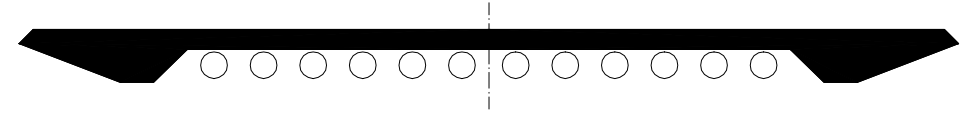

Figura 49 - Seções transversais. (STRASKY, 1999) 
Finalizando, STRASKY (1999) mostra algumas aplicações recentes do sistema estrutural. Uma delas que merece especial destaque é ilustrada na figura 50. A passarela se localiza em Maidstone, Reino Unido. Ela é formada por três trechos retos e o tabuleiro é formado por elementos compostos. Uma característica marcante é a presença de força horizontal inclusive nos apoios intermediários. Esta força é bastante elevada no apoio intermediário da esquerda e é resistida pela escada inclinada e por tirantes. Entre a extremidade esquerda e o primeiro apoio, existe uma escora, formando um sistema autoequilibrado.

a)
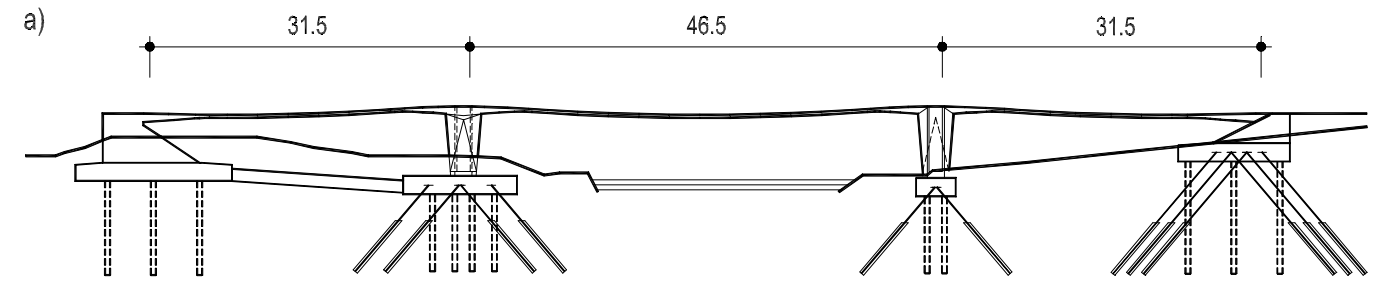

b)

c)

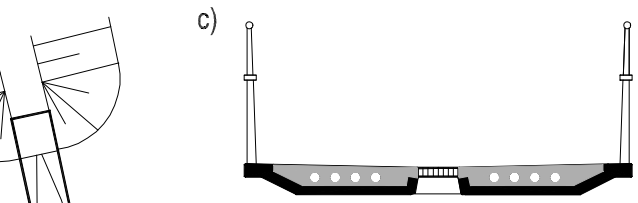

d)

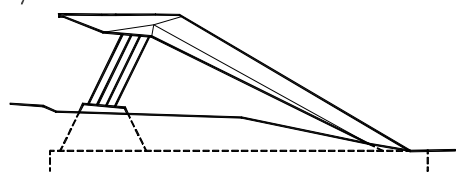

e)

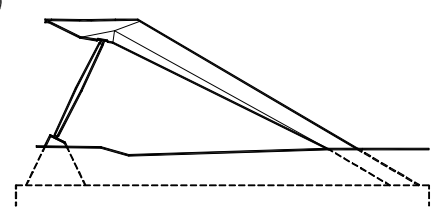

Figura 50 - Passarela formada por três trechos retos. (STRASKY, 1999)

\subsection{ESTRUTURA SUPORTADA POR CABOS ADICIONAIS}

Em casos em que, por qualquer motivo, não se constroem pilares intermediários e o vão é muito extenso, a passarela seria muito sensível a flutuações do vento e a outros efeitos dinâmicos. Como solução para esse problema, surge a possibilidade de fazer com que a estrutura seja sustentada por cabos adicionais com curvatura oposta ao tabuleiro. Um exemplo de passarela com essas características é descrita por STRASKY (1997) e STRASKY \& HUSTY (1998), podendo ser observada nas figuras 51 e 52.

Em razão da dificuldade e do custo da construção de pilares no interior do lago 
devido ao nível da água, optou-se por uma estrutura com um vão único de $250 \mathrm{~m}$ (v. figura 53). O tabuleiro possui forma curva para aumentar a altura livre no centro da passarela e assim possibilitar o tráfego de embarcações.

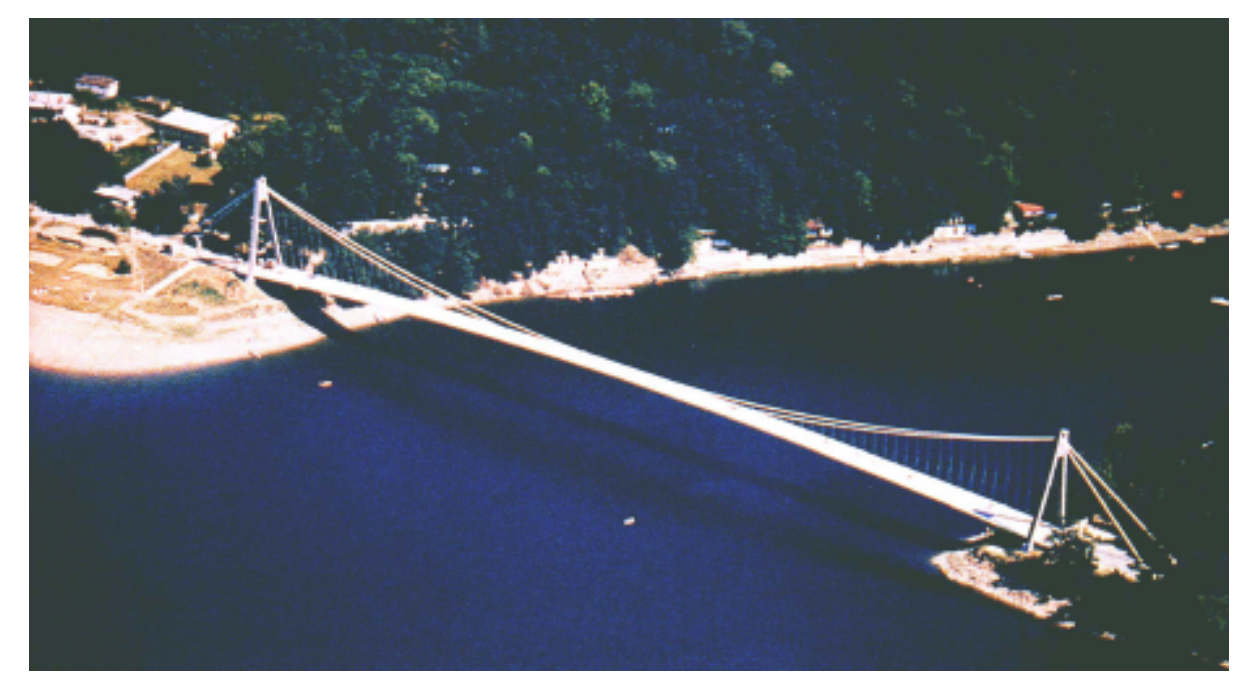

Figura 51 - Vista aérea da passarela sobre o lago Vranov, República Tcheca. (STRASKY, 1997)

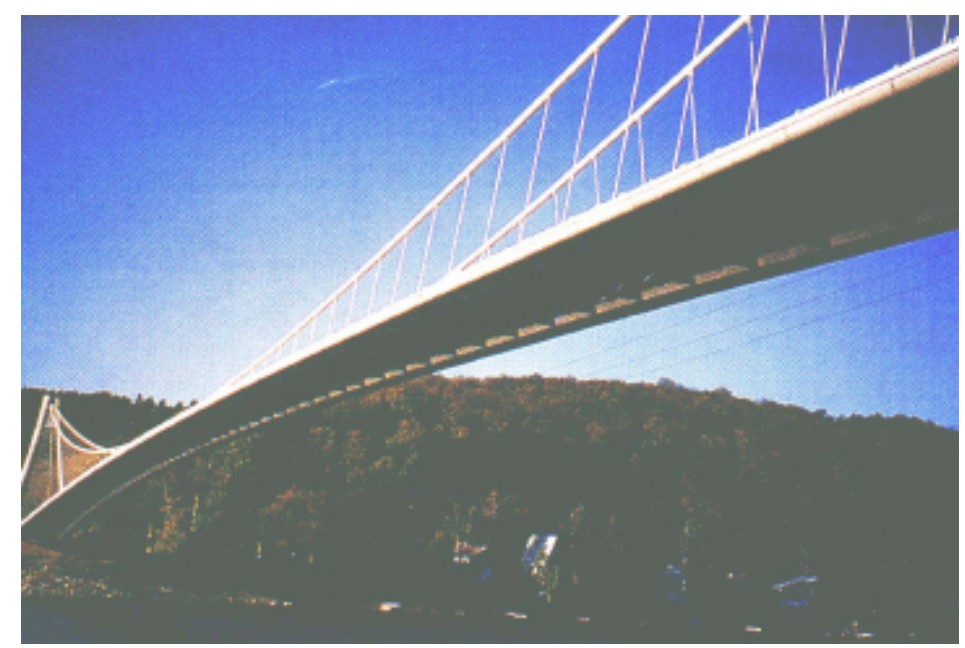

Figura 52 - Passarela sobre o lago Vranov. (STRASKY, 1997)
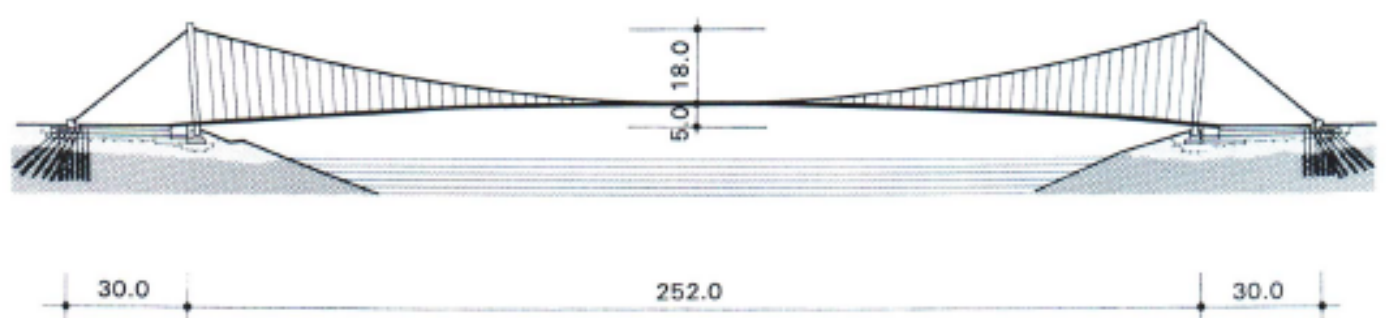

252.0

Figura 53 - Seção longitudinal da passarela. (STRASKY, 1997) 
O arranjo longitudinal adotado tem por função evitar os problemas de vibração e tombamento a que estão sujeitas estruturas pênseis leves. Após o estudo e a combinação de várias alternativas, foi adotado o tabuleiro curvo suspenso em cabos e conectado flexivelmente aos apoios, que por sua vez são conectados aos blocos de ancoragem através de vigas de concreto protendido ( $v$. figura 54). Dessa forma, foi criado um sistema parcialmente auto-equilibrado (v. figura 55c).

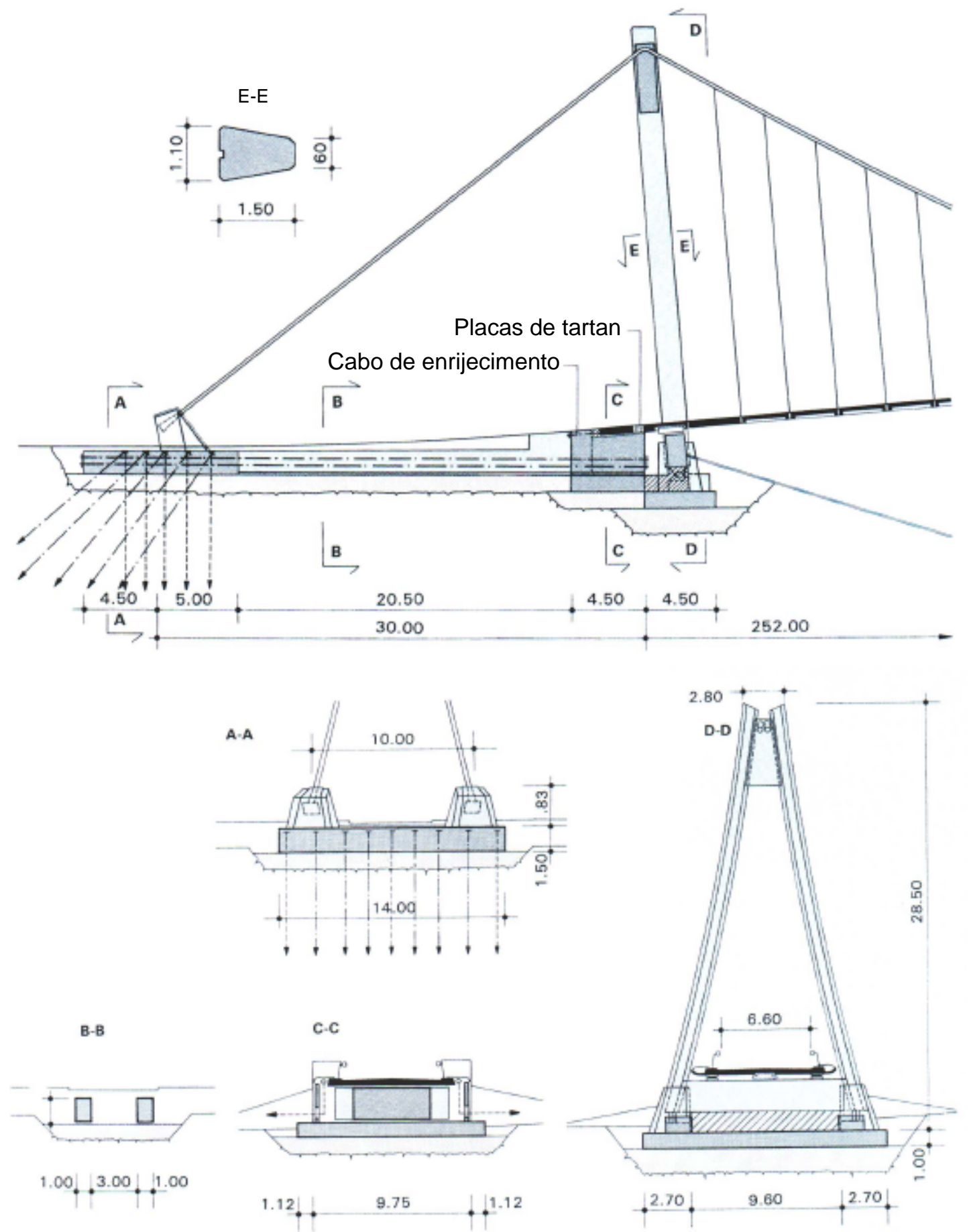

Figura 54 - Pilar, apoio e bloco de ancoragem. (STRASKY, 1997) 
a)

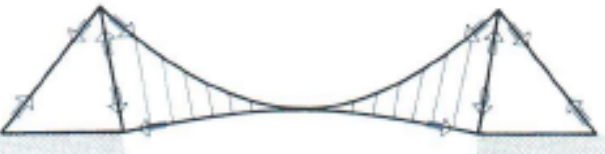

Sistema auto-equilibrado

b)

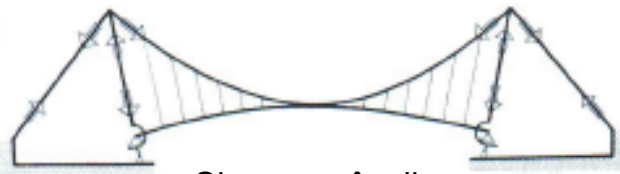

Sistema pênsil

c)

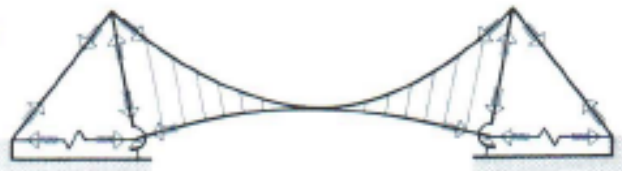

Sistema parcialmente auto-equilibrado

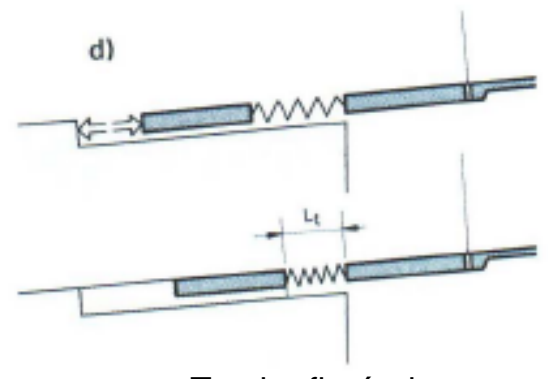

Trecho flexível

Figura 55 - Arranjo longitudinal. (STRASKY, 1997)

Os trechos flexíveis são formados por placas de tartan que são pressionadas contra a estrutura já montada através de macacos (v. figura 55d). Após a compressão, o espaço entre o apoio e o elemento do tabuleiro é concretado. Mesmo com o máximo encurtamento do tabuleiro devido à fluência, retração e variação de temperatura, ainda permanece uma mínima tensão de compressão na junta.

Para a ação variável, variação de temperatura e efeitos do vento, a estrutura forma um sistema fechado em que a carga é resistida tanto pela tabuleiro comprimido quanto pelos cabos de sustentação tracionados. Devido ao comportamento não-linear das placas de tartan, a parcela de carga resistida pelo tabuleiro e pelos cabos depende da temperatura e da idade da estrutura. As placas de tartan permitem grandes deformações sem mudança significativa nas tensões, impermeabilizam o tabuleiro e podem servir como trecho flexível ou junta de expansão.

O enrijecimento da estrutura na direção transversal se fez necessário devido às altas tensões oriundas da ação do vento agindo em um tabuleiro bastante estreito (3,40 m entre corrimão) em relação ao comprimento do vão. A alternativa adotada foi um alargamento do tabuleiro em direção aos pilares (v. figura 56), proporcionando um aumento da rigidez à flexão na direção transversal.

Os pilares utilizados são em forma de $\mathrm{A}$, com pernas curvas conectadas no topo e na base por diafragmas (v. figura 54). As tensões de flexão que surgem são combatidas com o traçado adequado de cabos de protensão. 


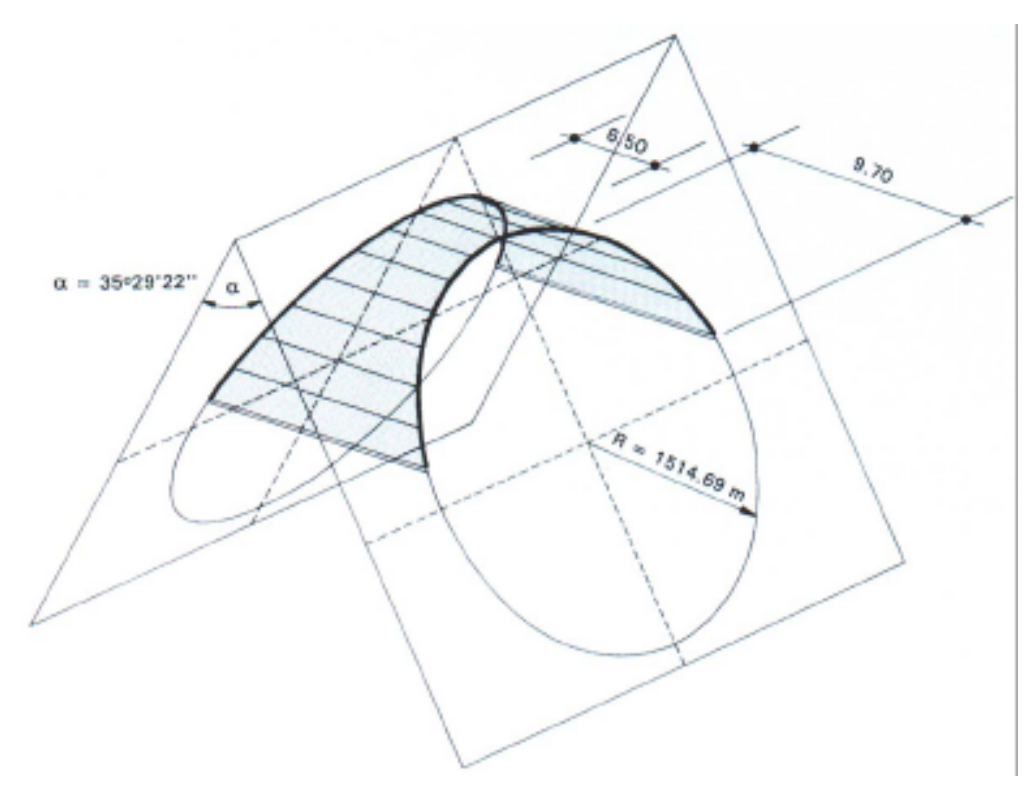

Figura 56 - Geometria do tabuleiro. (STRASKY, 1997)

O tabuleiro é formado por elementos pré-moldados de concreto cuja seção transversal é mostrada na figura 57, com exceção dos elementos de extremidade que são maciços. Cada elemento tem $3 \mathrm{~m}$ de comprimento e largura variável, conforme a geometria da seção transversal. Nas bordas dos elementos estão alojadas as tubulações de água e gás, cobertas com uma carenagem de aço para assegurar a estabilidade aerodinâmica da passarela.

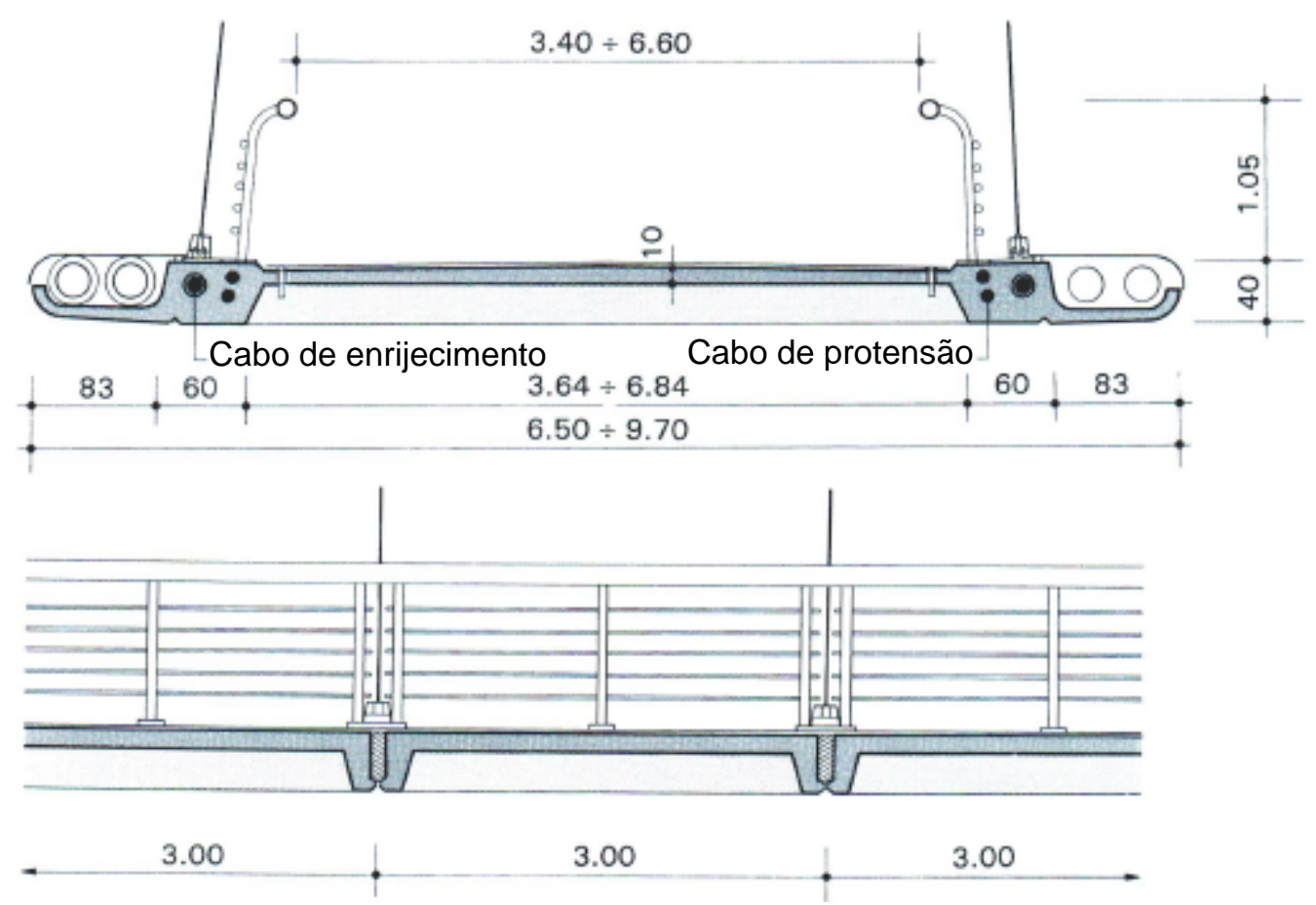

Figura 57 - Seção transversal e longitudinal do tabuleiro. (STRASKY, 1997) 
A estrutura é estabilizada por cabos de enrijecimento ancorados nos apoios (v. figuras 54 e 57). A configuração desses cabos em função da forma do tabuleiro faz com que seu funcionamento seja equivalente ao de um cabo-treliça na posição horizontal. Ainda existem cabos de protensão (v. figura 57 ) que são ancorados nos últimos elementos prémoldados.

O procedimento de execução pode ser resumido da seguinte forma:

$\checkmark$ Inicialmente foram moldados os blocos de ancoragens e os apoios, seguidos da instalação dos tirantes que irão transmitir a tração dos cabos de sustentação ao subsolo. Alguns tirantes e algumas barras de protensão dos blocos de ancoragem foram tracionadas;

$\checkmark$ Os pilares foram moldados na posição horizontal e erguidos para a posição definitiva em duas etapas. Na primeira etapa, os pilares foram içados até uma posição intermediária através de cabos instalados no seu topo e em torres temporárias (v. figura 58a). $\mathrm{Na}$ segunda etapa, os pilares atingiram a posição vertical através de cabos instalados em seus topos (v. figura $58 \mathrm{~b}$ e $58 \mathrm{c}$ );

$\checkmark$ Os cabos utilizados para a movimentação dos pilares também foram usados para a montagem dos tubos de aço em cujo interior serão alojadas as cordoalhas de sustentação. Os tubos com os pendurais eram suspensos nesses cabos e em seguida deslizavam até sua posição final (v. figura $58 \mathrm{~d}$ );

$\checkmark$ A montagem do tabuleiro pré-moldado se deu de maneira similar à montagem das passarelas pênseis sustentadas por cabos livremente suspensos (v. figura 58e). 0 tabuleiro foi adquirindo a sua forma do centro do vão para os apoios, elemento por elemento. Cada elemento era acoplado a uma plataforma apoiada em cabos provisórios ancorados nos apoios e que deslizava em direção ao centro do vão, sendo então o elemento unido ao anterior e aos pendurais (v. figura 59 e 60). Assim, a forma do tabuleiro foi mudando de côncava para convexa, de acordo com o comprimento dos pendurais e a deformação dos cabos de sustentação;

$\checkmark$ Durante a montagem dos elementos, as barras de protensão restantes dos blocos de ancoragem e dos tirantes foram tracionadas para balancear a tração dos cabos de sustentação;

$\checkmark$ Após a disposição de todos os elementos e efetuadas suas conexões, os cabos de protensão e os cabos de enrijecimento foram tracionados e temporariamente ancorados nos apoios. O efeito desse tracionamento é o surgimento de forças radiais (v. figura 58f). Em seguida, os cabos de sustentação foram grauteados e os tubos de aço foram unidos com solda. $O$ afrouxamento dos cabos de protensão e de enrijecimento irá então gerar tensões de compressão no graute e nos tubos de aço. O próximo passo é cortar os cabos de protensão e transferir suas ancoragens para os elementos de extremidade;

$\checkmark$ Finalmente, as juntas entre os elementos foram moldadas e o tabuleiro foi protendido pelos cabos de protensão e por barras ancoradas nos elementos de extremidade; 
$\checkmark$ As juntas de expansão foram colocadas e compressão foi introduzida através de macacos. Finalizando, os cabos de enrijecimento foram novamente tracionados e ancorados nos apoios;

$\checkmark$ Completando os trabalhos, a estrutura foi verificada através de testes estáticos (provade-carga) e dinâmicos.

a)
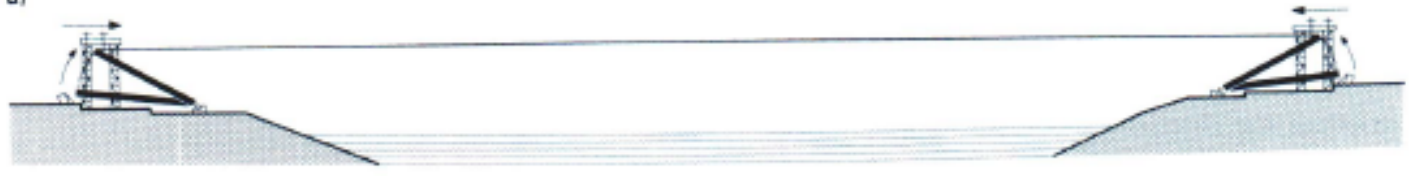

b)
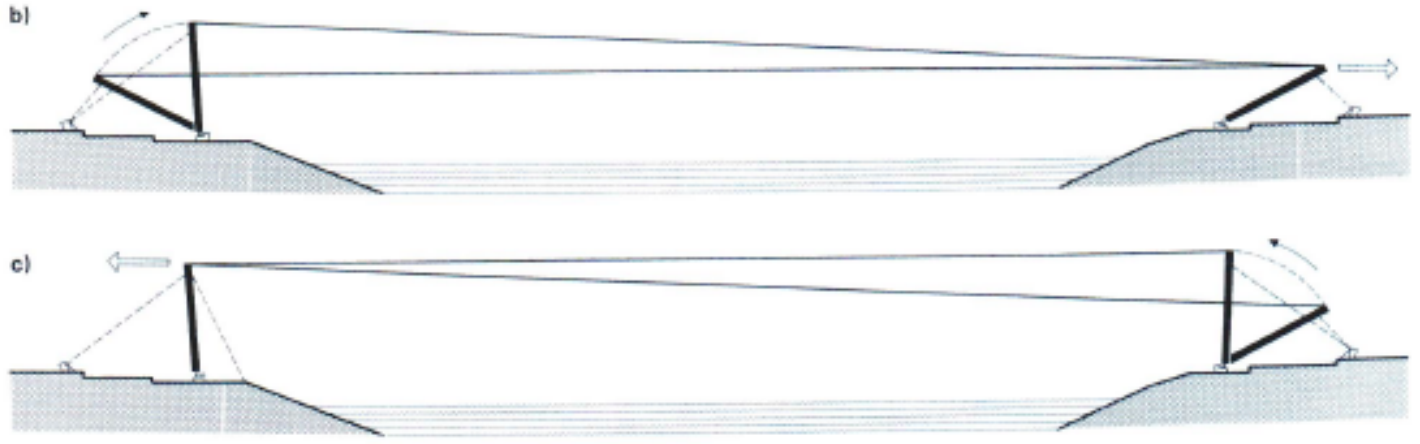

d)
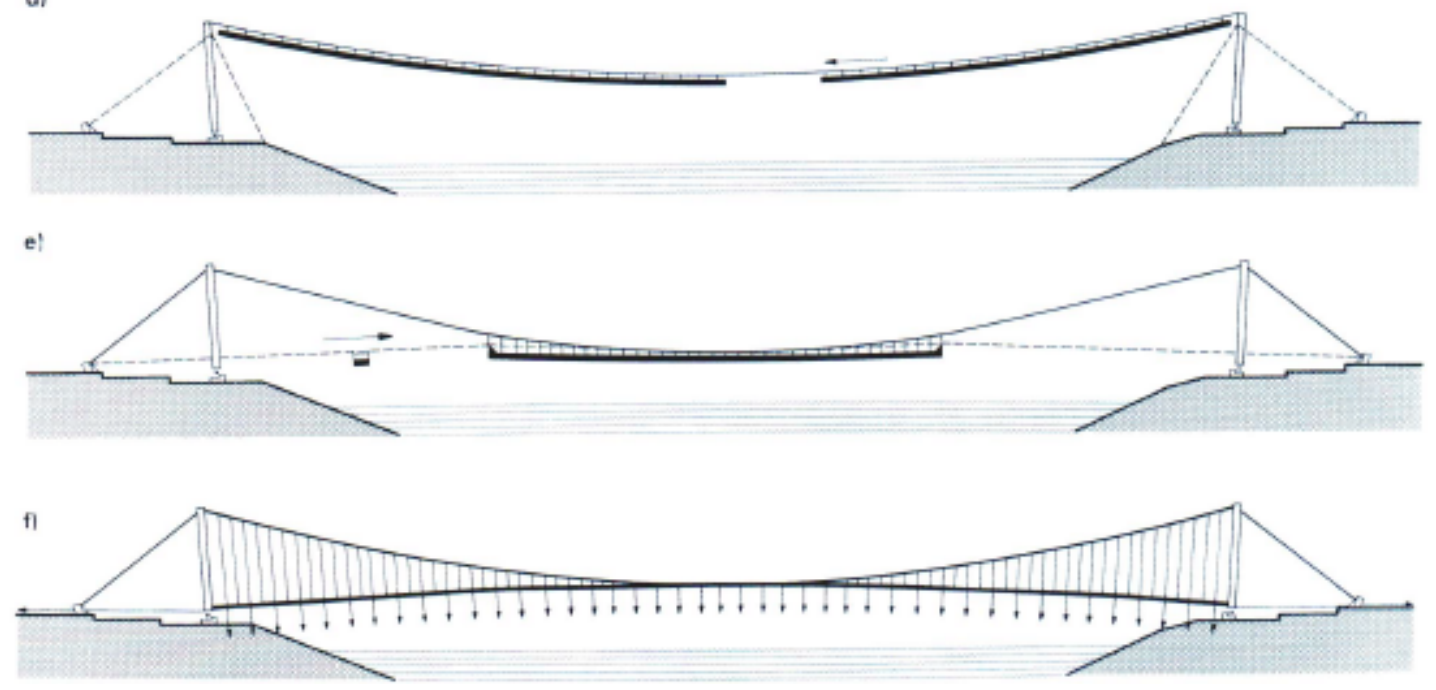

Figura 58- Sequência de execução. (STRASKY, 1997) 


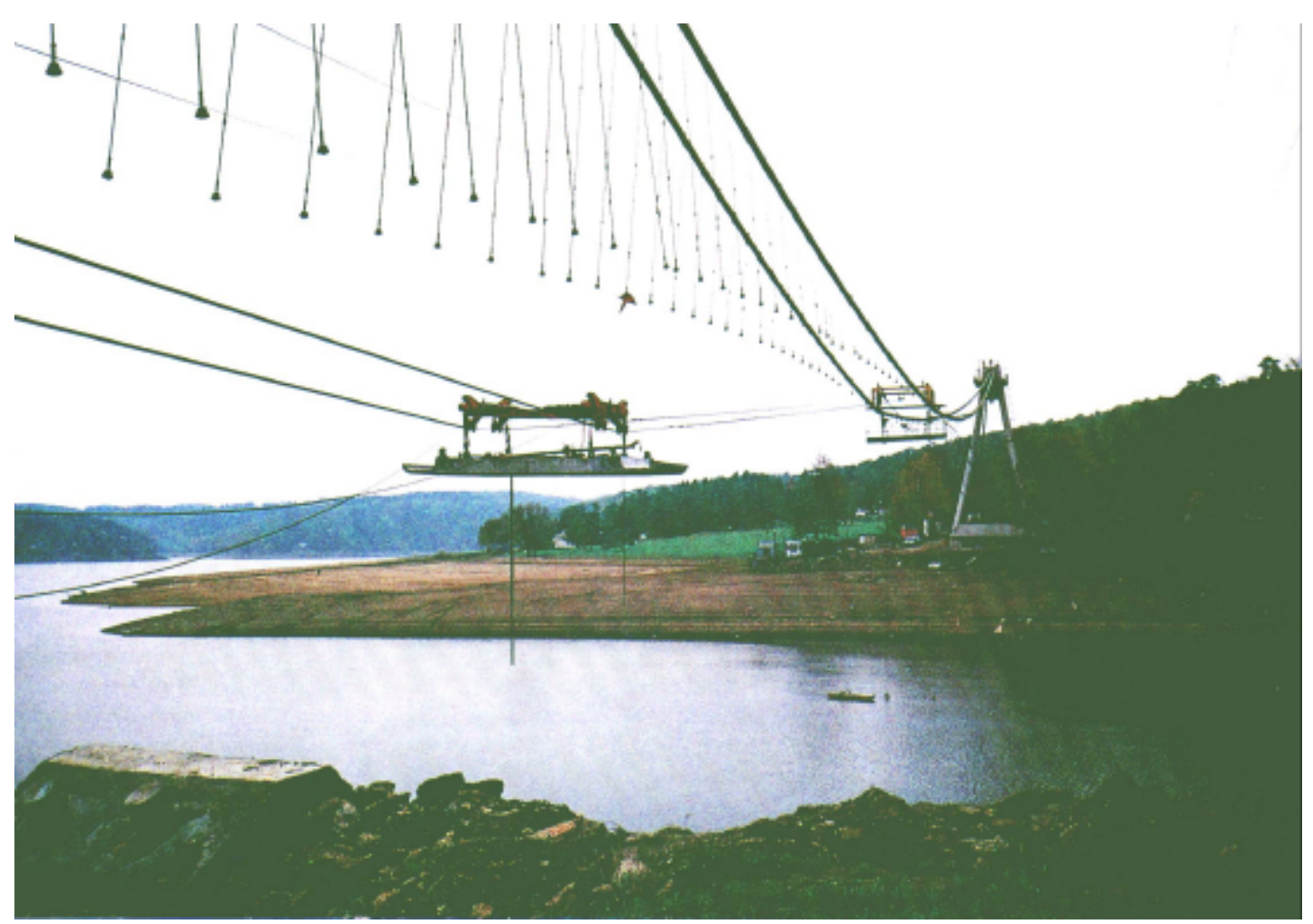

Figura 59 - Montagem do primeiro elemento do tabuleiro.

(STRASKY \& HUSTY, 1998)

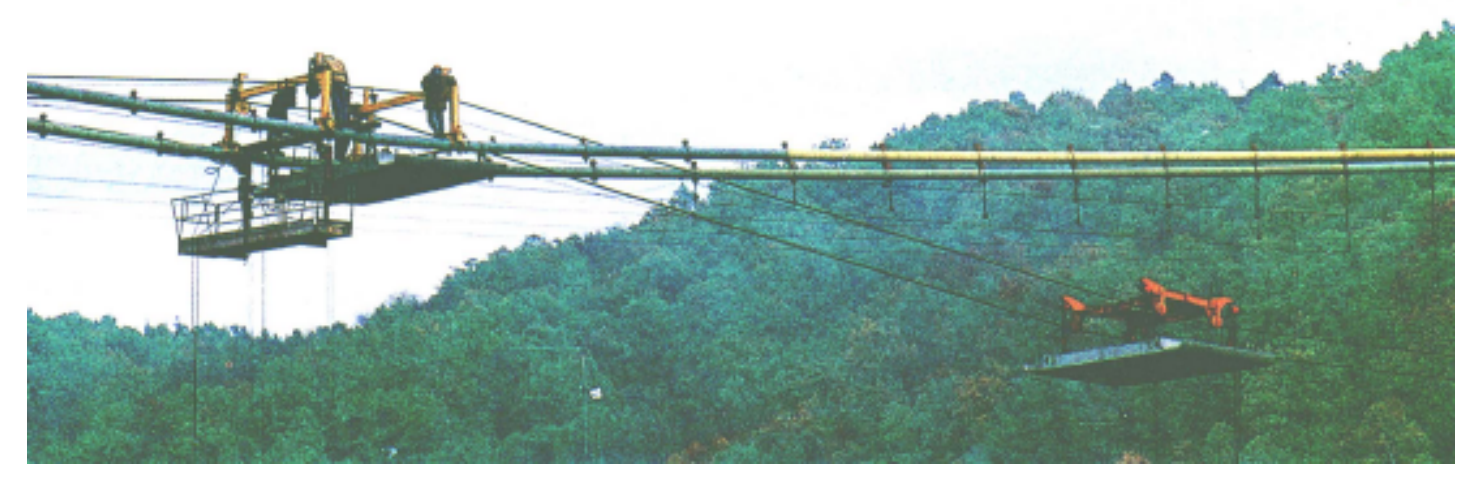

Figura 60 - Montagem do segundo elemento. (STRASKY \& HUSTY, 1998)

\subsection{ESTRUTURA SUPORTADA POR UM ARCO}

Além de reduzir a flecha e as declividades, a grande vantagem aqui introduzida é a possibilidade de se utilizar uma escora ligando a extremidade do tabuleiro às fundações do arco. Dessa forma, a força horizontal nos cabos é balanceada contra a componente horizontal do arco. Esta solução foi adotada na passarela sobre o rio Radbuza em Plzen, República Tcheca (v. figuras 61, 62 e 63). 


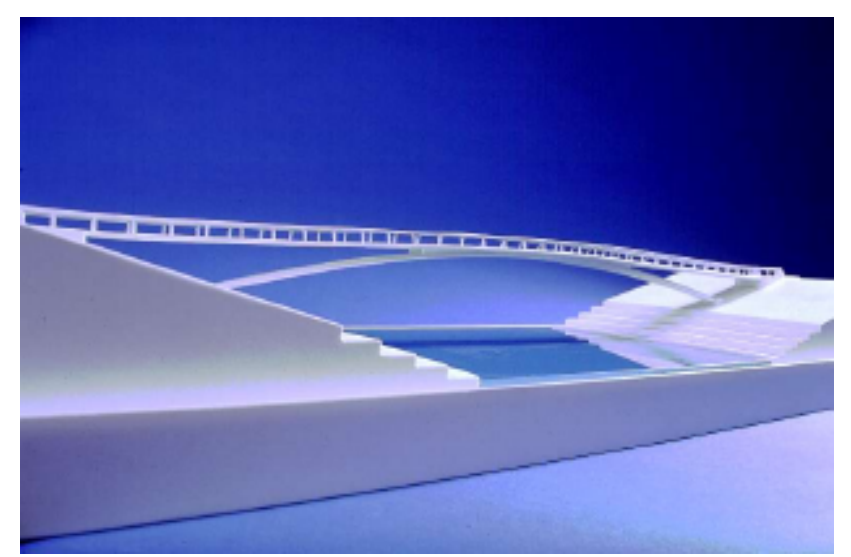

Figura 61 - Passarela em Plzen - modelo arquitetônico. (STRASKY, 1999)

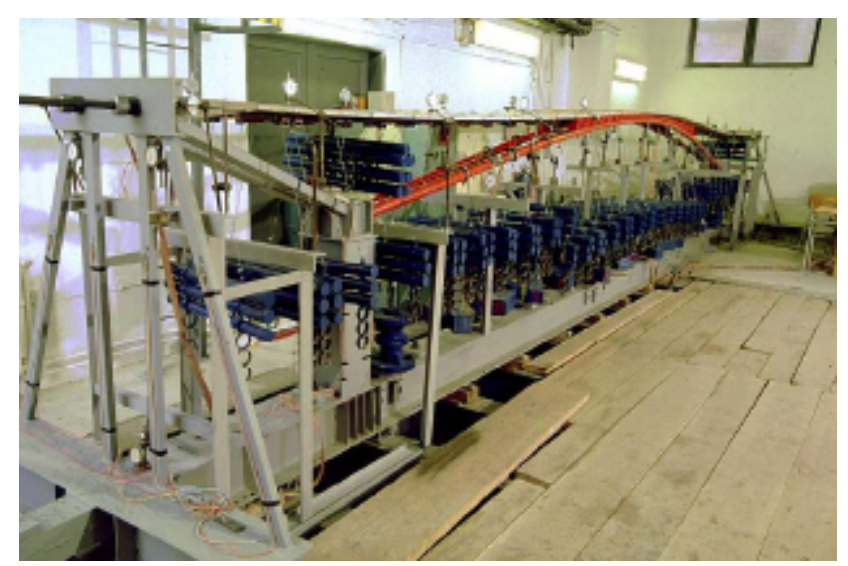

Figura 62 - Passarela em PIzen - modelo estático. (STRASKY. 1999)

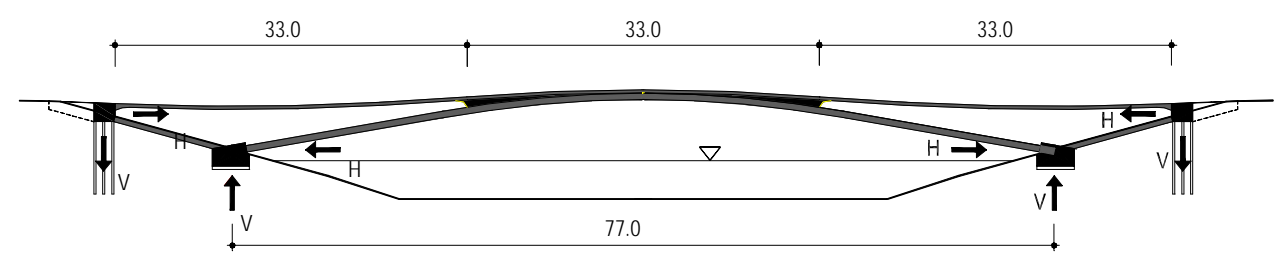

Figura 63 - Passarela em Plzen - elevação. (STRASKY, 1999)

O vão dessa estrutura é de $80 \mathrm{~m}$. A rocha se encontra a $10 \mathrm{~m}$ da superfície, tornando o custo das fundações bastante elevado caso fosse construída uma passarela pênsil convencional.

O arco é formado por dois tubos de aço preenchidos com concreto e o tabuleiro é formado por elementos de seção composta. O apoio no centro do vão se prolonga por um pequeno trecho em direção às extremidades, diminuindo a inclinação da passarela nessa região. As escoras ligando as fundações do arco ao tabuleiro são moldadas no local.

O comportamento da estrutura foi verificado através de testes dinâmicos e por um 
ensaio em túnel de vento. O modelo estático foi feito em escala 1:10 (v. figura 62).

Outra obra que utiliza um sistema híbrido é a passarela Bercy-Tolbiac, em Paris, cuja conclusão era prevista para o ano de 1999 e que pode ser vista nas figuras 64 e 65.

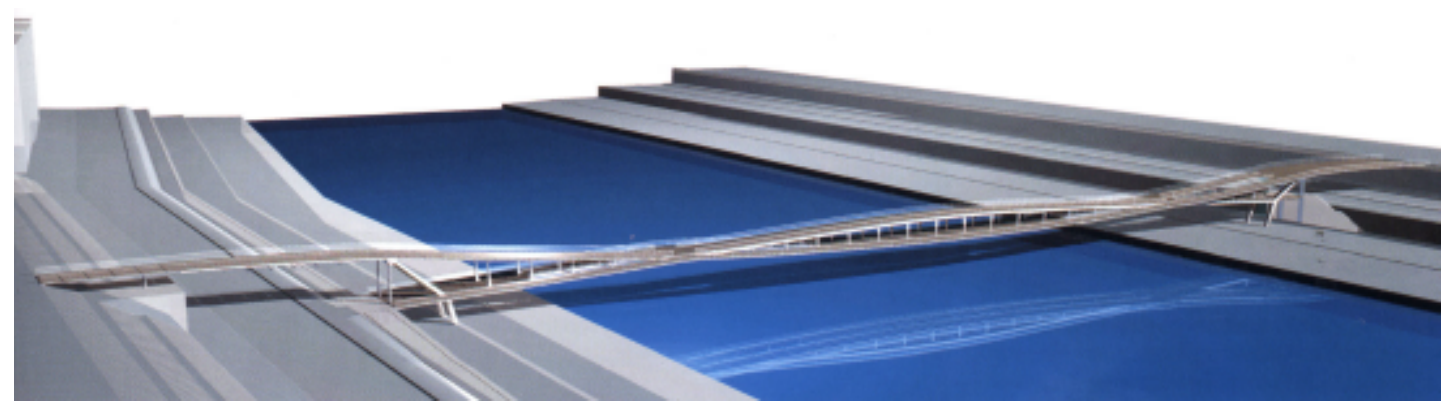

Figura 64 - Passarela Bercy-Tolbiac. (DETAIL, 1999b)

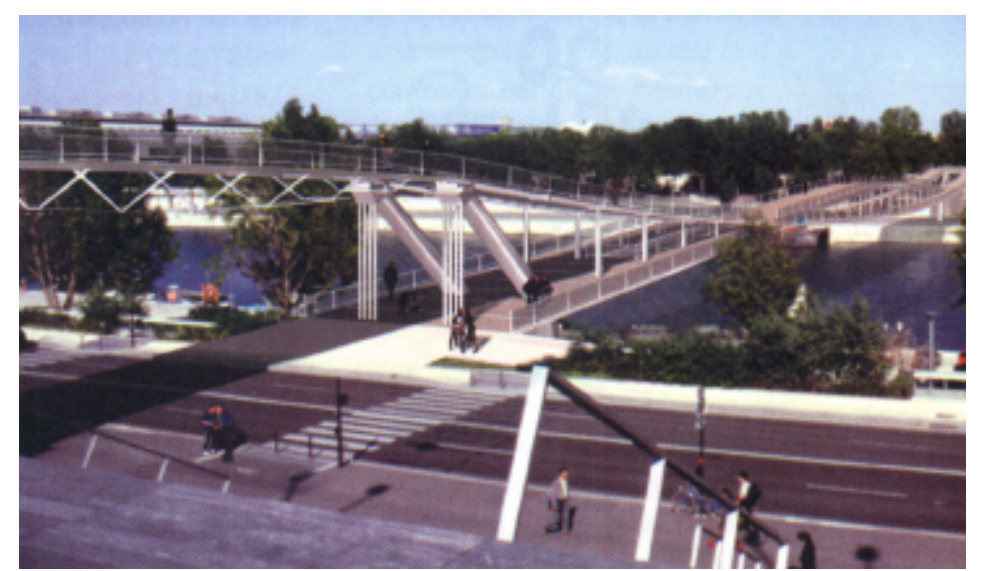

Figura 65 - Passarela Bercy-Tolbiac. (TECHNIQUES ET ARCHITECTURE ,1999) 
Nesse capítulo é abordada a análise estática de uma passarela pênsil protendida formada por elementos pré-moldados de concreto. A partir de agora, o trabalho irá se restringir ao estudo das estruturas suportadas por cabos livremente suspensos. As particularidades das duas variações apresentadas brevemente no capítulo anterior (estrutura suportada por cabos adicionais e estrutura suportada por um arco) ficam como sugestão para um futuro estudo.

Primeiramente, será explorado o comportamento das estruturas com um único vão e apoios nivelados. Assim, serão desenvolvidas formulações, mesmo que simplificadas, para o cálculo de esforços e deslocamentos sob algumas situações de carregamento.

Em seguida, serão comentados sucintamente procedimentos para a análise de estruturas contínuas.

\subsection{ESTRUTURAS COM UM ÚNICO VÃO}

Para o desenvolvimento da teoria que governa o comportamento da passarela pênsil, é preciso recordar o processo construtivo à qual está sujeita.

Primeiramente, são dispostos os cabos de sustentação. A flecha desses cabos é determinada em função da inclinação desejada para a passarela, diretamente ligada ao conforto dos usuários. Uma vez dispostos esses cabos, os elementos pré-moldados são colocados sob eles e deslizam até atingir a sua posição de projeto, efetuando-se assim a montagem completa do tabuleiro. Em seguida, ocorre a concretagem das juntas e da região onde estão alojados os cabos de sustentação. Quando esse concreto atingir resistência suficiente, a estrutura é protendida por um segundo grupo de cabos ancorados atrás dos blocos de fundação, de maneira que seu único efeito são forças distribuídas verticais atuando em um esquema de arco invertido (v. figura 66), desde que os apoios sejam considerados indeslocáveis. 


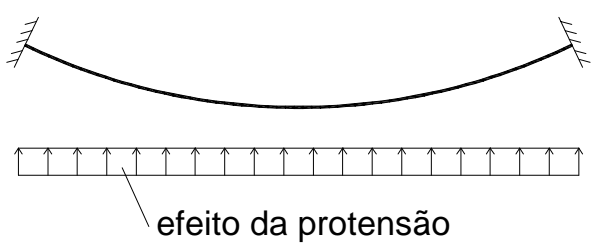

Figura 66 - Efeito da protensão na estrutura.

O mesmo efeito do processo de protensão mencionado acima pode ser conseguido através da colocação de sobrecarga (sacos de água, por exemplo) antes da concretagem das juntas. Após essa concretagem, a sobrecarga é retirada e a passarela fica protendida.

Devido às características peculiares da estrutura, diversos aspectos devem ser levados em consideração, principalmente o comportamento não-linear geométrico e as perdas de protensão.

O desenvolvimento das equações que será feito a seguir é baseado em DEL ARCO \& BENGOECHEA (1994) e DEL ARCO \& BENGOECHEA (1996a). A formulação desenvolvida, apesar de simples, permite compreender o funcionamento da estrutura, além de ser bastante útil, principalmente em fases de pré-dimensionamento.

\subsubsection{Configuração inicial}

O primeiro passo para a análise de tais estruturas é o estudo dos cabos de sustentação.

Uma vez dispostos, os cabos de sustentação assumem a forma de uma catenária. Entretanto, devido à pequena relação flecha/vão (inferior a 1/25), o traçado é muito bem representado por uma parábola do segundo grau ou mesmo por um arco circular de raio constante. Em todo o trabalho será utilizada a formulação da parábola. Dessa forma, a figura 67 mostra a forma do cabo e seu carregamento, onde $f$ é a flecha, $L$ é o comprimento do vão e $q$ é o carregamento distribuído.

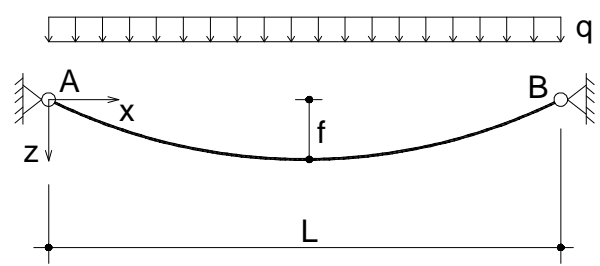

Figura 67 - Cabo livremente suspenso com apoios nivelados.

As condições de equilíbrio aplicadas a um elemento infinitesimal de cabo de comprimento ds (v. figura 68), fornecem: 


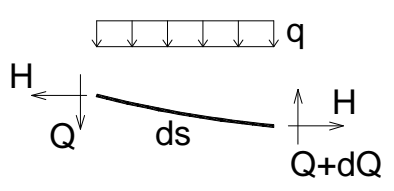

Figura 68 - Elemento infinitesimal.

$\frac{d^{2} z}{d x^{2}}=z^{\prime \prime}=-\frac{q}{H}$

$z(x)=\frac{q}{2 \cdot H} \cdot x \cdot(L-x)$

$H=\frac{q \cdot L^{2}}{8 \cdot f}$

A força de tração $T$ e o comprimento $s$ do cabo são dados por:

$$
\begin{aligned}
& T=H \cdot \sqrt{1+\left[\frac{q}{2 \cdot H} \cdot(L-2 \cdot x)\right]^{2}} \\
& S=L \cdot\left[1+\frac{q^{2} \cdot L^{2}}{24 \cdot H^{2}}-\frac{q^{4} \cdot L^{4}}{640 \cdot H^{4}}\right]
\end{aligned}
$$

Uma vez definida a configuração inicial de equilíbrio do cabo, o estudo da deformação devido a um acréscimo de carga $\Delta q$ pode ser feito a partir das seguintes equações, de acordo com BARBATO (1991):

$\theta \cdot \overline{\mathrm{H}}^{2}+\beta \cdot \overline{\mathrm{H}}+\gamma=0$

$\theta=L+\frac{q^{2} \cdot L^{3}}{8 \cdot H^{2}}$

$\beta=-\theta \cdot H+(E \cdot A+H) \cdot\left[\frac{q^{2} \cdot L^{3}}{12 \cdot H^{2}}-\left(u_{B}-u_{A}\right)+\alpha \cdot \Delta T \cdot L \cdot\left(1+\frac{q^{2} \cdot L^{2}}{12 \cdot H^{2}}\right)\right]$

$\gamma=-(E \cdot A+H) \cdot\left(\frac{q \cdot L^{3}}{12 \cdot H}\right) \cdot(q+\Delta q)$

onde:

$\overline{\mathrm{H}}$ - força horizontal correspondente à posição deformada;

E - módulo de elasticidade do aço;

A - área da seção transversal dos cabos utilizados; 
$\mathrm{u}_{\mathrm{B}}$ - deslocamento horizontal do apoio da direita;

$\mathrm{u}_{\mathrm{A}}$ - deslocamento horizontal do apoio da esquerda;

$\alpha$ - coeficiente de dilatação térmica do aço;

$\Delta \mathrm{T}$ - variação de temperatura.

Uma vez determinado $\overline{\mathrm{H}}$, todos os demais parâmetros que caracterizam a curva de equilíbrio do cabo deformado podem ser calculados.

No caso da passarela, deve-se estudar a deformação do cabo devido a seu peso próprio e ao peso próprio dos elementos pré-moldados. Essa configuração deformada será referência para a continuação das deduções, sendo esquematizada na figura 69 .
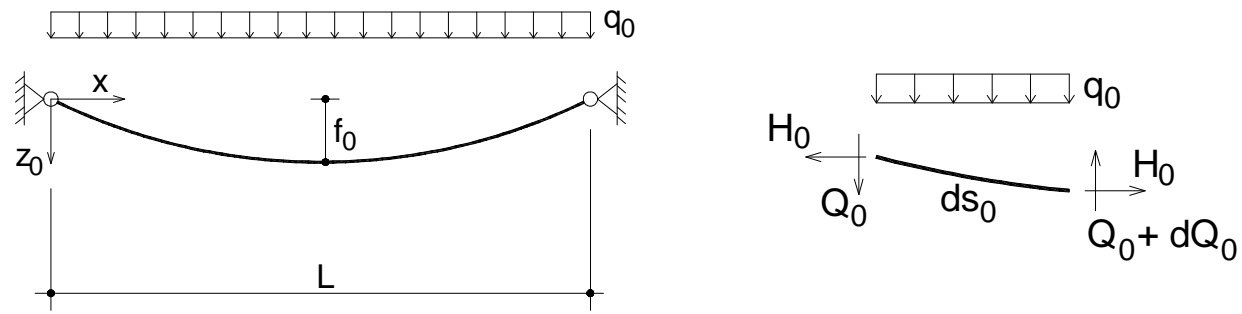

Figura 69 - Configuração de referência para continuação das deduções.

onde:

$q_{0}$ - soma do peso próprio dos cabos e do peso próprio dos elementos pré-moldados;

$\mathrm{H}_{0}=\frac{\mathrm{q}_{0} \cdot \mathrm{L}^{2}}{8 \cdot \mathrm{f}_{0}}$

$\mathrm{z}_{0}(\mathrm{x})=\frac{\mathrm{q}_{0}}{2 \cdot \mathrm{H}_{0}} \cdot \mathrm{x} \cdot(\mathrm{L}-\mathrm{x})$

\subsubsection{Equações de governo da estrutura (cabos + concreto)}

Após a concretagem das juntas e da região onde estão localizados os cabos de sustentação, a estrutura se comporta como um cabo suspenso com pequena rigidez a flexão. Portanto, a rigidez a flexão do tabuleiro deve constar na equação de equilíbrio. Adicionando-se uma carga distribuída uniformemente $q$, cujo acréscimo de força horizontal será $h$, a estrutura se deforma e a nova geometria é mostrada na figura 70 .

Admitindo-se que a forma da passarela seja bastante abatida, serão feitas as seguintes considerações, de acordo com DAWE (1971) e DEL ARCO \& BENGOECHEA (1994): 
$\left(z_{0}^{\prime}\right)^{2}<<1$

$\left(w^{\prime}\right)^{2}<<1$

$\left(u^{\prime}\right)<<1$

onde:

$z_{0}^{\prime}$ - inclinação da tangente ao cabo na configuração inicial;

$\mathrm{w}^{\prime}$ - variação do deslocamento vertical ao longo do eixo $\mathrm{x}$;

$u^{\prime}$ - variação do deslocamento horizontal ao longo do eixo $x$.
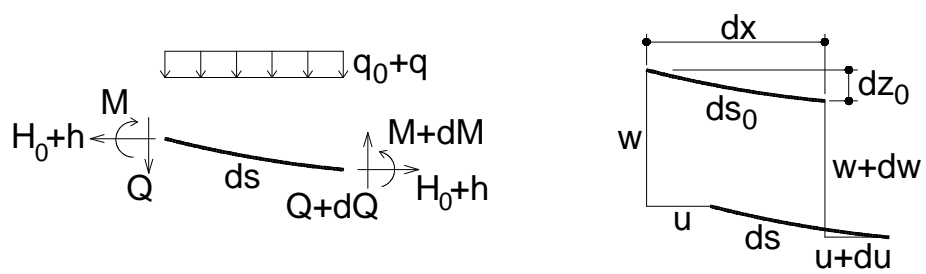

Figura 70 - Configuração deformada da estrutura.

O equilíbrio será feito na posição deformada, o que garantirá o comportamento nãolinear da estrutura.

a) Equilíbrio na direção vertical:

$Q+d Q-\left(q_{0}+q\right) \cdot(d x+d u)-Q=0 \rightarrow d Q=\left(q_{0}+q\right) \cdot(d x+d u)$

Dividindo-se por $\mathrm{dx}$ :

$\frac{d Q}{d x}=\left(q_{0}+q\right) \cdot\left(1+u^{\prime}\right)$

Utilizando (12), tem-se: $\frac{d Q}{d x}=\left(q_{0}+q\right)$, ou ainda, $Q^{\prime}=\left(q_{0}+q\right)$

b) Equilíbrio de momentos:

$$
\begin{aligned}
& -M+(q 0+q) \cdot \frac{(d x+d u)^{2}}{2}+\left(H_{0}+h\right) \cdot\left(d z_{0}+d w\right)+Q \cdot(d x+d u)+M+d M=0 \\
& \rightarrow\left(q_{0}+q\right) \cdot \frac{d x^{2}}{2} \cdot\left(1+\frac{d u}{d x}\right)^{2}+\left(H_{0}+h\right) \cdot\left(d z_{0}+d w\right)+Q \cdot d x \cdot\left(1+\frac{d u}{d x}\right)+d M=0
\end{aligned}
$$


Considerando-se novamente que $\left(u^{\prime}\right) \ll 1$ :

$\left(q_{0}+q\right) \cdot \frac{d x^{2}}{2}+\left(H_{0}+h\right) \cdot\left(d z_{0}+d w\right)+Q \cdot d x+d M=0$

Dividindo-se por dx, obtém-se:

$\left(q_{0}+q\right) \cdot \frac{d x}{2}+\left(H_{0}+h\right) \cdot\left(z_{0}^{\prime}+w^{\prime}\right)+Q+M^{\prime}=0$

$\mathrm{E}$, finalmente, desprezando a primeira parcela em relação às demais:

$\left(H_{0}+h\right) \cdot\left(z_{0}^{\prime}+w^{\prime}\right)+Q+M^{\prime}=0$

Admitindo pequenas deformações, material elástico e a hipótese de que a seção plana permanece plana e perpendicular ao eixo do centro de gravidade após as deformações, sabe-se que:

$$
\begin{aligned}
& M(x)=-E \cdot l \cdot w^{\prime \prime} \\
& h=E \cdot A \cdot\left(u^{\prime}+z_{0}^{\prime} \cdot w^{\prime}\right)
\end{aligned}
$$

onde:

$M(x)$ - momento fletor;

$\mathrm{E} \cdot \mathrm{I}$ - rigidez a flexão da estrutura;

$\mathrm{h}$ - acréscimo de força horizontal;

E $\cdot A$ - rigidez axial da estrutura (cabos aderidos + concreto).

Como observação, salienta-se que a equação 16 é deduzida para cabos, ou seja, na ausência de momentos fletores.

Substituindo-se (15) em (14), chega-se a (17), cuja resolução fornece os deslocamentos verticais ao longo da estrutura.

$-E \cdot I \cdot w^{\prime \prime \prime}+\left(H_{0}+h\right) \cdot\left(z_{0}^{\prime}+w^{\prime}\right)+Q=0$

Se for admitido que a carga q não tem valor constante ao longo do vão, a equação de governo deverá ser uma equação de quarta ordem, que pode ser obtida a partir da equação 14, por simples derivação. Assim, para o caso de carregamento não uniforme, temse: 
$-E \cdot I \cdot w^{I V}+\left(H_{0}+h\right) \cdot w^{\prime \prime}+h \cdot z_{0}^{\prime \prime}+q(x)=0$

A integração da equação 16 entre dois apoios $A$ (esquerda) e $B$ (direita), e impondose uma variação de temperatura $\Delta T$, leva a:

$h=\frac{E \cdot A}{L} \cdot\left(u_{B}-u_{A}+w_{B} \cdot z_{0 B}^{\prime}-w_{A} \cdot z_{0 A}^{\prime}+\frac{q_{0}}{H_{0}} \cdot \int_{A}^{B} w \cdot d x\right)-E \cdot A \cdot \alpha \cdot \Delta T$

onde:

$\mathrm{u}_{\mathrm{A}}$ - deslocamento horizontal do apoio da esquerda;

$\mathrm{u}_{\mathrm{B}}$ - deslocamento horizontal do apoio da direita;

$w_{A}$ - recalque do apoio da esquerda;

$\mathrm{w}_{\mathrm{B}}$ - recalque do apoio da direita;

$\alpha$ - coeficiente de dilatação térmica;

$\Delta \mathrm{T}$ - variação de temperatura.

As equações (17), (18) e (19) são as mesmas equações que se obtém de uma análise de pontes pênseis pela deflection theory. Maiores detalhes sobre essa teoria podem ser encontrados em STEINMAN (1929), PUGSLEY (1968) e DEL ARCO \& BENGOECHEA (1996b).

\subsubsection{Resolução analítica das equações de governo}

Nesse trabalho será deduzido apenas o caso de carga distribuída uniformemente ao longo do vão e variação uniforme de temperatura. Assim, somente a equação 17 será resolvida analiticamente.

A equação 17 é uma equação diferencial ordinária linear de terceira ordem. Sua solução geral é obtida pela soma da solução geral da equação homogênea $\left(-E \cdot l \cdot w^{\prime \prime \prime}+\left(H_{0}+h\right) \cdot w^{\prime}=0\right)$ com uma solução particular da equação não-homogênea $\left(-E \cdot I \cdot w^{\prime \prime \prime}+\left(H_{0}+h\right) \cdot\left(z_{0}^{\prime}+w^{\prime}\right)+Q=0\right)$.

a) Solução geral da equação homogênea

O processo para obtenção da solução homogênea será transformar (17) em um sistema de equações de primeira ordem. Assim: 


$$
\begin{aligned}
& w_{1}(x)=w(x) \\
& w_{2}(x)=w_{1}^{\prime}(x)=w^{\prime}(x) \\
& w_{3}(x)=w_{2}^{\prime}(x)=w^{\prime \prime}(x) \\
& w_{3}^{\prime}(x)=w^{\prime \prime \prime}(x)=\frac{Q}{E \cdot 1}+\frac{\left(H_{0}+h\right)}{E \cdot 1} \cdot\left(z_{0}^{\prime}+w^{\prime}\right)
\end{aligned}
$$

$$
\text { Definindo-se } \gamma=\sqrt{\frac{\left(\mathrm{H}_{0}+h\right)}{E \cdot I}}
$$

$w_{3}^{\prime}(x)=\frac{Q}{E \cdot l}+\gamma^{2} \cdot\left(z_{0}^{\prime}+w_{2}\right)$

Mas,

$$
\begin{aligned}
& z_{0}(x)=\frac{q_{0}}{2 \cdot H_{0}} \cdot x \cdot(L-x) \\
& z_{0}^{\prime}(x)=\frac{q_{0} \cdot L}{2 \cdot H_{0}}-\frac{q_{0} \cdot x}{H_{0}} \\
& Q^{\prime}=\left(q_{0}+q\right) \\
& Q=\left(q_{0}+q\right) \cdot x-\frac{\left(q_{0}+q\right) \cdot L}{2}
\end{aligned}
$$

Substituindo (22) e (23) em (21):

$w_{3}^{\prime}(x)=\frac{\left(q+q_{0}\right) \cdot x}{E l}-\frac{\left(q+q_{0}\right) \cdot L}{2 \cdot E l}+\gamma^{2} \cdot\left(\frac{q_{0} \cdot L}{2 \cdot H_{0}}-\frac{q_{0} \cdot x}{H_{0}}\right)+\gamma^{2} \cdot w_{2}$

Portanto, o sistema obtido é:

$$
\left\{\begin{array}{l}
w_{1}^{\prime} \\
w_{2}^{\prime} \\
w_{3}^{\prime}
\end{array}\right\}=\left[\begin{array}{ccc}
0 & 1 & 0 \\
0 & 0 & 1 \\
0 & \gamma^{2} & 0
\end{array}\right] \cdot\left\{\begin{array}{l}
w_{1} \\
w_{2} \\
w_{3}
\end{array}\right\}+\left\{\begin{array}{c}
0 \\
0 \\
\frac{\left(q+q_{0}\right) \cdot x}{E l}-\frac{\left(q+q_{0}\right) \cdot L}{2 \cdot E l}+\gamma^{2} \cdot\left(\frac{q_{0} \cdot L}{2 \cdot H_{0}}-\frac{q_{0} \cdot x}{H_{0}}\right.
\end{array}\right\}
$$

O sistema homogêneo é dado por:

$$
\left\{w^{\prime}\right\}=\left[\begin{array}{ccc}
0 & 1 & 0 \\
0 & 0 & 1 \\
0 & \gamma^{2} & 0
\end{array}\right] \cdot\{w\}=[A] \cdot\{w\}
$$


Sua solução é:

$$
[w(x)]=\left[\begin{array}{ccc}
1 & e^{\gamma \cdot x} & e^{-\gamma \cdot x} \\
0 & \gamma \cdot e^{\gamma \cdot x} & -\gamma \cdot e^{-\gamma \cdot x} \\
0 & \gamma^{2} \cdot e^{\gamma \cdot x} & \gamma^{2} \cdot e^{-\gamma \cdot x}
\end{array}\right]
$$

Cada coluna de (26) é uma solução de (25) e como seu determinante é diferente de zero para qualquer $x$ pertencente aos números Reais, $[\mathrm{w}(\mathrm{x})]$ é a Matriz Fundamental do sistema homogêneo, ou seja, suas colunas são linearmente independentes. Assim, a solução geral do sistema é dada por uma combinação linear dessas soluções.

Lembrando ainda que $w_{1}(x)=w(x)$, apenas a primeira linha de (26) é a solução procurada. Então:

$w(x)=c_{1} \cdot e^{\gamma \cdot x}+c_{2} \cdot e^{-\gamma \cdot x}+c_{3}$

onde $c_{1}, c_{2}$ e $c_{3}$ são coeficientes que dependem das condições de contorno.

b) Solução particular da equação não-homogênea

A solução particular da equação não-homogênea foi obtida através do Método de Variação das Constantes, que pode ser visto com detalhes em ELSGOLTZ (1969).

Finalmente, a solução geral de (17), é dada por:

$$
\begin{aligned}
& w(x)=c_{1} \cdot e^{\gamma \cdot x}+c_{2} \cdot e^{-\gamma \cdot x}+c_{3}-\frac{\left(q+q_{0}\right) \cdot x^{2}}{2 \cdot\left(H_{0}+h\right)}+\frac{\left(q+q_{0}\right) \cdot L \cdot x}{2 \cdot\left(H_{0}+h\right)}-\frac{q_{0} \cdot L \cdot x}{2 \cdot H_{0}}+\frac{q_{0} \cdot x^{2}}{2 \cdot H_{0}}+ \\
& -\frac{\left(q+q_{0}\right)}{\left(H_{0}+h\right) \cdot \gamma^{2}}+\frac{q_{0}}{H_{0} \cdot \gamma^{2}}
\end{aligned}
$$

DEL ARCO \& BENGOECHEA (1994) resolvem a equação (17) dividindo-a em duas:

$$
\begin{aligned}
& -E \cdot I \cdot w_{1}^{\prime \prime \prime}+\left(H_{0}+h\right) \cdot w_{1}^{\prime}=0 \\
& \left(H_{0}+h\right) \cdot z_{0}^{\prime}+\left(H_{0}+h\right) \cdot w_{2}^{\prime}+Q=0
\end{aligned}
$$

A solução é dada por $w_{1}+w_{2}$. Na realidade, esse procedimento é utilizado no estudo de reservatórios cilíndricos e cascas. A equação 29 é homogênea e corresponde à solução de flexão (unicamente devido aos vínculos) e que depende das condições de contorno. A 
equação 30 leva à solução particular, que depende da carga externa aplicada e que difere muito pouco da solução de membrana (BARBATO, 1975). Dessa forma, a parcela correspondente à força cortante pode ser retirada da equação, ou seja, admite-se funicular das cargas na solução particular.

\subsubsection{Caso de uma estrutura biengastada}

A equação 28, possui três constantes e portanto são três as condições de contorno a serem impostas. São elas:

$w(0)=0 ; \quad w^{\prime}(0)=0 ; \quad w^{\prime}(L)=0 ;$

Impondo-se tais restrições, tem-se a fórmula para cálculo dos deslocamentos verticais $w$ ao longo do eixo $x$ de uma estrutura biengastada:

$$
\begin{aligned}
& w(x)=\left[\frac{\left(q+q_{0}\right) \cdot L \cdot\left(1+e^{\gamma \cdot L}\right)}{2 \cdot\left(H_{0}+h\right) \cdot \gamma \cdot \operatorname{senh}(\gamma \cdot L)}-\frac{q_{0} \cdot L \cdot\left(1+e^{\gamma \cdot L}\right)}{2 \cdot H_{0} \cdot \gamma \cdot \operatorname{senh}(\gamma \cdot L)}\right] \cdot[\cosh (\gamma \cdot x)-1]-\frac{\left(q+q_{0}\right) \cdot L \cdot e^{\gamma \cdot x}}{2 \cdot\left(H_{0}+h\right) \cdot \gamma}+ \\
& +\frac{q_{0} \cdot L \cdot e^{\gamma \cdot x}}{2 \cdot H_{0} \cdot \gamma}-\frac{\left(q+q_{0}\right) \cdot x^{2}}{2 \cdot\left(H_{0}+h\right)}+\frac{\left(q+q_{0}\right) \cdot L \cdot x}{2 \cdot\left(H_{0}+h\right)}-\frac{q_{0} \cdot L \cdot x}{2 \cdot H_{0}}+\frac{q_{0} \cdot x^{2}}{2 \cdot H_{0}}+\frac{\left(q+q_{0}\right) \cdot L}{2 \cdot\left(H_{0}+h\right) \cdot \gamma}-\frac{q_{0} \cdot L}{2 \cdot H_{0} \cdot \gamma}
\end{aligned}
$$

Substituindo (31) em (19), é obtida a força horizontal $h$ (de valor constante ao longo do eixo $x$ ):

$$
\begin{aligned}
& h=\frac{E \cdot A}{L} \cdot \frac{q_{0}}{H_{0}} \cdot\left\{\left[\frac{\left(q+q_{0}\right) \cdot L \cdot\left(1+e^{\gamma \cdot L}\right)}{2 \cdot\left(H_{0}+h\right) \cdot \gamma \cdot \operatorname{senh}(\gamma \cdot L)}-\frac{q_{0} \cdot L \cdot\left(1+e^{\gamma \cdot L}\right)}{2 \cdot H_{0} \cdot \gamma \cdot \operatorname{senh}(\gamma \cdot L)}\right] \cdot\left[\frac{\operatorname{senh}(\gamma \cdot L)}{\gamma}-L\right]+\right. \\
& \left.-\frac{\left(q+q_{0}\right) \cdot L \cdot\left(e^{\gamma \cdot L}-1\right)}{2 \cdot\left(H_{0}+h\right) \cdot \gamma^{2}}+\frac{q_{0} \cdot L \cdot\left(e^{\gamma \cdot L}-1\right)}{2 \cdot H_{0} \cdot \gamma^{2}}+\frac{\left(q+q_{0}\right) \cdot L^{3}}{12 \cdot\left(H_{0}+h\right)}-\frac{q_{0} \cdot L^{3}}{12 \cdot H_{0}}+\frac{\left(q+q_{0}\right) \cdot L^{2}}{2 \cdot\left(H_{0}+h\right) \cdot \gamma}-\frac{q_{0} \cdot L^{2}}{2 \cdot H_{0} \cdot \gamma}\right\}+ \\
& +\frac{E \cdot A}{L} \cdot\left(u_{B}-u_{A}+w_{B} \cdot z_{O B}^{\prime}-w_{A} \cdot z_{0 A}^{\prime}\right)-E \cdot A \cdot \alpha \cdot \Delta T
\end{aligned}
$$

Lembrando que $M(x)=-E \cdot \mid \cdot w^{\prime \prime}$, tem-se:

$$
M(x)=-E \cdot I \cdot\left\{\left[\frac{\left(q+q_{0}\right) \cdot L \cdot\left(1+e^{\gamma \cdot L}\right)}{2 \cdot\left(H_{0}+h\right) \cdot \gamma \cdot \operatorname{senh}(\gamma \cdot L)}-\frac{q_{0} \cdot L \cdot\left(1+e^{\gamma \cdot L}\right)}{2 \cdot H_{0} \cdot \gamma \cdot \operatorname{senh}(\gamma \cdot L)}\right] \cdot\left[\gamma^{2} \cdot \cosh (\gamma \cdot x)\right]+\right.
$$




$$
\left.-\frac{\left(q+q_{0}\right) \cdot L \cdot e^{\gamma \cdot x} \cdot \gamma}{2 \cdot\left(H_{0}+h\right)}+\frac{q_{0} \cdot L \cdot e^{\gamma \cdot x} \cdot \gamma}{2 \cdot H_{0}}-\frac{\left(q+q_{0}\right)}{\left(H_{0}+h\right)}+\frac{q_{0}}{H_{0}}\right\}
$$

Para a resolução do problema, a equação 32 deve ser resolvida iterativamente. Obtido o valor do incremento de força horizontal, os deslocamentos e os momentos fletores ao longo da estrutura são calculados com as fórmulas 31 e 33 .

DEL ARCO \& BENGOECHEA (1994) incluem na solução o efeito de uma carga concentrada no meio do vão. As equações, de acordo com esses autores, são:

$$
w(x) \approx \frac{\alpha_{0}}{\gamma} \cdot\left(e^{-\gamma \cdot x}-1\right)+\frac{\alpha_{1} \cdot(1-\cosh (\gamma \cdot x))}{\gamma \cdot \operatorname{senh}\left(\frac{\gamma \cdot L}{2}\right)}+\frac{\alpha_{0}-\alpha_{1}}{L} \cdot x \cdot(L-x)+\alpha_{1} \cdot x ; \quad 0 \leq x \leq \frac{L}{2}
$$

onde

$$
\begin{aligned}
& \alpha_{0}=\frac{\frac{F}{L}+q-q_{0} \cdot \frac{h}{H_{0}}}{2 \cdot\left(H_{0}+h\right)} \cdot L \\
& \alpha_{1}=\frac{F}{2 \cdot\left(H_{0}+h\right)} \\
& h=\frac{E \cdot A}{L} \cdot \frac{q_{0}}{H_{0}} \cdot\left(\frac{2 \cdot \alpha_{0}+\alpha_{1}}{12} \cdot L^{2}+2 \cdot \frac{\alpha_{0}-\alpha_{1}}{\gamma^{2}}-\frac{\alpha_{0} \cdot L}{\gamma}\right)-E \cdot A \cdot \alpha \cdot \Delta T \\
& M(x)=E \cdot I \cdot\left(2 \cdot \frac{\alpha_{0}-\alpha_{1}}{L}-\alpha_{0} \cdot \gamma \cdot e^{-\gamma \cdot x}+\alpha_{1} \cdot \gamma \cdot \frac{\cosh (\gamma \cdot x)}{\operatorname{senh}\left(\frac{\gamma \cdot L}{2}\right)}\right) ; \quad 0 \leq x \leq \frac{L}{2}
\end{aligned}
$$

\subsubsection{Caso de uma estrutura biapoiada}

REDFIELD et al (1992) não aconselham o uso de estruturas bi-apoiadas devido ao fato dos cabos estarem sujeitos a fadiga. No entanto, esse efeito pode ser minimizado com a utilização de baixas tensões em serviço para os cabos de sustentação.

No caso de uma passarela biapoiada, as condições de contorno a serem impostas são: 
$w(0)=0 ; \quad w^{\prime \prime}(0)=0 ; \quad w^{\prime \prime}(L)=0$

Assim, as fórmulas para cálculo dos deslocamentos $w(x)$, da força horizontal $h$, e dos momentos fletores $M(x)$ em uma estrutura biapoiada, são respectivamente:

$$
\begin{aligned}
& w(x)=\left[-\frac{\left(q+q_{0}\right) \cdot\left(e^{\gamma \cdot L}-1\right)}{\left(H_{0}+h\right) \cdot \gamma^{2} \cdot \operatorname{senh}(\gamma \cdot L)}-\frac{q_{0} \cdot\left(1-e^{\gamma \cdot L}\right)}{H_{0} \cdot \gamma^{2} \cdot \operatorname{senh}(\gamma \cdot L)}\right] \cdot \operatorname{senh}(\gamma \cdot x)+\frac{\left(q+q_{0}\right) \cdot e^{\gamma \cdot x}}{\left(H_{0}+h\right) \cdot \gamma^{2}}+ \\
& -\frac{q_{0} \cdot e^{\gamma \cdot x}}{H_{0} \cdot \gamma^{2}}-\frac{\left(q+q_{0}\right) \cdot x^{2}}{2 \cdot\left(H_{0}+h\right)}+\frac{\left(q+q_{0}\right) \cdot L \cdot x}{2 \cdot\left(H_{0}+h\right)}-\frac{q_{0} \cdot L \cdot x}{2 \cdot H_{0}}+\frac{q_{0} \cdot x^{2}}{2 \cdot H_{0}}-\frac{\left(q+q_{0}\right)}{\left(H_{0}+h\right) \cdot \gamma^{2}}+\frac{q_{0}}{H_{0} \cdot \gamma^{2}}
\end{aligned}
$$

$$
\begin{aligned}
& h=\frac{E \cdot A}{L} \cdot \frac{q_{0}}{H_{0}} \cdot\left\{\left[-\frac{\left(q+q_{0}\right) \cdot\left(e^{\gamma \cdot L}-1\right)}{\left(H_{0}+h\right) \cdot \gamma^{2} \cdot \operatorname{senh}(\gamma \cdot L)}-\frac{q_{0} \cdot\left(1-e^{\gamma \cdot L}\right)}{H_{0} \cdot \gamma^{2} \cdot \operatorname{senh}(\gamma \cdot L)}\right] \cdot\left[\frac{\cosh (\gamma \cdot L)}{\gamma}-\frac{1}{\gamma}\right]+\right. \\
& \left.+\frac{\left(q+q_{0}\right) \cdot\left(e^{\gamma \cdot L}-1\right)}{\left(H_{0}+h\right) \cdot \gamma^{3}}-\frac{q_{0} \cdot\left(e^{\gamma \cdot L}-1\right)}{H_{0} \cdot \gamma^{3}}+\frac{\left(q+q_{0}\right) \cdot L^{3}}{12 \cdot\left(H_{0}+h\right)}-\frac{q_{0} \cdot L^{3}}{12 \cdot H_{0}}-\frac{\left(q+q_{0}\right) \cdot L}{\left(H_{0}+h\right) \cdot \gamma^{2}}+\frac{q_{0} \cdot L}{H_{0} \cdot \gamma^{2}}\right\}+ \\
& +\frac{E \cdot A}{L} \cdot\left(u_{B}-u_{A}+w_{B} \cdot z_{0 B}^{\prime}-w_{A} \cdot z_{0 A}^{\prime}\right)-E \cdot A \cdot \alpha \cdot \Delta T \\
& M(x)=-E \cdot I \cdot\left\{\left[-\frac{\left(q+q_{0}\right) \cdot\left(e^{\gamma \cdot L}-1\right)}{\left(H_{0}+h\right) \cdot \gamma^{2} \cdot \operatorname{senh}(\gamma \cdot L)}-\frac{q_{0} \cdot\left(1-e^{\gamma \cdot L}\right)}{H_{0} \cdot \gamma^{2} \cdot \operatorname{senh}(\gamma \cdot L)}\right] \cdot\left[\gamma^{2} \cdot \operatorname{senh}(\gamma \cdot x)\right]+\right. \\
& \left.+\frac{\left(q+q_{0}\right) \cdot e^{\gamma \cdot x}}{\left(H_{0}+h\right)}-\frac{q_{0} \cdot e^{\gamma \cdot x}}{H_{0}}-\frac{\left(q+q_{0}\right)}{\left(H_{0}+h\right)}+\frac{q_{0}}{H_{0}}\right\}
\end{aligned}
$$

\subsubsection{Introdução da protensão}

Apesar da protensão dever estar sempre presente e ser introduzida antes mesmo de qualquer outro carregamento, decidiu-se, por facilidade, inseri-la nas equações apenas agora.

Duas hipóteses devem ser feitas: os blocos de fundação são indeslocáveis, ou seja, o único efeito da protensão são forças distribuídas (v. figura 66); a força de protensão $P_{0}$ é assumida constante ao longo do vão e ao longo do tempo.

Uma primeira alternativa para se analisar o efeito da protensão seria utilizar a formulação já desenvolvida nos itens 3.1.4 e 3.1.5, bastando fazer com que $q$ seja negativo e dado por: 
$q=-P_{0} \cdot$ curvatura $=-P_{0} \cdot \frac{z_{0}^{\prime \prime}(x)}{\left[1+\left(z_{0}^{\prime}(x)\right)^{2}\right]^{3 / 2}} \cong-P_{0} \cdot z_{0}^{\prime \prime}(x)=-\frac{8 \cdot P_{0} \cdot f_{0}}{L^{2}}$

No entanto, a formulação mostrada nos itens 3.1.4 e 3.1.5 não admite $q$ com valor negativo (para cima) se seu valor for maior que as demais cargas para baixo. DEL ARCO (2001b) justifica esse fato argumentando que a estrutura é basicamente um cabo, haja visto que sua rigidez é muito pequena. Assim, se $q$ negativo for maior que as demais cargas para baixo, a estrutura sofreria uma espécie de "flambagem", ou ainda, o arco ficaria instável (cabo invertido). Matematicamente, tal fato justifica-se analisando o parâmetro $\gamma$, que aparece em todas as equações e é dado por:

$\gamma=\sqrt{\frac{\mathrm{H}_{0}+\mathrm{h}}{\mathrm{E} \cdot \mathrm{l}}}$

Quando $q$ negativo é maior que as cargas para baixo, $h$ (de valor negativo) supera $\mathrm{H}_{0}$, resultando em raiz negativa. Como o problema físico deve possuir valor Real, está caracterizada a instabilidade.

Como consequência, torna-se inviável a introdução da protensão utilizando um $q$ negativo.

DEL ARCO (2001a) alerta que devido ao fato da estrutura possuir comportamento não-linear geométrico, a curvatura depende das condições iniciais e dos deslocamentos, ou seja, a curvatura é variável com os deslocamentos. Dessa forma, a equação 42 não tem valor constante e a protensão deve ser introduzida nas equações de maneira não-linear. DEL ARCO (2001a) afirma ainda que esse é o motivo pelo qual a maioria dos programas de análise estrutural falha ao tratar esse tipo de estrutura pênsil. Assim, de acordo com a figura 71:

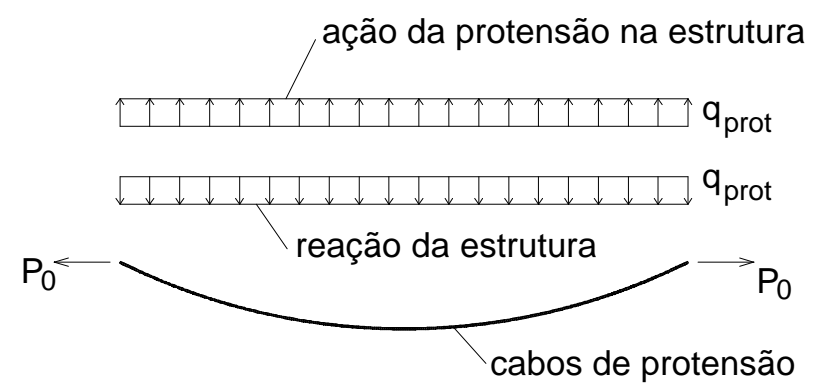

Figura 71 - Introdução da protensão.

$$
\frac{d^{2} z_{0}}{d x^{2}}+\frac{d^{2} w}{d x^{2}}=-\frac{q_{\text {prot }}}{P_{0}} \rightarrow-q_{\text {prot }}=P_{0} \cdot\left(z_{0}^{\prime \prime}+w^{\prime \prime}\right)
$$


e

$Q_{\text {prot }}=-\int q_{\text {prot }} d x=P_{0} \cdot\left(z_{0}^{\prime}+w^{\prime}\right)$

Agora, basta introduzir $Q_{\text {prot }}$ na equação 17:

$-E \cdot \mid \cdot w^{\prime \prime \prime}+\left(H_{0}+h\right) \cdot\left(z_{0}^{\prime}+w^{\prime}\right)+Q+Q_{\text {prot }}=0$

Utilizando-se de (44):

$-E \cdot l \cdot w^{\prime \prime \prime}+\left(H_{0}+h\right) \cdot\left(z_{0}^{\prime}+w^{\prime}\right)+Q+P_{0} \cdot\left(z_{0}^{\prime}+w^{\prime}\right)=0$

Finalmente:

$-E \cdot l \cdot w^{\prime \prime \prime}+\left(H_{0}+h+P_{0}\right) \cdot\left(z_{0}^{\prime}+w^{\prime}\right)+Q=0$

A solução da equação 45 é idêntica à apresentada no item 3.1.3, bastando fazer $\mathrm{h}=\mathrm{h}+\mathrm{P}_{0}$. Da mesma forma deve-se proceder com as equações de força horizontal, deslocamentos e momento fletor dos itens 3.1.4 e 3.1.5, e também com a equação 20.

Ao contrário do que acontece quando se impõe um q negativo, quando a protensão é inserida da maneira descrita acima, não existe problema de instabilidade, e portanto seu valor pode ser qualquer. Conforme a estrutura vai se deslocando para cima, o efeito da protensão vai diminuindo. Numa situação hipotética, quando a estrutura se aproximasse da forma reta, o efeito da protensão tenderia para zero.

Do ponto de vista matemático, a questão novamente é esclarecida a partir do parâmetro $\gamma$. Agora,

$\gamma=\sqrt{\frac{H_{0}+h+P_{0}}{E \cdot I}}$

Considerando-se unicamente a força de protensão, se a estrutura fosse indeformável, $h$ seria igual a - $P_{0}$. Como a estrutura se deforma, tornando-se mais abatida, $h$ (de valor negativo) será sempre menor em módulo do que $P_{0}$. Assim, a raiz $\sqrt{\frac{H_{0}+h+P_{0}}{E \cdot I}}$ será sempre positiva, não sendo verificados problemas de instabilidade. 


\subsubsection{Perdas de protensão}

As perdas de protensão fazem com que a estrutura tenha sua flecha reduzida e fique menos comprimida. De fato, uma das combinações de ações críticas no projeto de uma passarela pênsil protendida é a aplicação da ação variável uniformemente distribuída e de uma variação negativa de temperatura a tempo infinito. Nessa situação, o tabuleiro pode ficar tracionado, o que é indesejável do ponto de vista da durabilidade.

Em princípio, as perdas de protensão são causadas pela fluência e retração do concreto e pela relaxação do aço. O efeito da retração pode ser bastante reduzido, bastando que ocorra uma dosagem adequada, e que os elementos pré-moldados sejam produzidos com certo tempo antes da sua aplicação. A relaxação do aço pode ser minimizada com o uso de aços de baixa relaxação (RB) e com a utilização de baixas tensões em serviço. Nesse contexto, a fluência torna-se a principal causa das perdas de protensão.

Em vista do exposto acima, torna-se necessário avaliar ou estimar as perdas de protensão e recalcular os esforços e deslocamentos ao longo da estrutura. A formulação que estuda a passarela a tempo infinito foi desenvolvida por DEL ARCO \& BENGOECHEA (1994). Esses autores consideraram apenas a fluência, e desprezaram totalmente o efeito da retração do concreto e da relaxação do aço.

Sejam $w_{0}(x), M_{0}(x)$ e $h_{0}$, respectivamente os deslocamentos, os momentos fletores e o incremento de força horizontal, após a introdução da protensão e da carga permanente (tempo $t_{0}$ ). Sejam $\Delta w(x)$ e $\Delta h$, as variações dos deslocamentos e da força horizontal, provocados pela fluência. Vale destacar que a força horizontal atua em toda a seção, inclusive nos cabos de protensão, que nesse momento já estão aderidos ao concreto.

A equação diferencial de equilíbrio no tempo $t_{0}$ é:

$Q+M_{0}^{\prime}+\left(H_{0}+h_{0}+P_{0}\right) \cdot\left(z_{0}^{\prime}+w_{0}^{\prime}\right)=0$

No tempo $t$, cujo elemento infinitesimal é mostrado na figura 72 , a equação diferencial é:

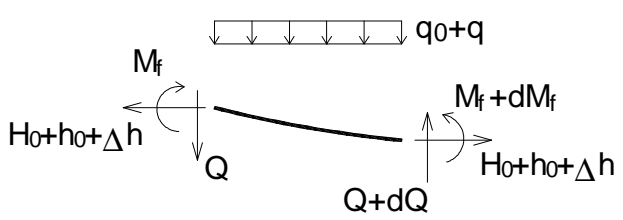

Figura 72 - Elemento infinitesimal no tempo $t$. 
$Q+M_{f}^{\prime}+\left(H_{0}+h_{0}+P_{0}+\Delta h\right) \cdot\left(z_{0}^{\prime}+w_{0}^{\prime}+\Delta w^{\prime}\right)=0$

Subtraindo-se (46) de (47), chega-se a:

$\Delta \mathrm{M}^{\prime}+\Delta \mathrm{h} \cdot\left(\mathrm{z}_{0}^{\prime}+\mathrm{w}_{0}^{\prime}+\Delta \mathrm{w}^{\prime}\right)+\Delta \mathrm{w}^{\prime} \cdot\left(\mathrm{H}_{0}+\mathrm{h}_{0}+\mathrm{P}_{0}\right)=0$

A equação 48 deve ser resolvida com as condições de contorno da passarela, fazendo uso das equações que relacionam esforços e deslocamentos. DEL ARCO \& BENGOECHEA (1994) adotam o modelo proposto pelo CEB (1990). Assumindo que o módulo de elasticidade inicial do concreto no instante de aplicação da carga $\left(E_{\mathrm{c}_{0}}\right)$ seja igual ao módulo de elasticidade inicial do concreto aos 28 dias $\left(E_{c_{28}}\right)$, define-se:

$E_{c_{\text {ef }}}=\frac{E_{c_{0}}}{1+\phi}$

$E_{c_{a j}}=\frac{E_{c_{0}}}{1+\chi \cdot \phi}$

onde:

$\phi$ - coeficiente de fluência;

$\chi$ - coeficiente de envelhecimento.

A deformação total no concreto $\varepsilon_{\mathrm{C}}(\mathrm{t})$ é dada então por:

$\varepsilon_{\mathrm{C}}(\mathrm{t})=\frac{\sigma_{\mathrm{C}}\left(\mathrm{t}_{0}\right)}{\mathrm{E}_{\mathrm{C}_{\mathrm{ef}}}}+\frac{\Delta \sigma_{\mathrm{C}}\left(\mathrm{t}_{0}\right)}{\mathrm{E}_{\mathrm{C}_{\mathrm{aj}}}}$

onde:

$\sigma_{\mathrm{C}}\left(\mathrm{t}_{0}\right)$ - tensão no concreto devido ao carregamento aplicado em $\mathrm{t}_{0}$;

$\Delta \sigma\left(t_{0}\right)$ - variação total de tensão no concreto.

Manipulando-se (49), (50) e (51), a variação total de tensão no concreto fica:

$\Delta \sigma_{\mathrm{C}}=\frac{\varepsilon_{\mathrm{C}}(\mathrm{t}) \cdot \mathrm{E}_{\mathrm{C}_{0}}-\sigma_{\mathrm{C}}\left(\mathrm{t}_{0}\right) \cdot(1+\phi)}{1+\chi \cdot \phi}=\varepsilon_{\mathrm{C}}(\mathrm{t}) \cdot \mathrm{E}_{\mathrm{C}_{\mathrm{aj}}}-\frac{\sigma_{\mathrm{C}}\left(\mathrm{t}_{0}\right) \cdot(1+\phi)}{1+\chi \cdot \phi}$

Lembrando que: 
$\mathrm{h}=\mathrm{E} \cdot \mathrm{A} \cdot \varepsilon$

$\varepsilon=u^{\prime}+z_{0}^{\prime} \cdot w^{\prime}$

$M(x)=-E \cdot I \cdot w^{\prime \prime}$

Tem-se:

$\Delta h_{c}=E_{C_{a j}} \cdot A_{c} \cdot\left(u_{f}^{\prime}+z_{0}^{\prime} \cdot w_{f}^{\prime}\right)-\frac{h_{0_{c}}}{1+\chi \cdot \phi}-\frac{h_{0_{c}} \cdot \phi}{1+\chi \cdot \phi}$

Se $h_{0_{C}}=E_{C_{0}} \cdot A_{C} \cdot \varepsilon_{i}$, então:

$\Delta h_{c}=E_{c_{a j}} \cdot A_{C} \cdot\left(u_{f}^{\prime}+z_{0}^{\prime} \cdot w_{f}^{\prime}\right)-\varepsilon_{i} \cdot A_{C} \cdot E_{c_{a j}}-\frac{h_{0_{C}} \cdot \phi}{1+\chi \cdot \phi}$

$\Delta h_{c}=E_{C_{a j}} \cdot A_{c} \cdot\left(u_{f}^{\prime}+z_{0}^{\prime} \cdot w_{f}^{\prime}\right)-E_{c_{a j}} \cdot A_{c} \cdot\left(u_{i}^{\prime}+z_{0}^{\prime} \cdot w_{i}^{\prime}\right)-\frac{h_{0_{c}} \cdot \phi}{1+\chi \cdot \phi}$

$\Delta h_{C}=E_{C_{a j}} \cdot A_{C} \cdot\left(\Delta u^{\prime}+z_{0}^{\prime} \cdot \Delta w^{\prime}\right)-\frac{h_{0_{C}} \cdot \phi}{1+\chi \cdot \phi}$

Finalmente, como $\Delta h=\Delta h_{c}+\Delta h_{s}$, chega-se a:

$\Delta h=\Delta h_{c}+\Delta h_{s}=\left(E_{C_{a j}} \cdot A_{C}+E_{s} \cdot A_{s}\right) \cdot\left(z_{0}^{\prime} \cdot \Delta w^{\prime}+\Delta u^{\prime}\right)-h_{0_{c}} \cdot \frac{\phi}{1+\chi \cdot \phi}$

sendo

$h_{0_{c}}=\frac{E_{c_{0}} \cdot A_{c}}{E_{c_{0}} \cdot A_{c}+E_{s} \cdot A_{s}} \cdot h_{0}$

onde:

$\mathrm{h}_{0_{\mathrm{C}}}$ - parcela da força normal que atua no concreto;

$A_{C}$ - área de concreto;

$A_{S}$ - somatória da área de aço dos cabos de sustentação e de protensão.

Partindo-se das mesmas equações utilizadas acima e sabendo ainda que $\varepsilon=-y \cdot w^{\prime \prime}$ e $\sigma=\frac{M}{l} \cdot y$, a variação do momento fletor é: 


$$
\begin{aligned}
& \Delta M=\frac{\varepsilon_{C}(t) \cdot E_{C_{a j}} \cdot I}{y}-\frac{M_{0}}{1+\chi \cdot \phi}-\frac{M_{0} \cdot \phi}{1+\chi \cdot \phi}=-E_{C_{a j}} \cdot I \cdot w_{f}^{\prime \prime}-M_{0} \cdot \frac{E_{C_{a j}}}{E_{c_{0}}}-\frac{M_{0} \cdot \phi}{1+\chi \cdot \phi} \\
& \Delta M=-E_{C_{a j}} \cdot I \cdot w_{f}^{\prime \prime}+\frac{E_{C_{a j}} \cdot E_{C_{0}} \cdot I \cdot w_{0}^{\prime \prime}}{E_{c_{0}}}=-E_{c_{a j}} \cdot I \cdot\left(w_{f}^{\prime \prime}-w_{0}^{\prime \prime}\right)-\frac{M_{0} \cdot \phi}{1+\chi \cdot \phi} \\
& \Delta M=-E_{C_{a j}} \cdot I \cdot \Delta w^{\prime \prime}-M_{0} \cdot \frac{\phi}{1+\chi \cdot \phi}
\end{aligned}
$$

A resolução da equação 48 é análoga à apresentada no item 3.1.3. DEL ARCO \& BENGOECHEA (1994) apresentam a solução para o caso de uma estrutura biengastada, mostrada a seguir.

$$
\begin{aligned}
& \Delta \mathrm{h}=\frac{\mathrm{E}_{\mathrm{C}_{\mathrm{aj}}} \cdot \mathrm{A}_{\mathrm{C}}+\mathrm{E}_{\mathrm{S}} \cdot \mathrm{A}_{\mathrm{S}}}{\mathrm{L}} \cdot \frac{\mathrm{q}_{0}}{\mathrm{H}_{0}} \cdot\left(\alpha_{11} \cdot \frac{\mathrm{L}^{2}}{6}+\left(\alpha_{11}+\alpha_{21}\right) \cdot\left(\frac{2}{\gamma^{2}}-\frac{\mathrm{L}}{\gamma}\right)-\alpha_{21} \cdot\left(\frac{2}{\gamma_{0}^{2}}-\frac{\mathrm{L}}{\gamma_{0}}\right)\right)+ \\
& -\mathrm{h}_{\mathrm{O}_{\mathrm{C}}} \cdot \frac{\phi}{1+\chi \cdot \phi}
\end{aligned}
$$

onde:

$$
\begin{aligned}
& H_{1}=H_{0}+h_{0}+P_{0} \\
& q_{1}=H_{1} \cdot\left(\frac{q_{0}}{H_{0}}+2 \cdot \frac{\alpha_{10}}{L}\right) \\
& \gamma=\sqrt{\frac{H_{1}+\Delta h}{E_{c_{a j}} \cdot l}} \\
& \beta=\frac{\gamma^{2}}{\gamma^{2}-\gamma_{0}^{2}} \\
& \alpha=\frac{-\Delta h \cdot \frac{q_{1}}{H_{1}} \cdot L}{2 \cdot\left(H_{1}+\Delta h\right)}
\end{aligned}
$$


$\alpha_{21}=\frac{\Delta h+E_{\mathrm{C}_{0}} \cdot 1 \cdot \gamma_{0}{ }^{2} \cdot \frac{\phi}{1+\chi \cdot \phi}}{H_{1}+\Delta h} \cdot \alpha_{10} \cdot \beta$

$\alpha_{10}=\frac{\frac{F}{L}+q-q_{0} \cdot \frac{\left(h_{0}+P_{0}\right)}{H_{0}}}{2 \cdot\left(H_{0}+h_{0}+P_{0}\right)} \cdot L\left(\right.$ calculado no tempo $\left.t_{0}\right)$

$\gamma_{0}=\sqrt{\frac{\mathrm{H}_{0}+\mathrm{h}_{0}+\mathrm{P}_{0}}{\mathrm{E}_{\mathrm{c}_{0}} \cdot \mathrm{l}}}$ (calculado no tempo $\mathrm{t}_{0}$ )

Uma vez definido o valor de $\Delta \mathrm{h}$, a variação dos deslocamentos no centro do vão, a variação do momento fletor no centro do vão e nos apoios, e a variação da força horizontal no concreto, são dados respectivamente, por:

$$
\begin{aligned}
& \Delta \mathrm{w}\left(\frac{\mathrm{L}}{2}\right)=\alpha_{11} \cdot\left(\frac{\mathrm{L}}{4}-\frac{1}{\gamma}\right)-\alpha_{21} \cdot\left(\frac{1}{\gamma}-\frac{1}{\gamma_{0}}\right) \\
& \Delta \mathrm{M}\left(\frac{\mathrm{L}}{2}\right)=\mathrm{E}_{\mathrm{C}_{\mathrm{aj}}} \cdot I \cdot \frac{2 \cdot \alpha_{11}}{\mathrm{~L}}-\mathrm{M}_{0}\left(\frac{\mathrm{L}}{2}\right) \cdot \frac{\phi}{1+\chi \cdot \phi} \\
& \Delta \mathrm{M}(0)=\mathrm{E}_{\mathrm{C}_{\mathrm{aj}}} \cdot I \cdot\left(\frac{2 \cdot \alpha_{11}}{\mathrm{~L}}-\gamma \cdot \alpha_{11}-\left(\gamma-\gamma_{0}\right) \cdot \alpha_{21}\right)-\mathrm{M}_{0}(0) \cdot \frac{\phi}{1+\chi \cdot \phi} \\
& \Delta \mathrm{h}_{\mathrm{C}}=\frac{\mathrm{E}_{\mathrm{C}_{a j}} \cdot \mathrm{A}_{\mathrm{C}}}{\mathrm{L}} \cdot \frac{\mathrm{q}_{0}}{\mathrm{H}_{0}} \cdot\left(\alpha_{11} \cdot \frac{\mathrm{L}^{2}}{6}+\left(\alpha_{11}+\alpha_{21}\right) \cdot\left(\frac{2}{\gamma^{2}}-\frac{\mathrm{L}}{\gamma}\right)-\alpha_{21} \cdot\left(\frac{2}{\gamma_{0}^{2}}-\frac{\mathrm{L}}{\gamma_{0}}\right)\right)-\mathrm{h}_{0_{\mathrm{C}}} \cdot \frac{\phi}{1+\chi \cdot \phi}
\end{aligned}
$$

Deve-se ressaltar que a formulação desenvolvida acima avalia apenas a perda de protensão. Portanto, as ações a serem consideradas são a carga permanente e a própria força de protensão. Não é possível prosseguir a análise, ou seja, uma vez obtida a configuração após as perdas, não é permitido incluir outras ações, como variação de temperatura e sobrecarga de pedestres. Uma alternativa para estimar o comportamento da estrutura a tempo infinito sob diversos carregamentos, é fazer uma atualização de geometria e forças, e em seguida reiniciar a análise. Esse procedimento é aproximado e será melhor detalhado no capítulo 5 . 


\subsubsection{Equações e soluções na forma adimensionalizada}

DEL ARCO \& BENGOECHEA (1996a) adimensionalizam as equações envolvidas no problema e fornecem a solução para o caso de uma passarela biengastada. Esse tratamento permite compreender o funcionamento da estrutura e tirar algumas conclusões importantes, sendo reproduzido a seguir.

Inicialmente, deve-se definir alguns parâmetros:

$\bar{x}=\frac{X}{L}$

$\bar{w}=\frac{H_{0} \cdot w}{q_{0} \cdot L^{2}}$

$\overline{\mathrm{P}}_{0}=\frac{\mathrm{P}_{0}}{\mathrm{H}_{0}}$

$\overline{\mathrm{h}}=\frac{\mathrm{h}}{\mathrm{H}_{0}}$

$\bar{M}=\frac{M}{q_{0} \cdot L^{2}}$

$\bar{q}=\frac{q}{q_{0}}$

$\Theta=\frac{E \cdot A \cdot \alpha \cdot \Delta T}{H_{0}}$

$\alpha^{2}=\frac{E_{c} \cdot I_{C}}{H_{0} \cdot L^{2}}$

$\lambda^{2}=\left(\frac{\mathrm{q}_{0} \cdot \mathrm{L}}{\mathrm{H}_{0}}\right)^{2} \cdot \frac{\mathrm{E} \cdot \mathrm{A}}{\mathrm{H}_{0}}$

Utilizando-se desses parâmetros, (18), (15) e (19) resultam respectivamente em:

$$
\begin{aligned}
& \alpha^{2} \cdot \frac{d^{4} \bar{w}}{d \bar{x}^{4}}-\left(1+\bar{h}+\bar{P}_{0}\right) \cdot \frac{d^{2} \bar{w}}{d \bar{x}^{2}}=\bar{q}(\bar{x})-\left(\bar{h}+\bar{P}_{0}\right) \\
& \bar{M}=-\alpha^{2} \cdot \frac{d^{2} \bar{w}}{d \bar{x}^{2}} \\
& \bar{h}=\lambda^{2} \cdot \int_{A}^{B} \bar{w} \cdot d \bar{x}-\Theta
\end{aligned}
$$

De acordo com DEL ARCO \& BENGOECHEA (1996a), o comportamento estrutural 
depende basicamente dos parâmetros $\alpha^{2}, \lambda^{2}$.

O parâmetro $\alpha^{2}$ representa a influência da rigidez à flexão, em geral de valor bem pequeno nesse tipo de estrutura. Assim, o comportamento da passarela se aproxima bastante ao de um cabo livremente suspenso. Como exemplo, DEL ARCO \& BENGOECHEA (1996a) citam a passarela em Redding (STRASKY, 1999), que possui $\alpha^{2}=1,3 \cdot 10^{-3}$.

Por sua vez, o comportamento de um cabo livremente suspenso depende basicamente de $\lambda^{2}$. Considerando-se uma carga uniformemente distribuída, $\alpha^{2}=0$ (despreza-se a rigidez a flexão) e admitindo-se que os apoios são indeslocáveis, a integração da equação 77 e sua substituição em 79, levam a:

$$
\begin{aligned}
& \bar{w}(\bar{x})=\frac{\bar{q}-\left(\bar{h}+\bar{P}_{0}\right)}{2 \cdot\left(1+\bar{h}+\bar{P}_{0}\right)} \cdot \bar{x} \cdot(1-\bar{x}) \\
& \bar{h}=\lambda^{2} \cdot \frac{\bar{q}-\left(\bar{h}+\bar{P}_{0}\right)}{12 \cdot\left(1+\bar{h}+\bar{P}_{0}\right)}
\end{aligned}
$$

Analisando as equações 80 e 81 , duas situações podem ocorrer:

$$
\begin{aligned}
& \lambda^{2} \rightarrow 0, \bar{h} \rightarrow 0, \bar{w}(\bar{x}) \rightarrow \frac{\bar{q}-\bar{P}_{0}}{2 \cdot\left(1+\overline{P_{0}}\right)} \cdot \bar{x} \cdot(1-\bar{x}) \\
& \lambda^{2} \rightarrow \infty, \bar{h} \rightarrow \bar{q}-\overline{P_{0}}, \bar{w}(\bar{x}) \rightarrow 0
\end{aligned}
$$

Quando $\lambda^{2} \rightarrow 0$, o cabo se deforma sem incremento de força horizontal. Quando $\lambda^{2} \rightarrow \infty$, o cabo se comporta como inextensível. Portanto, para que os deslocamentos sejam pequenos em uma passarela pênsil, $\lambda^{2}$ deve ser elevado. Em pontes pênseis tradicionais, $\lambda^{2}$ varia entre 100 e 400. De acordo com DEL ARCO \& BENGOECHEA (1996a), nas estruturas aqui tratadas, sem a introdução da protensão, $\frac{E \cdot A}{H_{0}} \approx 400$ e com relações flecha/vão usuais (da ordem de 1/50), $\lambda^{2} \approx 10$. Assim, mantendo-se a relação flecha/vão e o peso próprio, a única maneira de aumentar $\lambda^{2}$ é aumentar a rigidez axial, o que é possível com a introdução da protensão.

Por outro lado, a introdução da protensão não basta para controlar os movimentos devido a uma carga antisimétrica. Nessa situação, o incremento de força horizontal é nulo e é necessária uma redução na relação sobrecarga/peso próprio para que se tenha movimentos toleráveis. Daí, uma importante conclusão de DEL ARCO \& BENGOECHEA (1996a): a passarela pênsil só é viável devido à combinação da protensão e do peso próprio, 
que garantem juntos a rigidez da estrutura.

\subsubsection{Caso de uma estrutura biengastada}

DEL ARCO \& BENGOECHEA (1996a) apresentam expressões analíticas para o cálculo do incremento de força horizontal, dos deslocamentos e dos momentos fletores em estruturas biengastadas submetidas a carregamento uniformemente distribuído e a uma força de protensão constante $P_{0}$.

O valor de $\overline{\mathrm{h}}$ é dado por:

$\overline{\mathrm{h}}=\lambda^{2} \cdot\left(\frac{1}{6}+\frac{2}{\gamma^{2}}-\frac{1}{\gamma}\right) \cdot \frac{\overline{\mathrm{q}}-\overline{\mathrm{h}}-\overline{\mathrm{P}}_{0}}{2 \cdot\left(1+\overline{\mathrm{h}}+\overline{\mathrm{P}}_{0}\right)}-\Theta$

onde:

$\gamma^{2}=\frac{1+\overline{\mathrm{h}}+\overline{\mathrm{P}}_{0}}{\alpha^{2}}$

Os deslocamentos $\overline{\mathrm{w}}$ e os momentos fletores $\overline{\mathrm{M}}$ são dados por:

$\bar{w}\left(\frac{1}{2}\right)=\frac{\bar{q}-\left(\bar{h}+\bar{P}_{0}\right)}{2 \cdot\left(1+\bar{h}+\bar{P}_{0}\right)} \cdot\left(\frac{1}{4}-\frac{1}{\gamma}\right)$

$\bar{M}(0)=-(\gamma-2) \cdot \alpha^{2} \cdot \frac{\bar{q}-\left(\bar{h}+\bar{P}_{0}\right)}{2 \cdot\left(1+\bar{h}+\bar{P}_{0}\right)}$

$\overline{\mathrm{M}}\left(\frac{1}{2}\right)=2 \cdot \alpha^{2} \cdot \frac{\overline{\mathrm{q}}-\left(\overline{\mathrm{h}}+\overline{\mathrm{P}}_{0}\right)}{2 \cdot\left(1+\overline{\mathrm{h}}+\overline{\mathrm{P}}_{0}\right)}$

Observando as equações de momentos fletores, nota-se que no meio do vão o momento é proporcional a $\alpha^{2}$, enquanto que nos apoios ele é aproximadamente proporcional a $\alpha$. Dessa forma, como já dito no capítulo 2 , os momentos fletores somente são significativos nos apoios, motivo pelo qual essa região deve ser cuidadosamente projetada. Em geral, a solução adotada é aumentar a espessura gradativamente nas proximidades dessa região. De acordo com a equação 84 , o aumento de $\alpha^{2}$ não é suficiente para reduzir os deslocamentos. Portanto, é conveniente que $\alpha^{2}$ seja pequeno.

Para transformar os valores adimensionais obtidos pelas fórmulas acima em valores dimensionais, basta utilizar-se das relações (69), (71) e (72). 


\subsubsection{Perdas de protensão para o caso biengastado}

As perdas de protensão são tratadas da mesma maneira apresentada no item 3.1.7. A adimensionalização das equações feita por DEL ARCO \& BENGOECHEA (1996a) leva a:

$-\frac{d^{2} \Delta \bar{M}}{d \bar{x}^{2}}-\left(1+\bar{h}_{0}+\bar{P}_{0}+\Delta \bar{h}\right) \cdot \frac{d^{2} \Delta \overline{\mathrm{w}}}{d \bar{x}^{2}}=-\Delta \bar{h} \cdot\left(1-\frac{d^{2} \Delta \overline{\mathrm{w}}_{0}}{d \bar{x}^{2}}\right)$

$\Delta \overline{\mathrm{h}}=\lambda^{2} \int_{0}^{1} \Delta \overline{\mathrm{w}} \cdot \mathrm{d} \overline{\mathrm{x}}-\overline{\mathrm{h}}_{0_{\mathrm{c}}} \cdot \frac{\phi}{1+\chi \cdot \phi}$

$\Delta \overline{\mathrm{M}}(\overline{\mathrm{x}})=-\frac{\alpha^{2}}{1+\chi \cdot \phi} \cdot \frac{\mathrm{d}^{2} \Delta \overline{\mathrm{w}}}{d \overline{\mathrm{x}}^{2}}-\overline{\mathrm{M}}_{0}(\overline{\mathrm{x}}) \cdot \frac{\phi}{1+\chi \cdot \phi}$

$\lambda^{2} \infty=\left(\frac{\mathrm{q}_{0} \cdot \mathrm{L}}{\mathrm{H}_{0}}\right)^{2} \cdot \frac{1}{\mathrm{H}_{0}} \cdot\left(\frac{\mathrm{E}_{\mathrm{C}} \cdot \mathrm{A}_{\mathrm{C}}}{1+\chi \cdot \phi}+\mathrm{E}_{\mathrm{s}} \cdot \mathrm{A}_{\mathrm{s}}\right)$

A integração da equação 87 é possível, mas complexa. Como alternativa, DEL ARCO \& BENGOECHEA (1996a) afirmam que consegue-se uma boa aproximação se a rigidez à flexão é desprezada. Assim, a variação da força horizontal obtida é dada por:

$$
\begin{aligned}
& \Delta \overline{\mathrm{h}}^{2}+\Delta \overline{\mathrm{h}} \cdot\left(1+\overline{\mathrm{h}}_{0}+\overline{\mathrm{P}}_{0}+\overline{\mathrm{h}}_{0_{\mathrm{c}}} \cdot \frac{\phi}{1+\chi \cdot \phi}+\lambda^{2} \cdot \frac{1+\overline{\mathrm{q}}}{12 \cdot\left(1+\overline{\mathrm{h}}_{0}+\overline{\mathrm{P}}_{0}\right)}\right)+ \\
& +\left(1+\overline{\mathrm{h}}_{0}+\overline{\mathrm{P}}_{0}\right) \cdot \overline{\mathrm{h}}_{0_{\mathrm{c}}} \cdot \frac{\phi}{1+\chi \cdot \phi}=0
\end{aligned}
$$

A variação da força horizontal no concreto é:

$\Delta \bar{h}_{C}=\frac{\frac{E_{C} \cdot A_{C}}{1+\chi \cdot \phi}}{\frac{E_{C} \cdot A_{C}}{1+\chi \cdot \phi}+E_{S} \cdot A_{S}} \cdot \Delta \bar{h}-\frac{E_{S} \cdot A_{S}}{\frac{E_{C} \cdot A_{C}}{1+\chi \cdot \phi}+E_{S} \cdot A_{S}} \cdot \bar{h}_{0_{C}} \cdot \frac{\phi}{1+\chi \cdot \phi}$

onde:

$A_{S}$ - somatória da área de aço dos cabos de sustentação e de protensão.

O primeiro termo da equação 92 aparece devido ao comportamento não-linear da estrutura e o segundo devido à redistribuição interna de tensões.

A variação da flecha é dada por: 
$\Delta \overline{\mathrm{w}}\left(\frac{1}{2}\right)=\frac{-\Delta \overline{\mathrm{h}} \cdot(1+\overline{\mathrm{q}})}{8 \cdot\left(1+\overline{\mathrm{h}}_{0}+\overline{\mathrm{P}}_{0}+\Delta \overline{\mathrm{h}}\right) \cdot\left(1+\overline{\mathrm{h}}_{0}+\overline{\mathrm{P}}_{0}\right)}$

A variação dos momentos fletores no meio do vão é:

$\Delta \overline{\mathrm{M}}\left(\frac{1}{2}\right)=-\frac{\alpha^{2}}{1+\chi \cdot \phi} \cdot \frac{\Delta \overline{\mathrm{h}} \cdot(1+\overline{\mathrm{q}})}{\left(1+\overline{\mathrm{h}}_{0}+\overline{\mathrm{P}}_{0}+\Delta \overline{\mathrm{h}}\right) \cdot\left(1+\overline{\mathrm{h}}_{0}+\overline{\mathrm{P}}_{0}\right)}-\overline{\mathrm{M}}_{0}\left(\frac{1}{2}\right) \cdot \frac{\phi}{1+\chi \cdot \phi}$

A variação dos momentos fletores nos apoios é feita por equilíbrio, representando dessa forma apenas uma estimativa do valor correto.

$\Delta \overline{\mathrm{M}}(0)=\Delta \overline{\mathrm{M}}\left(\frac{1}{2}\right)+\Delta \overline{\mathrm{h}}\left[\frac{1}{8}+\overline{\mathrm{w}}_{0}\left(\frac{1}{2}\right)+\Delta \overline{\mathrm{w}}\left(\frac{1}{2}\right)\right]+\left(1+\overline{\mathrm{h}}_{0}+\overline{\mathrm{P}}_{0}\right) \cdot \Delta \overline{\mathrm{w}}\left(\frac{1}{2}\right)$

\subsection{INTRODUÇÃO À ANÁLISE DE ESTRUTURAS CONTÍNUAS}

A análise das estruturas contínuas é similar à análise das estruturas de um único vão. Novamente, duas fases podem ser distinguidas.

A primeira fase ocorre durante a montagem da estrutura, quando os elementos prémoldados repousam sobre os cabos de sustentação, antes da concretagem das juntas e da introdução da protensão. Portanto, deve-se estudar o comportamento de um cabo contínuo livremente suspenso. O desenvolvimento dessa teoria pode ser encontrado em KADLCAK (1995). A representação estática dos cabos de sustentação pode ser vista na figura 73.

Entre os diversos fatores a serem considerados, estão o desenvolvimento de atrito nas selas dos pilares intermediários e a deformação dos cabos dentro dos blocos de ancoragem. Em uma análise mais refinada, pode ser levado em conta inclusive o deslocamento horizontal dos blocos de fundação.
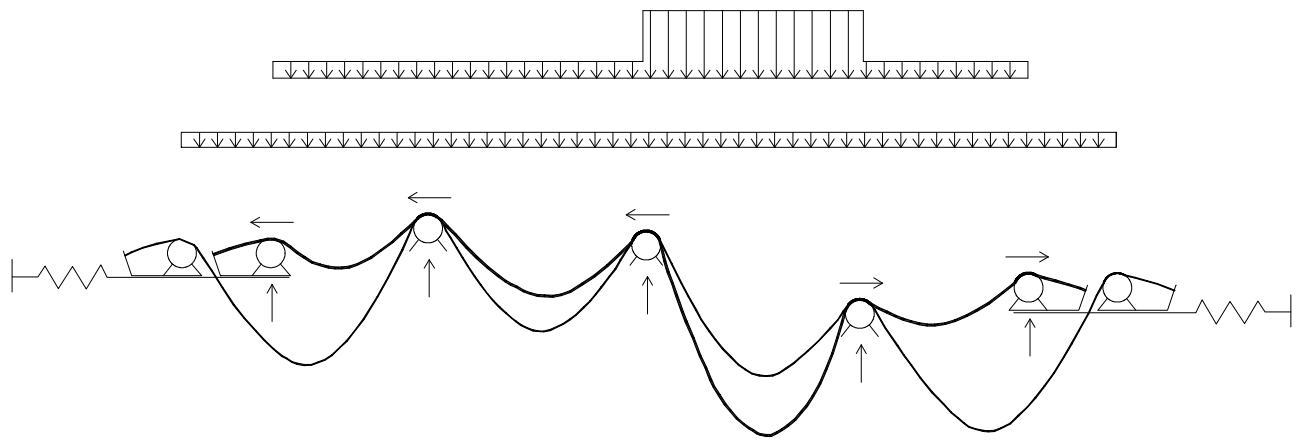

Figura 73 - Representação estática dos cabos de sustentação.

(STRASKY \& PIRNER, 1986) 
A segunda fase corresponde ao comportamento em serviço da estrutura, ou seja, após a concretagem das juntas e a aplicação da protensão. Momentos fletores significativos só ocorrem sob pontos de carga e nos apoios. De acordo com STRASKY \& PIRNER (1986), as tensões são relativamente baixas e não afetam o comportamento global da estrutura. Assim, STRASKY \& PIRNER (1986) sugerem a análise de estruturas contínuas em serviço, apoiadas nas extremidades sobre almofadas de elastômero, através de dois passos:

a) Primeiramente, a estrutura é tratada como um cabo contínuo perfeitamente flexível. Dessa forma, obtém-se a força horizontal incógnita e os deslocamentos dos apoios;

b) Em seguida, são usadas fórmulas para os cálculos das tensões de flexão e cisalhamento em cada vão. STRASKY \& PIRNER (1986) recomendam as expressões analíticas encontradas em KOLLBRUNNER et al (1980) ${ }^{3}$ para pontes estaiadas, similares às expressões desenvolvidas no item 3.1 para o cálculo dos momentos fletores e dos deslocamentos.

Os pilares intermediários são estudados através das reações provenientes de vãos vizinhos, como mostrado na figura 74 .

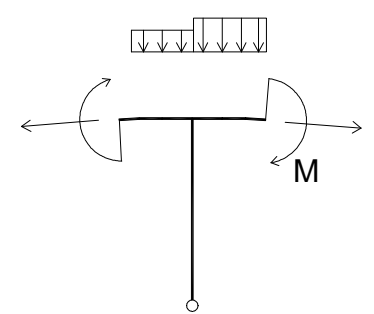

Figura 74 - Carregamento no apoio intermediário. (STRASKY \& PIRNER, 1986)

Como pôde ser constatado, o texto acima é apenas uma introdução na análise de estruturas contínuas. Um aprofundamento na análise de tais estruturas não é objetivo dessa dissertação, ficando como sugestão para futuros estudos.

${ }^{3}$ KOLLBRUNNER, C.F.; HAJDIN, N.; STIPANIC, B. (1980). Contribution to the Analysis of CableStayed Bridges. Institute for Engineering Research. Verlag Schulthess AG, Zurich. 


\section{CONSIDERAÇOES SOBRE A ANÁLISE DINÂMICA E AS FUNDAÇÕES}

Como as passarelas em questão são bastante susceptíveis a ações dinâmicas, esse capítulo irá abordar certos aspectos relativos a essa análise. Vale dizer que o texto tem caráter introdutório e irá fornecer apenas noções básicas de como se deve proceder tal análise.

Por fim, serão citadas alternativas para a ancoragem da força horizontal, cuja magnitude é bastante elevada nesse tipo de estrutura.

\subsection{COMENTÁRIOS SOBRE O COMPORTAMENTO DINÂMICO}

As passarelas pênseis são bastante susceptíveis a ações dinâmicas devido a sua baixa rigidez a flexão, pequena massa, baixa freqüência natural e baixo amortecimento. Portanto, o comportamento dinâmico precisa ser verificado ainda em fase de projeto, tanto através de modelos teóricos quanto através de ensaios de laboratório.

Em seguida, serão feitos comentários e algumas indicações de como tratar o problema. Devido à complexidade do assunto, uma análise mais profunda não será abordada aqui, mas pode ser consultada na bibliografia indicada.

\subsubsection{Introdução}

De acordo com TILLY et al (1984) o problema de vibrações em passarelas ficou evidenciado a partir do século 18, com o início das construções em aço. Um dos primeiros casos de colapso foi em 1831, quando cerca de 60 soldados marchavam sobre uma passarela metálica em Broughton. Depois desse incidente, foram colocados avisos nos acessos de inúmeras passarelas instruindo os soldados a pararem a marcha durante a travessia.

Atualmente, maior atenção é voltada para o estado limite de utilização. As vibrações no plano vertical, além de causar desconforto nos pedestres, podem danificar o 
pavimento. Como a sensação de desconforto é sentida muito antes do perigo de ruína da estrutura, em geral os limites da análise dinâmica são ditados pela sensibilidade humana.

As vibrações podem ser causadas por pedestres, pelo vento e até mesmo por atos de vandalismo. Entre esses fatores, TILLY et al (1984) afirmam que o principal carregamento é aquele imposto pelos pedestres. A ação aerodinâmica só passa a ser mais preocupante em estruturas longas e flexíveis, embora não deva ser ignorada.

\subsubsection{Níveis aceitáveis de vibração}

A reação dos pedestres à vibração é bastante variável e depende de diversos aspectos, de acordo com WHEELER (1982):

a) Psicológico e físico: cada pessoa reage diferentemente ao mesmo grau de vibração. Enquanto alguns nem a sentem, outros se assustam com um mínimo movimento. Sexo e idade influenciam;

b) Situações e circunstâncias: a reação depende se a pessoa está parada ou andando, sozinha ou acompanhada;

c) Grau de vibração, freqüência e tempo de exposição;

d) Expectativa e número de travessias: a reação do indivíduo depende do que ele espera do funcionamento da estrutura. Ao passar inúmeras vezes pela passarela, ele acaba se "acostumando" com eventuais movimentações.

Assim, é difícil impor limites e definir com exatidão quando o comportamento de uma estrutura é satisfatório ou não.

STRASKY (1999) afirma que o critério a ser adotado em passarelas pênseis é a limitação da velocidade e aceleração do movimento do tabuleiro. Em acordo com TILLY et al (1984), a máxima aceleração é limitada a:

$\mathrm{a}_{\text {máx }}=\frac{1}{2} \cdot \sqrt{\mathrm{f}_{1}}$

onde:

$a_{\text {máx }}$ - máxima aceleração permitida ao tabuleiro, em $\mathrm{m} / \mathrm{s}^{2}$;

$\mathrm{f}_{1}$ - primeira frequência de flexão, em $\mathrm{Hz}$.

A máxima velocidade aceitável de excitação do tabuleiro é:

$\mathrm{v}_{0}(2 \pi \mathrm{f})=24 \mathrm{~mm} / \mathrm{s}$ 
A figura 75, extraída de STRASKY \& PIRNER (1986), mostra os limites de conforto fornecidos por (96) e (97). O comportamento de algumas passarelas projetadas por esses autores sob algumas situações de carregamento também é mostrado.

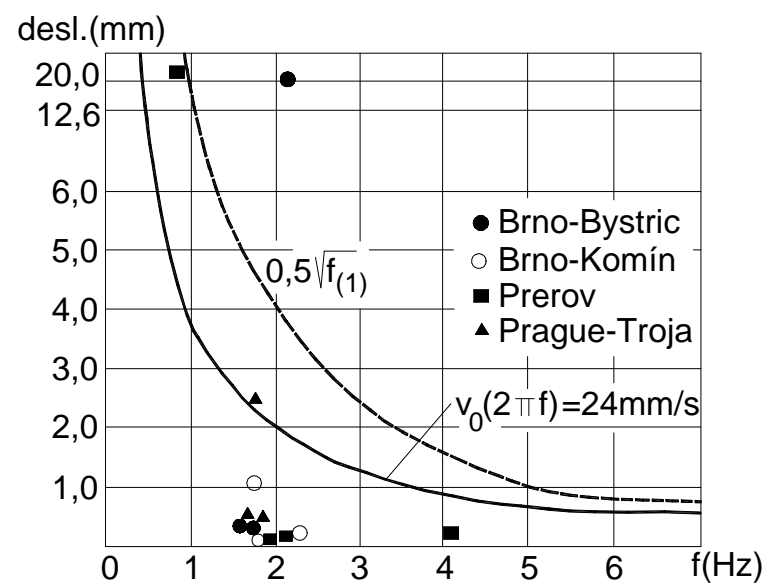

Figura 75 - Limites de desconforto devido à vibração. (STRASKY \& PIRNER, 1986)

Analisando a figura 75, o comportamento das passarelas indicadas é aceitável na grande maioria dos casos de carregamento. As exceções são as passarelas de Brno-Bystric submetida a um excitador mecânico, a passarela de Prerov submetida à ação de quatro pessoas no meio do maior vão e a passarela em Prague-Troja sujeita ao andar de duas pessoas com passos sincronizados de frequência igual à frequência natural da passarela, ou seja, na ressonância. No caso da ação de vândalos, é possível se desprezar o conforto dos pedestres da análise.

\subsubsection{Ação de pedestres}

A força que é transmitida pelo contato do pé com a estrutura depende se o indivíduo está simplesmente andando ou está correndo. Além disso, quando se está correndo, apenas um pé de cada vez está em contato com o chão. Curvas força/peso $x$ tempo podem ser vistas na figura 76 .
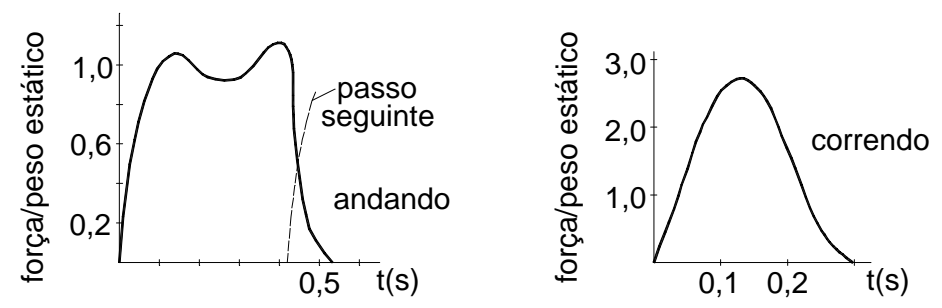

Figura 76 - Curvas força/peso $x$ tempo. (WHEELER, 1982) 
A figura 77 fornece a relação $\frac{\operatorname{máx}\left(F_{\text {est }}+F_{\text {din }}\right)}{F_{\text {est }}}$ em função da frequência do passo de uma pessoa.

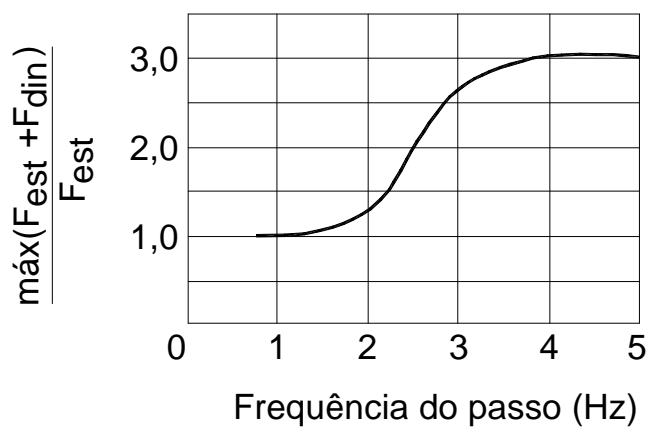

Figura 77 - Dependência da relação $\frac{\text { máx }\left(F_{\text {est }}+F_{\text {din }}\right)}{F_{\text {est }}}$ em função da frequência do passo. (STRASKY \& PIRNER, 1986)

A observação de uma série de pedestres passando por um determinado ponto possibilitou as seguintes conclusões quanto às freqüências de passo (passos/segundo), de acordo com TILLY et al (1984):

a) mais de $95 \%$ dos pedestres possuíam uma freqüência de passo entre 1,5 e 2,5 Hz (passos/segundo);

b) apenas $1 \%$ dos pedestres andavam a uma freqüência superior a $2,8 \mathrm{~Hz}$;

c) entre os praticantes de "cooper" a freqüência variava de 2,8 a $3,0 \mathrm{~Hz}$;

d) para aqueles que corriam, a freqüência raramente ultrapassava $3,5 \mathrm{~Hz}$, podendo chegar a $5 \mathrm{~Hz}$.

O comportamento da passarela depende do número de pessoas que a atravessam simultaneamente, cuja influência é medida pelo coeficiente $\delta_{N}$. A figura 78 fornece o valor de $\delta_{N}$ em função do número de pessoas que passam pela passarela por minuto com uma frequência de passo de $2 \mathrm{~Hz}$ (valor mais freqüente, como comprovado acima) e também de acordo com a frequência natural da estrutura. Dessa forma, uma aproximação do coeficiente de carregamento dinâmico $\left(\delta_{\text {load }}\right)$ para a frequência de passo mais comum (2 $\mathrm{Hz}$ ) é dada por $\delta_{\text {load }}=\frac{\operatorname{máx}\left(\mathrm{F}_{\mathrm{est}}+\mathrm{F}_{\mathrm{din}}\right)}{\mathrm{F}_{\mathrm{est}}} \cdot \delta_{\mathrm{N}}$. Por exemplo, para frequência natural de $1,5 \mathrm{~Hz}$ e para 125 pessoas atravessando a passarela por minuto, $\delta_{\text {load }}=1,33 \cdot 3=3,99$ (STRASKY \& PIRNER, 1986).

A resposta da estrutura à ação de pedestres é normalmente calculada utilizando 
como modelo uma pessoa andando de uma extremidade a outra da passarela. Entretanto, STRASKY \& PIRNER (1986) usam uma solução aproximada. A força harmônica passando ao longo da passarela é substituída por uma força harmônica atuando no meio do vão. A frequência utilizada é aquela mais frequentemente causada por pedestres, ou seja, $2 \mathrm{~Hz}$.

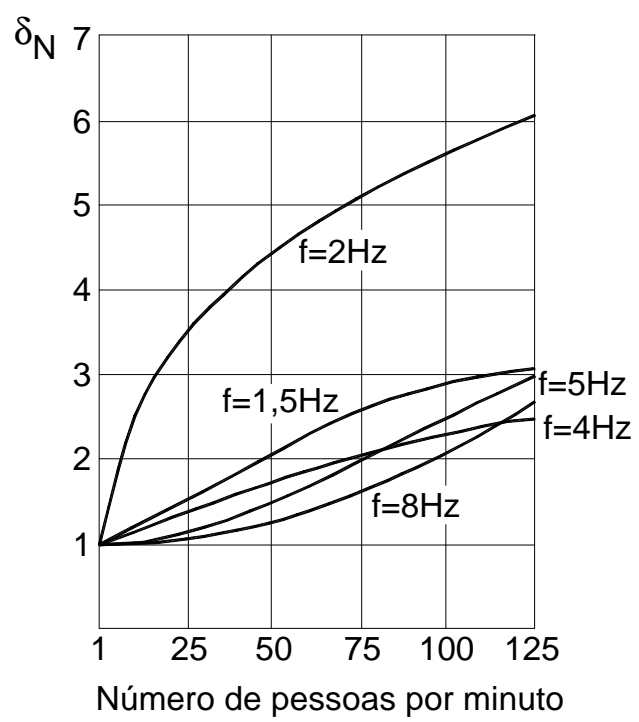

Figura 78 - Dependência de $\delta_{N}$ em função do número de pessoas.

(PIRNER ${ }^{4}$ apud STRASKY \& PIRNER, 1986)

Em STRASKY (1999), a ação dos pedestres é simulada por uma carga concentrada de $180 \mathrm{kN}$ movendo-se ao longo do vão principal. WHEELER (1982) afirma que, como ferramenta de projeto, um único pedestre atravessando a passarela é o modelo mais apropriado. Nesse caso, os critérios de aceitação estão bem estabelecidos.

Ainda em WHEELER (1982) encontram-se os seguintes comentários:

a) a probabilidade de haver uma multidão em passo sincronizado atravessando a passarela é muito pequena;

b) como a probabilidade de "corredores" atravessarem a passarela é menor que a probabilidade de pedestres, é proposta uma redução na resposta da estrutura quando a freqüência de passo for superior a $2 \mathrm{~Hz}$;

c) a ação de vândalos não é significativa, uma vez que por mais que se esforcem, é difícil a excitação em sincronia por parte dos mesmos.

\subsubsection{Frequências naturais das passarelas}

De acordo com PIRNER \& FISCHER (1998), a frequência natural das passarelas

\footnotetext{
${ }^{4}$ PIRNER, M. (1972). Studie razu lidskeho tela. UTAM, CSAV.
} 
pênseis cai linearmente com seus vãos. A figura 79 mostra a menor frequência natural de passarelas em função do seu vão, para vários casos e de acordo com diversos autores. 0 seu intervalo de variação é dado por:

$\frac{217}{L^{1,431}}<f<\frac{112}{L^{0,925}}$

onde:

$\mathrm{f}$ - menor frequência natural, em $\mathrm{Hz}$;

$L$ - vão, em metros.

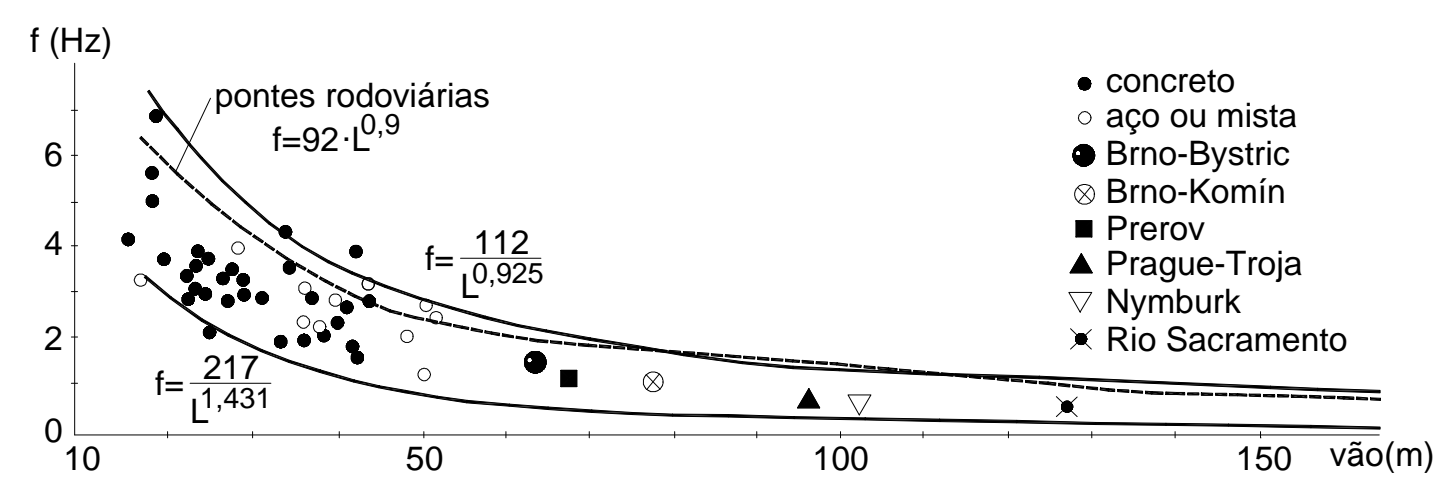

Figura 79 - Frequência natural em função do vão. (PIRNER \& FISCHER, 1998)

A referência usada para pontes rodoviárias é dada por:

$f=92 \cdot L^{0,9}$

A menor fraquência natural nas passarelas pênseis corresponde ao modo de vibrar anti-simétrico, quando o ponto central está em repouso. PIRNER \& FISCHER (1998) indicam que essa frequência é aproximadamente igual à segunda frequência de uma mola reta:

$f_{(2)}=\frac{1}{2 \cdot L} \cdot \sqrt{\frac{H}{m}}$

DEL ARCO \& BENGOECHEA (1996a) apresentam uma formulação que permite o cálculo das frequências naturais verticais de vibração, sendo mostrada a seguir.

Seguindo a utilização de parâmetros adimensionais descritos no item 3.1.8, as equações do movimento livre são escritas na forma:

$$
\alpha^{2} \cdot \frac{\partial^{4} \Delta \overline{\mathrm{w}}}{\partial \overline{\mathrm{x}}^{4}}-\left(1+\overline{\mathrm{h}}_{0}+\overline{\mathrm{P}}_{0}+\Delta \overline{\mathrm{h}}\right) \cdot \frac{\partial^{2} \Delta \overline{\mathrm{w}}}{\partial \overline{\mathrm{x}}^{2}}=-\frac{\partial^{2} \Delta \overline{\mathrm{w}}}{\partial \overline{\mathrm{t}}^{2}}-\Delta \overline{\mathrm{h}} \cdot\left(1-\frac{\mathrm{d}^{2} \overline{\mathrm{w}}_{0}}{\mathrm{~d}^{2}}\right)
$$


O tempo adimensional é dado por:

$\bar{t}=\frac{t}{L} \cdot \sqrt{\frac{H_{0}}{m}}$

onde:

m - massa por unidade de comprimento da estrutura.

Desprezando-se os termos de inércia longitudinais:

$$
\Delta \overline{\mathrm{h}}=\lambda^{2} \cdot \int_{0}^{1} \Delta \overline{\mathrm{w}} \cdot \mathrm{d} \overline{\mathrm{x}}
$$

As frequências verticais de modo anti-simétrico são obtidas por:

$\bar{w} \approx 2 \cdot n \cdot \pi \cdot \frac{\gamma}{\gamma-2} \cdot \sqrt{1+\bar{h}_{0}+\bar{P}_{0}} \cdot \sqrt{1+\frac{4 \cdot n^{2} \cdot \pi^{2}}{(\gamma-2)^{2}}}$

e

$\gamma^{2}=\frac{1+\overline{\mathrm{h}}_{0}+\overline{\mathrm{P}}_{0}}{\alpha^{2}}$

Para transformar (104) em forma dimensional, basta fazer:

$\mathrm{w}=\frac{\overline{\mathrm{w}}}{\mathrm{L}} \cdot \sqrt{\frac{\mathrm{H}_{0}}{\mathrm{~m}}}$

A equação 104 pode ser usada para estimar o efeito da rigidez a flexão de um cabo nas frequências de vibração anti-simétricas.

A determinação das frequências de vibração simétricas é bastante complicada. Desprezando a rigidez a flexão, uma aproximação é dada por:

$\bar{W}=\sqrt{1+\bar{h}_{0}+\bar{P}} \cdot f$

sendo

$\tan \left(\frac{f}{2}\right)=\frac{f}{2}-\frac{4}{\lambda^{2}} \cdot \frac{\left(1+\bar{h}_{0}+\bar{P}_{0}\right)^{2}}{1+\bar{q}} \cdot\left(\frac{f}{2}\right)^{3}$ 
STRASKY \& PIRNER (1986) também apresentam fórmulas para o cálculo das frequências naturais para o caso de passarelas com um único vão. A estrutura é tratada como um cabo isolado, sustentado por apoios indeslocáveis. Segundo os autores, a rigidez a flexão é desprezível em termos de engenharia, aparecendo somente na terceira frequência natural com ordem de grandeza de $2 \%$.

No caso de passarelas contínuas o comprimento do vão pode mudar durante as vibrações devido a movimentações horizontais dos pontos de apoio, o que resulta em variação das forças no cabo. Nesse caso, a passarela é modelada como um sistema de cabos conectados nos topos de pilares pendulares (v. figura 80). Maiores detalhes sobre essa teoria pode ser encontrada em STRASKY \& PIRNER (1986).

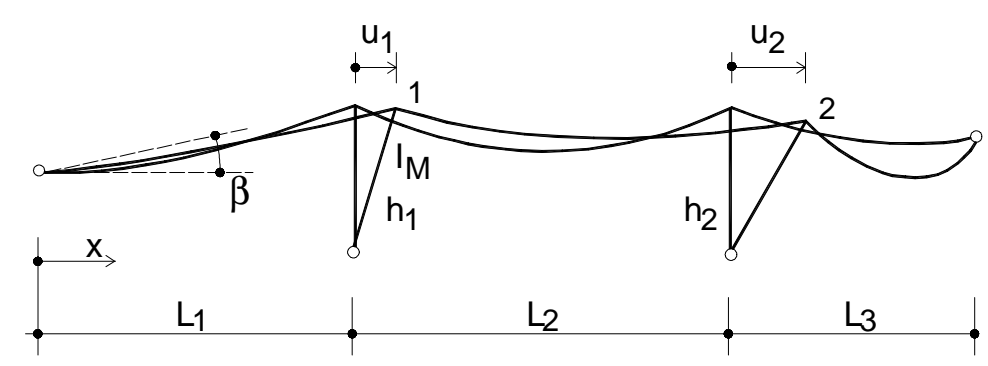

Figura 80 - Representação de uma estrutura contínua. (STRASKY \& PIRNER, 1986)

\subsubsection{Amortecimento e rigidez}

De acordo com STRASKY \& PIRNER (1986), o comportamento de uma estrutura depende, além do carregamento, de seu amortecimento e sua rigidez. O deslocamento dinâmico é inversamente proporcional à rigidez e inversamente proporcional à raiz quadrada do amortecimento. Isso indica que um aumento da rigidez é mais vantajoso do ponto de vista dinâmico. Entretanto, pelo fato do aumento de rigidez interferir significativamente na forma da estrutura, prefere-se um aumento no amortecimento.

O amortecimento é influenciado pelo material de construção empregado sendo que o aço possui os valores mais baixos e o concreto os valores mais altos. Geralmente é representado pelo decremento logarítmico, dado pela fórmula:

$\delta=\frac{1}{n} \cdot \ln \left(\frac{A_{0}}{A_{n}}\right)$

onde:

$A_{0}$ - amplitude inicial;

$A_{n}$ - amplitude após $n$ ciclos;

$\mathrm{n}$ - número de ciclos. 
Como evidenciado por (109), são requeridos ensaios de carregamento dinâmico para se conhecer o valor do amortecimento. PIRNER \& FISCHER (1998) indicam que os valores medidos nas passarelas pênseis construídas na República Tcheca correspondentes a vibrações na menor frequência natural ficam dentro dos limites de:

$0,010<$ amortecimento $<0,120$, com máxima aceleração medida de $0,75 \mathrm{~m} \cdot \mathrm{s}^{-2}$.

A rigidez é definida pela razão da deformação no meio do vão pelo valor da carga concentrada.

STRASKY \& PIRNER (1986) apresentam os seguintes limites para a rigidez e o amortecimento:

rigidez $\geq 8 \mathrm{kN} / \mathrm{mm}$;

amortecimento $\geq 0,03 \mathrm{log} \cdot \mathrm{dec}$

Valores inferiores aos mostrados acima podem significar um funcionamento deficiente da estrutura quanto a ações dinâmicas.

Maiores discussões quanto ao amortecimento podem ser encontradas em STRASKY \& PIRNER (1986).

\subsubsection{Estabilidade aerodinâmica}

PIRNER \& FISCHER (1998) salientam que a resposta das passarelas projetadas por Jiri Strasky à ação do vento é menor que a resposta devido à ação de pedestres, tanto individual quanto em grupos. Nenhuma das passarelas pênseis mostrou perda de estabilidade aerodinâmica.

Para comprovar o comportamento aerodinâmico favorável, STRASKY (1999) cita o exemplo de uma passarela em San Diego. A frequência de torção pura dessa estrutura é $f_{(7)}=3,2862$. A primeira frequência de flexão é $f_{(1)}=1,196$. Chamando $r$ igual a $\frac{f_{(7)}}{f_{(1)}}$, encontra-se $r=2,75$, que é maior que $r_{\text {crít }}=2,50$ (considerado como crítico para a estabilidade aerodinâmica das estruturas).

Baseados em ensaios realizados em túneis de vento, YOSHIMURA et al (1997) sugerem que modificações nas bordas dos elementos do tabuleiro podem melhorar as características aerodinâmicas. As modificações estudadas são em forma de meio-círculo e meia-elípse (figura 81), podendo ser acopladas na forma de carenagem ou incorporadas na seção transversal durante a moldagem do elemento pré-moldado. 


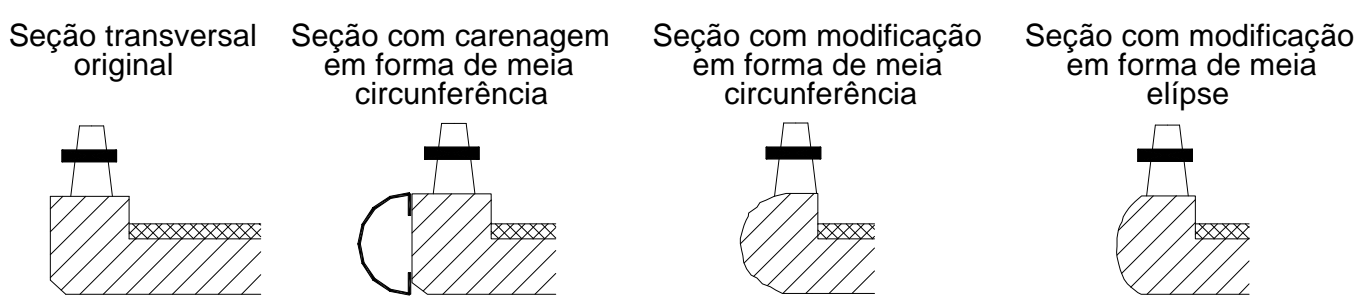

Figura 81 - Modificações de borda. (YOSHIMURA et al, 1997)

\subsubsection{Dispositivos para redução das vibrações}

Os amortecedores são geralmente os dispositivos mais eficazes na redução de vibrações.

De acordo com PIRNER \& FISCHER (1998), apesar das vibrações induzidas pelos pedestres e pelo vento não afetarem a estrutura, a passarela sobre o rio Sacramento em Redding (REDFIELD et al, 1992) com 127 metros de vão recebeu amortecedores que consistem de uma massa e uma mola movendo-se dentro das colunas do corrimão da passarela. $\mathrm{O}$ objetivo desses amortecedores instalados é reduzir as vibrações verticais.

\subsubsection{Testes dinâmicos}

STRASKY \& PIRNER (1986) apresentam as maneiras de se excitar os modos naturais de vibração em ensaios de carregamento dinâmico. É possível se utilizar a força humana, uma máquina que emite pulsos ou um excitador (eletrodinâmico ou mecânico). Passarelas com vãos maiores que 50 metros também vibram devido ao vento, geralmente em modos naturais. Assim, o vento também é usado nesses casos.

Dos métodos citados acima, o excitador ou grupo de excitadores fornece resultados menos dispersos e que melhor se correspondem com valores teóricos de frequências e com modos naturais de vibração.

\subsubsection{Conclusões da análise dinâmica}

De acordo com PIRNER \& FISCHER (1998), experimentos recentes mostram que o comportamento dinâmico das passarelas é favorável. O perigo de vibrações devido ao vento pode ser evitado com procedimentos adequados de projeto, incluindo análise teórica e ensaios em túneis de vento. Estruturas com plataformas de observação no meio do vão também se mostraram aerodinamicamente estáveis.

A passarela responde satisfatoriamente à ação de pedestres, desde que sua rigidez e seu amortecimento estejam dentro dos limites estabelecidos. A ação de vândalos, apesar de poder causar excesso de vibração, não danifica a estrutura. 
O corrimão pode ser usado para auxiliar no amortecimento de vibrações verticais.

\subsection{FUNDAÇÕES}

Sem dúvida, o principal inconveniente das passarelas pênseis são as elevadas forças horizontais a serem ancoradas, resultando em um custo elevado das fundações. Se as condições do subsolo não forem favoráveis, a obra pode inclusive se tornar inviável.

A seguir, a questão será brevemente discutida, sendo fornecidas algumas opções de fundações.

\subsubsection{Considerações gerais}

A força horizontal a ser ancorada depende do vão, da flecha e dos carregamentos que agem na estrutura. De acordo com STRASKY (1987), seu valor pode chegar a 30000 $\mathrm{kN}$, fazendo com que o custo das fundações represente uma parcela significativa no custo total da obra.

A comparação entre uma passarela pênsil e uma passarela em vigas ilustra com clareza alguns aspectos relativos aos custos das fundações (STRASKY, 1987). Ambas as estruturas foram projetadas para cruzar o rio Vltava, em Prague-Troja, na exTchecoslováquia, sendo que a passarela pênsil (v. figura 82 ) foi a estrutura efetivamente construída. Na tabela 2, são mostradas as características das duas estruturas estudadas. $\mathrm{Na}$ tabela 3 , tem-se os custos para os dois casos.

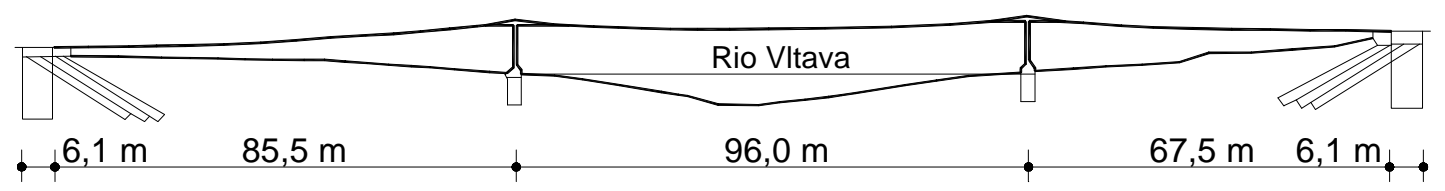

Figura 82 - Passarela em Prague-Troja. (STRASKY \& PIRNER, 1986)

Tabela 2 - Características das estruturas.

\begin{tabular}{|c|c|c|}
\hline & PASSARELA PÊNSIL & PASSARELA EM VIGAS \\
\hline Número de vãos & 3 & 4 \\
\hline Comprimentos dos vãos $(\mathrm{m})$ & $85,5-96,0-67,5$ & $25,5-59,0-96,0-66,5$ \\
\hline Comprimento total $(\mathrm{m})$ & 249,0 & 249,0 \\
\hline Tipo de fundação & $\begin{array}{c}\text { Paredes-diafragma e } \\
\text { micro-estacas }\end{array}$ & Paredes-diafragma \\
\hline Método executivo & $\begin{array}{c}\text { típico para passarelas } \\
\text { pênseis }\end{array}$ & $\begin{array}{c}\text { 3 vãos sobre cimbramentos e 1 } \\
\text { vão por balanços sucessivos }\end{array}$ \\
\hline
\end{tabular}


Tabela 3 - Custo da passarela em Prague-Troja, em milhões de unidade monetária da ex-

Tchecoslováquia. (STRASKY, 1987)

\begin{tabular}{|c|c|c|}
\hline & PASSARELA PÊNSIL & PASSARELA EM VIGAS \\
\hline Superestrutura & 2,236 & 6,605 \\
\hline Sub-estrutura & 0,920 & 0,995 \\
\hline Fundações & 4,661 & 1,020 \\
\hline TOTAL & 7,817 & 8,620 \\
\hline
\end{tabular}

Analisando a tabela 3, percebe-se que o custo relativo das fundações no caso da passarela pênsil foi de aproximadamente $60 \%$, enquanto que para a passarela em vigas foi de aproximadamente 12\%. Em termos absolutos, o custo das fundações da passarela pênsil custou mais de quatro vezes o custo das fundações da passarela em vigas.

Nesse exemplo, apesar do custo elevado das fundações, a passarela pênsil se mostrou mais econômica no geral, sendo a alternativa adotada.

São duas as situações em que as passarelas pênseis podem se tornar mais competitivas economicamente:

a) O uso de longos vãos: as fundações não representam uma parcela tão significativa em relação ao custo total da obra;

b) O uso de estruturas de vãos múltiplos: considerando-se vãos, flechas e carregamentos iguais, a força horizontal corresponde apenas à de um vão. Dessa forma, o número de vãos pode ser aumentado tanto quanto se queira e a força horizontal continua a mesma. Conclui-se que o custo por metro quadrado de passarela diminui com o aumento no número de vãos.

Quando as condições do subsolo não forem satisfatórias, resta como alternativa utilizar a passarela pênsil suportada por um arco, já descrita no item 2.3. Nesse caso, a escora ligando o trecho pênsil com as fundações do arco gera um sistema auto-equilibrado, livrando-se assim das indesejáveis forças horizontais a serem ancoradas.

\subsubsection{Alternativas para ancoragem da força horizontal}

STRASKY (1987) cita algumas alternativas para a ancoragem das elevadas forças horizontais. São elas:

a) Estacas ocas rígidas à flexão;

b) Estacas inclinadas;

c) Uma combinação de paredes-diafragma e micro-estacas;

d) Ancoragens em solo e rocha. 
Algumas configurações dos tipos de fundações citados acima podem ser observados nas figuras $82,83,84$ e 85 .

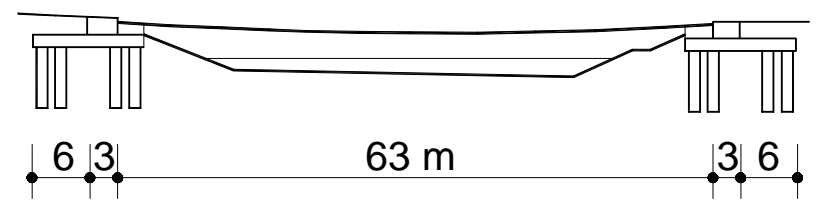

Figura 83 - Passarela em Brno-Bystrc. (STRASKY \& PIRNER, 1986)

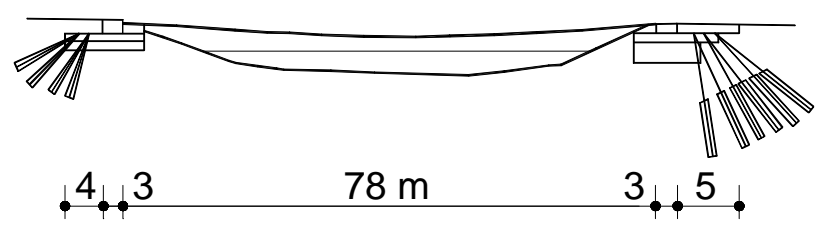

Figura 84 - Passarela em Brno-Komín. (STRASKY \& PIRNER, 1986)
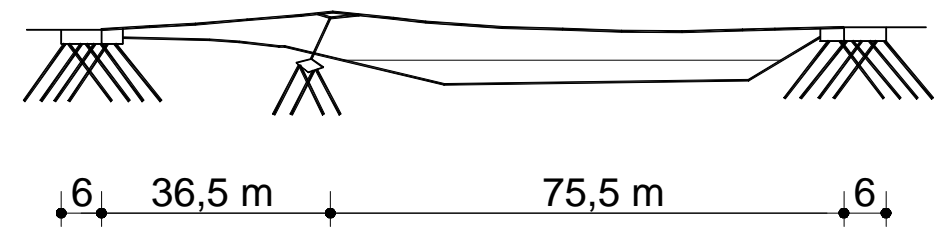

Figura 85 - Passarela em Zatec. (STRASKY \& PIRNER, 1986) 
Nesse capítulo será realizado um pré-dimensionamento de uma passarela pênsil protendida formada por elementos pré-moldados de concreto. Não se trata de um projeto completo, sendo abordados principalmente os tópicos que a diferenciam de uma estrutura convencional. Vale ressaltar que o exemplo aqui tratado não corresponde a nenhuma passarela construída.

\subsection{DADOS PARA A ANÁLISE}

\subsubsection{Descrição da estrutura estudada}

A passarela a ser analisada é constituída de um único vão com apoios nivelados, engastada em suas extremidades. Para a escolha do comprimento do vão foram levados em consideração dois pontos de vista:

a) Um possível campo de aplicação para as passarelas pênseis no Brasil é o cruzamento com rodovias. Dessa forma, seria interessante que o vão adotado se situasse dentro dos limites de tal aplicação;

b) As passarelas pênseis têm vocação para grandes vãos. Em outras palavras, é no uso de grandes vãos que elas se tornam mais atrativas, tanto do ponto de vista construtivo quanto do econômico.

Tentando conciliar os dois fatores discutidos acima, adota-se um vão de 40 metros.

Visando ao conforto dos usuários e ao acesso de deficientes físicos, em geral utilizam-se pequenas declividades e portanto pequenas relações flecha/vão, da ordem de 1/50. A fim de ilustrar alguns aspectos inerentes ao projeto das passarelas pênseis, a flecha inicial será determinada juntamente com o valor da força de protensão, no item 5.1.4. No entanto, qualquer que seja o valor admitido, a flecha inicial será reduzida posteriormente com a aplicação da protensão e o desenvolvimento da fluência do concreto. 
Um esquema longitudinal da estrutura pode ser visto na figura 86.

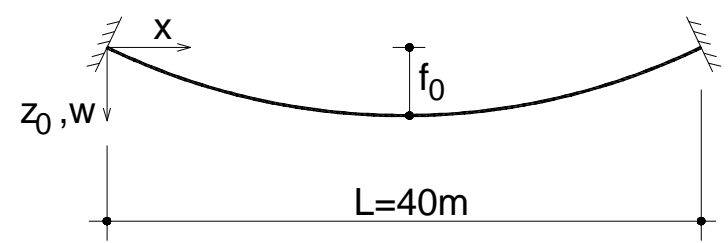

Figura 86 - Esquema longitudinal da estrutura.

A seção transversal dos elementos pré-moldados deve ter espaço suficiente para alojar os cabos de sustentação e de protensão. Em se tratando de um prédimensionamento, adota-se a seção mostrada na figura 87 , sendo:

$A_{C}=0,88 \mathrm{~m}^{2}$ (área da seção transversal de concreto)

$\mathrm{I}=0,0068 \mathrm{~m}^{4}$ (momento de inércia da seção transversal de concreto)

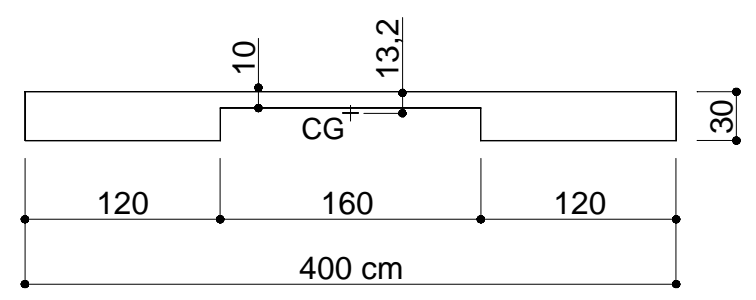

Figura 87 - Seção transversal para pré-dimensionamento.

\subsubsection{Materiais a serem empregados}

Aço (para os cabos de sustentação e protensão): CP-190 RB 12,7

$$
\begin{aligned}
& \mathrm{f}_{\mathrm{ptk}}=1900 \mathrm{MPa} \\
& \mathrm{f}_{\mathrm{pyk}}=1710 \mathrm{MPa} \\
& \mathrm{E}_{\mathrm{S}}=195000 \mathrm{MPa} \\
& \mathrm{A}_{S_{\text {nom }}}=0,987 \mathrm{~cm}^{2}
\end{aligned}
$$

Concreto: $\mathrm{f}_{\mathrm{ck}}=35 \mathrm{MPa}$

$$
\begin{aligned}
& E_{C}=5600 \cdot \sqrt{f_{c k}}=33130 \mathrm{MPa} \text { (Projeto de Revisão da NBR 6118) } \\
& E_{C S}=0,85 \cdot E_{C}=28160 \mathrm{MPa} \text { (Projeto de Revisão da NBR 6118) }
\end{aligned}
$$


onde:

$f_{p t k}$ - limite nominal de resistência à tração;

$f_{\text {pyk }}$ - tensão nominal para alongamento de 1\%;

ES - módulo de elasticidade;

$\mathrm{A}_{S_{\text {nom }}}$ - área nominal de aço;

$\mathrm{f}_{\mathrm{ck}}$ - resistência à compressão do concreto característica;

$\mathrm{E}_{\mathrm{C}}$ - módulo de elasticidade inicial do concreto;

$E_{C S}$ - módulo de elasticidade secante do concreto.

\subsubsection{Ações}

As ações que irão incidir na estrutura são:

$\checkmark$ Peso próprio dos elementos pré-moldados $\left(q_{0}\right)$ :

$q_{0}=A_{c} \cdot \gamma_{c}=0,88 \cdot 25=22 \mathrm{kN} / \mathrm{m}$

onde:

$\gamma_{c}$ - peso específico do concreto.

$\checkmark$ Peso próprio do corrimão e da pavimentação $\left(q_{g}\right)$ :

$q_{g}=5 \mathrm{kN} / \mathrm{m}$

$\checkmark$ Ação dos pedestres (carga uniformemente distribuída de intensidade $5 \mathrm{kN} / \mathrm{m}^{2}$, não majorada pelo coeficiente de impacto, de acordo com a NBR 7188):

$q=4 \cdot 5=20 \mathrm{kN} / \mathrm{m}$

$\checkmark$ Variação uniforme de temperatura:

$\Delta \mathrm{T}= \pm 15^{\circ} \mathrm{C}$

Está sendo desprezada a ação lateral do vento, devido à pequena espessura da passarela e devido à grande inércia da seção transversal na direção de atuação do vento.

\subsubsection{Determinação da flecha inicial e das áreas dos cabos de aço}

A flecha inicial $\left(f_{0}\right)$ a ser adotada tem influência direta na determinação das áreas dos cabos de sustentação e protensão. Flechas pequenas aumentam o conforto dos 
usuários, mas também aumentam o valor da força de protensão necessária e a quantidade de aço consumida. Assim, dentro de limites que atendam às condições de utilização da passarela, serão testados cinco valores de flechas. Baseado nos resultados obtidos, algumas conclusões podem ser tiradas e por fim é adotada a flecha inicial.

Primeiramente, será testado $\mathrm{f}_{0}=0,8 \mathrm{~m}(\mathrm{~L} / 50)$.

Após a colocação de todos os elementos pré-moldados, a carga que age nos cabos de sustentação é seu peso próprio e o peso próprio dos elementos pré-moldados $\left(q_{0}\right)$. 0 peso próprio dos cabos tem pequena magnitude em relação a $q_{0}$ e será desprezado. $A$ posterior aplicação da protensão vai reduzir a força de tração nos cabos de sustentação e comprimir o concreto. Dessa forma, a situação crítica para dimensionamento dos cabos de sustentação é no instante inicial.

A força $\mathrm{H}_{0}$, de valor constante ao longo do vão, é dada por:

$H_{0}=\frac{q_{0} \cdot L^{2}}{8 \cdot f_{0}}=\frac{22 \cdot 40^{2}}{8 \cdot 0,8}=5500 \mathrm{kN}$

A máxima força de tração ( $T_{\text {máx }}$ ) ocorre nos pontos de suspensão, cujo valor é:

$T_{\text {máx }}=H_{0} \cdot \sqrt{1+\left(\frac{q_{0} \cdot L}{2 \cdot H_{0}}\right)^{2}}=5500 \cdot \sqrt{1+\left(\frac{22 \cdot 40}{2 \cdot 5500}\right)^{2}}=5517,57 \mathrm{kN}$

O cálculo da área dos cabos de sustentação $\left(A_{\mathbf{S 1}}\right)$ no estado limite último, fornece:

$A_{s 1}=\frac{\gamma_{f} \cdot T_{\text {máx }}}{\frac{f_{\text {ptk }}}{\gamma_{s}}}=\frac{1,4 \cdot 5517,57}{\frac{190}{1,15}}=46,75 \mathrm{~cm}^{2}$

onde:

$\gamma_{f}$ - coeficiente de majoração das ações;

$\gamma_{S}$ - coeficiente de minoração da resistência do aço.

Em serviço, a fim de diminuir os efeitos da relaxação e fadiga do aço, DEL ARCO \& BENGOECHEA (1996a) recomendam limitar a tensão a 0,4 $\cdot \mathrm{f}_{\mathrm{ptk}}$. Assim:

$A_{s 1}=\frac{T_{\text {máx }}}{0,4 \cdot f_{\text {ptk }}}=\frac{5517,57}{0,4 \cdot 190}=72,60 \mathrm{~cm}^{2}$ 
Quatro cabos formados por 19 cordoalhas $\phi 12,7 \mathrm{~mm}-A_{\mathrm{S} 1}=75,01 \mathrm{~cm}^{2}$ atendem à quantidade de aço necessária para os cabos de sustentação se $f_{0}=0,8 \mathrm{~m}$.

Nessa aplicação numérica, a protensão será introduzida por cabos adicionais aos de sustentação. O mesmo efeito poderia ser conseguido com a utilização de uma sobrecarga antes da concretagem das juntas. Abaixo, as duas formas possíveis de protensão são comparadas:

a) Protensão por cabos adicionais aos de sustentação: à medida que os cabos de protensão vão sendo tracionados, a estrutura formada pelo arco invertido de concreto começa a reagir. Assim, a força de tração a ser resistida pelas fundações é a força de tração nos cabos, menos a força de compressão proveniente do arco de concreto;

b) Protensão através de sobrecarga: o arco de concreto começa a reagir somente após a concretagem das juntas e posterior retirada da sobrecarga. Antes disso, a força horizontal a ser resistida pelas fundações é simplesmente a soma do peso próprio dos elementos pré-moldados, mais a sobrecarga, resultando em esforços maiores a serem ancorados durante a fase de construção.

De acordo com DEL ARCO \& BENGOECHEA (1996a), a força de protensão deve ser determinada de maneira que não ocorram tensões de tração no meio do vão sob nenhuma combinação de ações. A combinação crítica de ações para o aparecimento de tração é a atuação simultânea de peso próprio, protensão, ação de pedestres e variação negativa de temperatura, a tempo infinito. Nos cálculos não serão admitidas tensões de tração apenas na situação em serviço. Serão utilizadas as ações com seus valores integrais.

Utilizando-se a formulação adimensionalizada do capítulo 3 e após algumas tentativas, chega-se à seguinte força de protensão para que não ocorra tração: $P_{0}=20000 \mathrm{kN}$ (após as perdas por escorregamento dos fios na ancoragem e acomodação da ancoragem; desprezado o atrito desenvolvido entre os cabos e as bainhas).

A fim de diminuir a relaxação dos aços de protensão, será utilizada uma tensão de $0,6 \mathrm{f}_{\mathrm{ptk}}$. Assim:

$A_{\mathrm{sp}}=\frac{P_{0}}{0,6 \cdot f_{\text {ptk }}}=\frac{20000}{0,6 \cdot 190}=175,44 \mathrm{~cm}^{2}$ (área dos cabos de protensão)

Assim, para $\mathrm{f}_{0}=0,8 \mathrm{~m}$ adotam-se 8 cabos formados por 22 cordoalhas $\phi 12,7 \mathrm{~mm}$ $A_{s p}=173,71 \mathrm{~cm}^{2}$. 
A tempo infinito, ou seja, considerando as perdas de protensão por fluência do concreto, a análise incluindo todas as ações citadas no item 5.1 .3 , fornece os seguintes resultados:

$\sigma_{\mathrm{N}}=-1593,91 \mathrm{kN} / \mathrm{m}^{2}$ (tensão de compressão no concreto devido apenas à força normal)

$M(L / 2)=-72,85 \mathrm{kN} \cdot \mathrm{m}$ (momento fletor no meio do vão)

$f=0,538 \mathrm{~m}$ (flecha final)

Admitindo-se que o centro de gravidade dos cabos de sustentação e protensão coincidam com o centro de gravidade da seção de concreto, a tensão devido aos esforços de flexão na borda superior é:

$\sigma_{F}=\frac{M}{l} \cdot y=\frac{72,85}{0,0068} \cdot 0,132=1414,15 \mathrm{kN} / \mathrm{m}^{2}$

Assim, a tensão de compressão resultante na borda superior é:

$\sigma_{\mathrm{R}}=-1593,91+1414,15=-179,76 \mathrm{kN} / \mathrm{m}^{2}=0,18 \mathrm{MPa}$

Variando-se o valor da flecha inicial, buscando-se uma força de protensão que conduza ao mesmo grau de compressão na borda superior obtido acima e procedendo-se de maneira similiar, obtém-se a tabela 4.

O gráfico da figura 88 possibilita algumas observações importantes. Primeiramente, a força de protensão necessária não varia linearmente com a variação da flecha inicial para um mesmo vão. No exemplo, uma variação de $40 \mathrm{~cm}$ na flecha inicial provoca uma aumento de mais de $100 \%$ na força de protensão a ser aplicada. Conclui-se que quanto menor a flecha inicial, mais a estrutura se desloca em termos relativos $\left(f_{0} / f\right)$ e portanto mais protensão é "perdida", ou ainda, quanto menor a flecha inicial menos eficiente é o efeito da protensão. Assim, a utilização de flechas muito reduzidas (inferiores a L/50) é inviável. Por outro lado, flechas maiores conduzem a menores forças de protensão e tornam as estruturas mais econômicas.

Vale lembrar que quanto maior a relação flecha/vão, mais aproximada é a teoria desenvolvida no capítulo 3 , uma vez que foram feitas as seguintes considerações:

$\left(z_{0}^{\prime}\right)^{2} \ll<;\left(w^{\prime}\right)^{2}<<1 ; u^{\prime}<<1$ 
Tabela 4 - Influência da relação flecha/vão.

\begin{tabular}{|c|c|c|c|c|}
\hline & $\begin{array}{c}f_{0}=0,90 m \\
(L / 44,4)\end{array}$ & $\begin{array}{c}f_{0}=1,00 m \\
(L / 40)\end{array}$ & $\begin{array}{c}f_{0}=1,10 m \\
(L / 36,4)\end{array}$ & $\begin{array}{c}f_{0}=1,20 \mathrm{~m} \\
(L / 33,3)\end{array}$ \\
\hline$A_{s 1}\left(\mathrm{~cm}^{2}\right)$ & 71,06 & 59,22 & 53,30 & 47,34 \\
\hline$P_{0}(\mathrm{kN})$ & 15500 & 12600 & 10600 & 9200 \\
\hline $\mathrm{A}_{\mathrm{sp}}\left(\mathrm{cm}^{2}\right)$ & 130,28 & 112,52 & 94,75 & 88,83 \\
\hline$\sigma_{\mathrm{N}}\left(\mathrm{kN} / \mathrm{m}^{2}\right)$ & $-1859,12$ & $-2066,42$ & $-2163,85$ & $-2189,12$ \\
\hline $\mathrm{M}_{\mathrm{L} / 2}(\mathrm{kN} \cdot \mathrm{m})$ & $-87,07$ & $-98,30$ & $-102,52$ & $-102,78$ \\
\hline $\mathrm{f}(\mathrm{m})$ & 0,665 & 0,794 & 0,922 & 1,047 \\
\hline$\sigma_{\mathrm{F}}\left(\mathrm{kN} / \mathrm{m}^{2}\right)$ & 1690,18 & 1908,18 & 1990,09 & 1995,14 \\
\hline$\sigma_{\mathrm{R}}(\mathrm{MPa})$ & 0,17 & 0,16 & 0,17 & 0,19 \\
\hline
\end{tabular}

A curva força de protensão necessária $\left(P_{0}\right)$ em função da flecha inicial $\left(f_{0}\right)$ é mostrada na figura 88 .

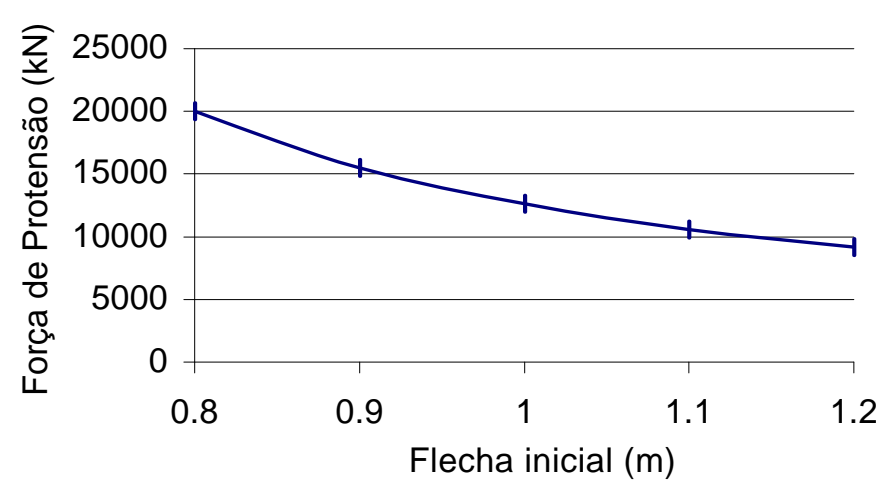

Figura 88 - Flecha inicial x Força de protensão.

Levando-se em conta todos os fatores envolvidos, adota-se para o exemplo uma flecha inicial de 1,0 m. A força de protensão adotada é $13000 \mathrm{kN}$. Dessa forma:

$$
\begin{aligned}
& \mathrm{H}_{0}=\frac{\mathrm{q}_{0} \cdot \mathrm{L}^{2}}{8 \cdot \mathrm{f}_{0}}=\frac{22 \cdot 40^{2}}{8 \cdot 1,0}=4400 \mathrm{kN} \\
& \mathrm{T}_{\text {máx }}=\mathrm{H}_{0} \cdot \sqrt{1+\left(\frac{\mathrm{q}_{0} \cdot \mathrm{L}}{2 \cdot \mathrm{H}_{0}}\right)^{2}}=4400 \cdot \sqrt{1+\left(\frac{22 \cdot 40}{2 \cdot 4400}\right)^{2}}=4421,95 \mathrm{kN}
\end{aligned}
$$


$A_{s 1}=\frac{T_{\text {máx }}}{0,4 \cdot f_{p t k}}=\frac{4421,95}{0,4 \cdot 190}=58,18 \mathrm{~cm}^{2}$

Adotam-se para os cabos de sustentação 6 cabos formados por 10 cordoalhas $\phi 12,7 \mathrm{~mm}-A_{\mathrm{s} 1}=59,22 \mathrm{~cm}^{2}$.

$A_{s p}=\frac{P_{0}}{0,6 \cdot f_{p t k}}=\frac{13000}{0,6 \cdot 190}=114,04 \mathrm{~cm}^{2}$

Adotam-se para os cabos de protensão 6 cabos formados por 19 cordoalhas $\phi 12,7 \mathrm{~mm}-A_{S p}=112,52 \mathrm{~cm}^{2}$.

\subsubsection{Resumo dos dados para a análise}

Tabela 5 - Resumo dos dados para a análise da passarela

\begin{tabular}{|l|l|l|l|l|l|}
\hline $\mathrm{L}=$ & $40 \mathrm{~m}$ & $\mathrm{E}_{\mathrm{C}}=$ & $33130 \mathrm{MPa}$ & $\mathrm{q}_{0}=$ & $22 \mathrm{kN} / \mathrm{m}$ \\
\hline $\mathrm{f}_{0}=$ & $1 \mathrm{~m}$ & $\mathrm{E}_{\mathrm{s}}=$ & $195000 \mathrm{MPa}$ & $\mathrm{q}_{\mathrm{g}}=$ & $5 \mathrm{kN} / \mathrm{m}$ \\
\hline $\mathrm{A}_{\mathrm{C}}=$ & $0,88 \mathrm{~m}^{2}$ & $\mathrm{~A}_{\mathrm{s} 1}=$ & $59,22 \mathrm{~cm}^{2}$ & $\mathrm{q}=$ & $20 \mathrm{kN} / \mathrm{m}$ \\
\hline $\mathrm{l}=$ & $0,0068 \mathrm{~m}^{4}$ & Asp $=$ & $112,52 \mathrm{~cm}^{2}$ & $\Delta \mathrm{T}=$ & $\pm 15^{\circ} \mathrm{C}$ \\
\hline $\mathrm{f}_{\mathrm{Ck}}=$ & $35 \mathrm{MPa}$ & $\alpha=$ & $10^{-5}{ }^{\circ} \mathrm{C}^{-1}$ & $\mathrm{P}_{0}=$ & $13000 \mathrm{kN}$ \\
\hline
\end{tabular}

Três observações devem ser feitas:

a) Considerando-se que só irão aparecer tensões de tração na região dos apoios e portanto em grande parte do vão não ocorrerá fissuração, nos cálculos será utilizado o valor integral do momento de inércia;

b) Partindo-se do princípio de que o nível de tensão no concreto não será muito elevado em grande parte do vão, nos cálculos será utilizado o módulo de elasticidade inicial do concreto. Além disso, são grandes as incertezas quanto ao valor real do módulo de elasticidade. Em se tratando de um projeto completo a ser executado, tal questão mereceria maior cuidado. Por fim, a adoção do módulo de elasticidade secante não traria grandes diferenças no que diz respeito a esforços e deslocamentos;

c) Admite-se que o centro de gravidade dos cabos de sustentação e protensão coincidem com o centro de gravidade da seção de concreto (transporte nulo). Assim, o momento de inércia da estrutura (cabos aderidos + concreto) é o valor do momento de inércia da 
seção transversal de concreto.

\subsection{RESULTADOS DA ANÁLISE ESTRUTURAL}

\subsubsection{Estado limite de utilização, tempo zero}

Em uma combinação de ações no estado limite de utilização, as cargas permanentes e a protensão não seriam afetadas por coeficientes de ponderação. Apenas a ação de pedestres e a variação de temperatura teriam seus valores alterados. Nesse exemplo, preferiu-se utilizar as ações com seus valores integrais no estado limite de utilização, embora seja possível o uso de coeficientes. Vale lembrar que a ação $q_{0}$ apenas estabiliza a estrutura e não causa momentos fletores.

Os resultados obtidos são mostrados na tabela 6 e nas figuras 89 e 90, onde:

$\mathrm{h}$ - incremento de força horizontal;

$h_{c}$ - parcela do incremento de força horizontal que atua apenas na seção de concreto;

$\mathrm{M}$ - momentos fletores;

$w-$ deslocamentos.

Tabela 6 - Estado limite de utilização, tempo zero.

\begin{tabular}{|c|c|c|c|c|c|c|}
\hline \multicolumn{7}{|c|}{ TEMPO $t_{0}$} \\
\hline Caso & Ações & $h$ & $h_{c}$ & $M(0)$ & $M(L / 2)$ & $w(L / 2)$ \\
\hline & & $(k N)$ & $(k N)$ & $(k N . m)$ & $(k N . m)$ & $(m)$ \\
\hline 1 & $q_{0}+P_{0}$ & $-11123,52$ & $-10699,71$ & 790,29 & $-256,85$ & $-0,132$ \\
\hline 2 & $q_{0}+P_{0}+q_{g}$ & $-10158,48$ & $-9771,44$ & 742,26 & $-229,47$ & $-0,120$ \\
\hline 3 & $q_{0}+P_{0}+q_{g}+\Delta T$ & $-10908,82$ & $-10493,19$ & 454,93 & $-146,18$ & $-0,075$ \\
\hline 4 & $q_{0}+P_{0}+q_{g}-\Delta T$ & $-9335,61$ & $-8979,92$ & 1037,54 & $-308,10$ & $-0,164$ \\
\hline 5 & $q_{0}+P_{0}+q_{g}+q$ & $-6514,83$ & $-6266,61$ & 522,17 & $-137,03$ & $-0,076$ \\
\hline 6 & $q_{0}+P_{0}+q_{g}+q+\Delta T$ & $-7384,35$ & $-7103,01$ & 222,87 & $-60,63$ & $-0,033$ \\
\hline 7 & $q_{0}+P_{0}+q_{g}+q-\Delta T$ & $-5572,84$ & $-5360,51$ & 828,37 & $-209,49$ & $-0,117$ \\
\hline
\end{tabular}

\subsubsection{Estado limite de utilização, tempo infinito}

Nesse momento, é preciso definir os coeficientes para a análise das perdas de protensão por fluência do concreto. 


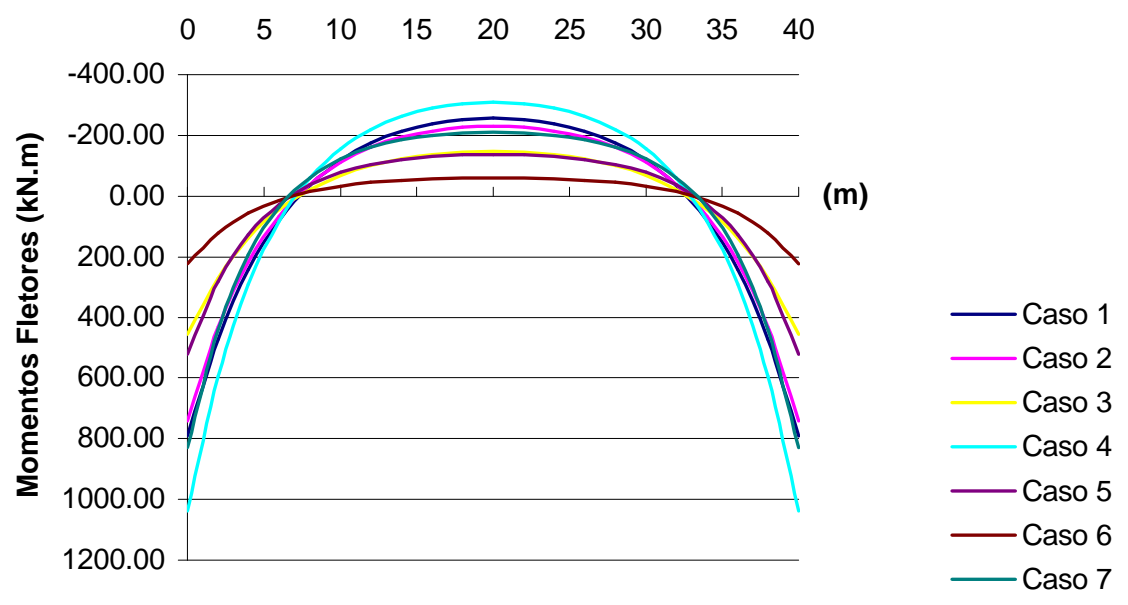

Figura 89 - Diagrama de momentos fletores.

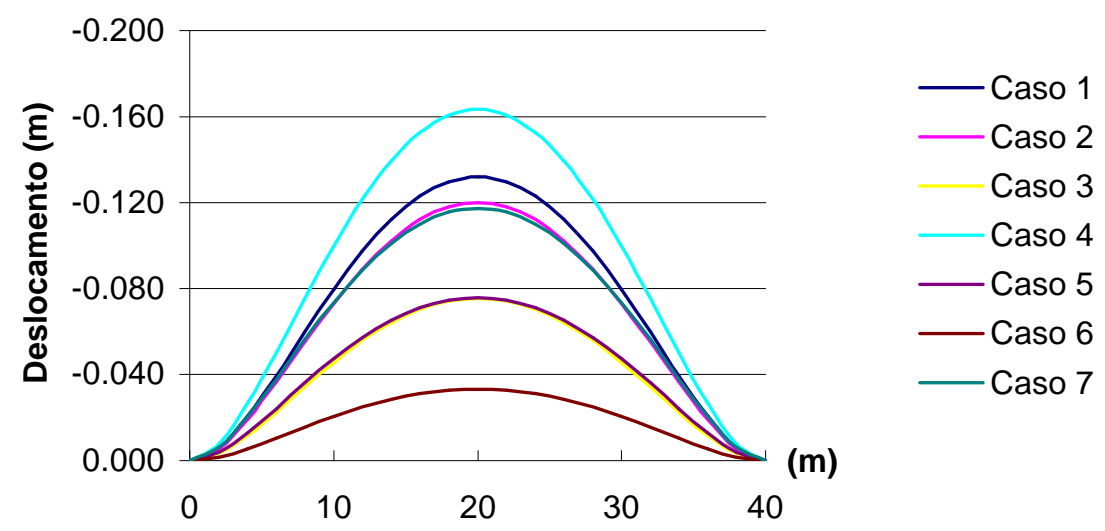

Figura 90 - Deslocamentos ao longo do vão.

a) Coeficiente de fluência $(\phi)$

Definem-se os seguintes parâmetros:

$A_{C}=0,88 m^{2}$ (área da seção transversal de concreto)

$\mathrm{u}=9,00 \mathrm{~m}$ (perímetro da seção transversal em contato com a atmosfera)

UR $=75 \%$ (umidade ambiente adotada)

Espessura eq. $=\frac{2 \cdot A_{C}}{u}=\frac{2 \cdot 0,88}{9,00}=19,56 m$ (espessura equivalente)

$t_{0}=60$ dias (instante de aplicação da carga)

Devido ao fato da seção transversal ainda estar em fase de pré-dimensionamento não é necessária grande precisão no cálculo da fluência. Assim, de acordo com os dados 
acima, o Projeto de Revisão da NBR 6118 indica $\phi=1,7$.

b) Coeficiente de envelhecimento ou coeficiente característico $(\chi)$

O projeto de revisão da NBR 6118 permite considerar o coeficiente de envelhecimento igual a 0,8 nos casos usuais onde a concretagem não se dá de uma só vez e a protensão não é aplicada de uma só vez.

A tempo infinito, serão repetidas as mesmas combinações de ações consideradas no item anterior, a menos do caso 1, que é uma situação transitória (pois logo após a protensão, assim que possível, é concretado o pavimento e executado o corrimão).

O resultado da análise para o caso 2 é mostrado na tabela 7.

Tabela 7 - Perdas de protensão para o caso 2.

\begin{tabular}{|l|l|l|l|}
\hline \multicolumn{5}{|c|}{ Caso 2 $\left(\mathrm{t}_{\infty}\right)$} \\
\hline$\Delta \mathrm{h}=$ & $1119,25 \mathrm{kN}$ & $\mathrm{h}_{\mathrm{f}}=$ & $-9039,23 \mathrm{kN}$ \\
\hline$\Delta \mathrm{h}_{\mathrm{c}}=$ & $2382,57 \mathrm{kN}$ & $\mathrm{h}_{\mathrm{cf}}=$ & $-7388,87 \mathrm{kN}$ \\
\hline$\Delta \mathrm{M}(0)=$ & $40,74 \mathrm{kN} \cdot \mathrm{m}$ & $\mathrm{M}_{\mathrm{f}}(0)=$ & $783,00 \mathrm{kN} \cdot \mathrm{m}$ \\
\hline$\Delta \mathrm{M}(\mathrm{L} / 2)=$ & $137,67 \mathrm{kN} \cdot \mathrm{m}$ & $\mathrm{M}_{\mathrm{f}}(\mathrm{L} / 2)=$ & $-91,80 \mathrm{kN} \cdot \mathrm{m}$ \\
\hline$\Delta \mathrm{w}(\mathrm{L} / 2)=$ & $-0,133 \mathrm{~m}$ & $\mathrm{w}_{\mathrm{f}}(\mathrm{L} / 2)=$ & $-0,253 \mathrm{~m}$ \\
\hline
\end{tabular}

Conforme já adiantado no final do item 3.1.7, para avaliar o comportamento da estrutura após as perdas de protensão sob os demais carregamentos, é preciso fazer uma atualização de geometria, conforme sugerido por DEL ARCO \& BENGOECHEA (1996a). Nesse procedimento, o caso 2 torna-se referência para a continuação dos cálculos. Primeiramente, devem ser definidos novos valores de $q_{0}, H_{0}, P_{0}$, da seguinte forma:

$$
\begin{aligned}
& \mathrm{q}_{0}=\mathrm{q}_{0_{\text {ant }}}+\mathrm{q}_{\mathrm{g}} \\
& \mathrm{H}_{0}=\mathrm{H}_{0_{\text {ant }}}+\mathrm{P}_{0 \text { ant }}+\mathrm{h}_{\text {caso2 }}+\Delta \mathrm{h}_{\text {caso2 }}=\mathrm{H}_{0}+\mathrm{P}_{0}+\mathrm{h}_{f_{\text {caso2 }}} \\
& \mathrm{P}_{0}=0
\end{aligned}
$$

Assim:

$$
\begin{aligned}
& \mathrm{q}_{0}=22+5=27 \mathrm{kN} / \mathrm{m} \\
& \mathrm{H}_{0}=4400+13000-10158,48+1119,25=4400+13000-9039,23=8360,77 \mathrm{kN} \\
& \mathrm{P}_{0}=0
\end{aligned}
$$


Agora, basta refazer os cálculos com as constantes acima, inserindo-se 0 carregamento desejado. Os resultados assim obtidos (tabela 8) devem ser somados com os valores do caso 2 (tabela 7) para se obter os resultados finais, mostrados na tabela 9.

É preciso ressaltar que esse procedimento é aproximado. Devido à existência de momentos fletores, as equações $\mathrm{z}_{0}=\frac{\mathrm{q}_{0}}{2 \cdot \mathrm{H}_{0}} \cdot \mathrm{x} \cdot(\mathrm{L}-\mathrm{x})$ e $\mathrm{f}_{0}=\frac{\mathrm{q}_{0} \cdot \mathrm{L}^{2}}{8 \cdot \mathrm{H}_{0}}$ não são rigorosamente corretas.

De maneira resumida, pode-se dizer que a estrutura do caso 2 é transformada em um cabo. Em seguida, adiciona-se a rigidez à flexão do tabuleiro nas equações de equilíbrio (sem protensão) e analisa-se a estrutura sob outros carregamentos.

Tabela 8 - Resultado do acréscimo de carregamento.

\begin{tabular}{|c|c|c|c|c|c|}
\hline \multicolumn{6}{|c|}{${\text { TEMPO } \mathrm{t}_{\infty}}^{\mathrm{g}}$} \\
\hline $\mathrm{Ações}$ & $\mathrm{h}$ & $\mathrm{h}_{\mathrm{c}}$ & $\mathrm{M}(0)$ & $\mathrm{M}(\mathrm{L} / 2)$ & $\mathrm{w}(\mathrm{L} / 2)$ \\
\hline & $(\mathrm{kN})$ & $(\mathrm{kN})$ & $(\mathrm{kN} . \mathrm{m})$ & $(\mathrm{kN} . \mathrm{m})$ & $(\mathrm{m})$ \\
\hline $\mathrm{q}_{0}+\Delta \mathrm{T}$ & $-1386,65$ & $-1243,78$ & $-365,26$ & 114,46 & 0,060 \\
\hline $\mathrm{q}_{0}-\Delta \mathrm{T}$ & 1587,96 & 1424,34 & 372,15 & $-101,52$ & $-0,055$ \\
\hline $\mathrm{q}_{0}+\mathrm{q}$ & 3993,10 & 3581,67 & $-477,34$ & 118,34 & 0,067 \\
\hline $\mathrm{q}_{0}+\mathrm{q}+\Delta \mathrm{T}$ & 2464,90 & 2210,93 & $-848,27$ & 223,15 & 0,123 \\
\hline $\mathrm{q}_{0}+\mathrm{q}-\Delta \mathrm{T}$ & 5699,75 & 5112,48 & $-102,04$ & 23,81 & 0,014 \\
\hline
\end{tabular}

Tabela 9 - Resultados finais.

\begin{tabular}{|c|c|c|c|c|c|}
\hline \multicolumn{7}{|c|}{ TEMPO $_{\infty}$} \\
\hline Caso & $\mathrm{h}_{\mathrm{f}}$ & $\mathrm{h}_{\mathrm{cf}}$ & $\mathrm{M}_{\mathrm{f}}(0)$ & $\mathrm{M}_{\mathrm{f}}(\mathrm{L} / 2)$ & $\mathrm{w}_{\mathrm{f}}(\mathrm{L} / 2)$ \\
\hline & $(\mathrm{kN})$ & $(\mathrm{kN})$ & $(\mathrm{kN} \cdot \mathrm{m})$ & $(\mathrm{kN} \cdot \mathrm{m})$ & $(\mathrm{m})$ \\
\hline 3 & $-10425,88$ & $-8632,65$ & 417,74 & 22,66 & $-0,193$ \\
\hline 4 & $-7451,27$ & $-5964,53$ & 1155,15 & $-193,32$ & $-0,308$ \\
\hline 5 & $-5046,13$ & $-3807,20$ & 305,66 & 26,54 & $-0,186$ \\
\hline 6 & $-6574,33$ & $-5177,94$ & $-65,27$ & 131,35 & $-0,130$ \\
\hline 7 & $-3339,48$ & $-2276,39$ & 680,96 & $-67,99$ & $-0,239$ \\
\hline
\end{tabular}

\subsubsection{Estado limite último, tempo zero}

De acordo com a NBR 8681, as combinações últimas normais de ações são obtidas a partir de: 
$F_{d}=\sum_{i=1}^{m} \gamma_{g i} \cdot F_{G i, k}+\gamma_{q} \cdot\left[F_{Q 1, k}+\sum_{j=2}^{n} \psi_{0 j} \cdot F_{Q j, k}\right]$

onde:

$\mathrm{F}_{\mathrm{Gi}, \mathrm{K}}$ - valor característico das ações permanentes;

$\mathrm{F}_{\mathrm{Q} 1, \mathrm{k}}$ - valor característico da ação variável considerada como ação principal;

$\psi_{0 \mathrm{j}} \cdot \mathrm{F}_{\mathrm{Qj}, \mathrm{k}}$ - valor reduzido de combinação de cada uma das demais ações variáveis.

Analisando-se as ações, determinaram-se oito combinações possivelmente críticas:
1) $q_{0}+1,2 \cdot P_{0}$
2) $q_{0}+0,9 \cdot P_{0}+1,4 \cdot q_{g}+1,4 \cdot q$
3) $q_{0}+1,2 \cdot P_{0}+0,9 \cdot q_{g}+1,2 \cdot(-\Delta T)$
4) $q_{0}+0,9 \cdot P_{0}+1,4 \cdot q_{g}+1,4 \cdot q+1,2 \cdot 0,6 \cdot(-\Delta T)$
5) $q_{0}+0,9 \cdot P_{0}+1,4 \cdot q_{g}+1,2 \cdot(-\Delta T)+1,4 \cdot 0,4 \cdot q$
6) $q_{0}+1,2 \cdot P_{0}+0,9 \cdot q_{g}+1,2 \cdot(+\Delta T)$
7) $q_{0}+0,9 \cdot P_{0}+1,4 \cdot q_{g}+1,4 \cdot q+1,2 \cdot 0,6 \cdot(+\Delta T)$
8) $q_{0}+0,9 \cdot P_{0}+1,4 \cdot q_{g}+1,2 \cdot(+\Delta T)+1,4 \cdot 0,4 \cdot q$

Os esforços e deslocamentos para as combinações podem ser vistos na tabela $10 \mathrm{e}$ nas figuras 91 e 92.

Tabela 10 - Estado limite último, tempo zero.

\begin{tabular}{|c|c|c|c|c|c|}
\hline \multicolumn{7}{|c|}{${\text { TEMPO } \mathrm{t}_{0}}^{\mathrm{T}}$} \\
\hline Comb. & $\mathrm{h}$ & $\mathrm{h}_{\mathrm{c}}$ & $\mathrm{M}(0)$ & $\mathrm{M}(\mathrm{L} / 2)$ & $\mathrm{w}(\mathrm{L} / 2)$ \\
\hline & $(\mathrm{kN})$ & $(\mathrm{kN})$ & $(\mathrm{kN} . \mathrm{m})$ & $(\mathrm{kN} . \mathrm{m})$ & $(\mathrm{m})$ \\
\hline 1 & $-13282,76$ & $-12776,68$ & 956,07 & $-303,59$ & $-0,157$ \\
\hline 2 & $-3771,60$ & $-3627,90$ & 312,11 & $-77,45$ & $-0,044$ \\
\hline 3 & $-11347,72$ & $-10915,37$ & 1275,49 & $-368,49$ & $-0,197$ \\
\hline 4 & $-3080,88$ & $-2963,49$ & 533,53 & $-129,09$ & $-0,073$ \\
\hline 5 & $-5594,12$ & $-5380,98$ & 877,90 & $-233,98$ & $-0,129$ \\
\hline 6 & $-13331,06$ & $-12823,14$ & 566,06 & $-180,20$ & $-0,093$ \\
\hline 7 & $-4425,81$ & $-4257,18$ & 94,02 & $-23,92$ & $-0,013$ \\
\hline 8 & $-7631,12$ & $-7340,37$ & 164,35 & $-47,88$ & $-0,026$ \\
\hline
\end{tabular}




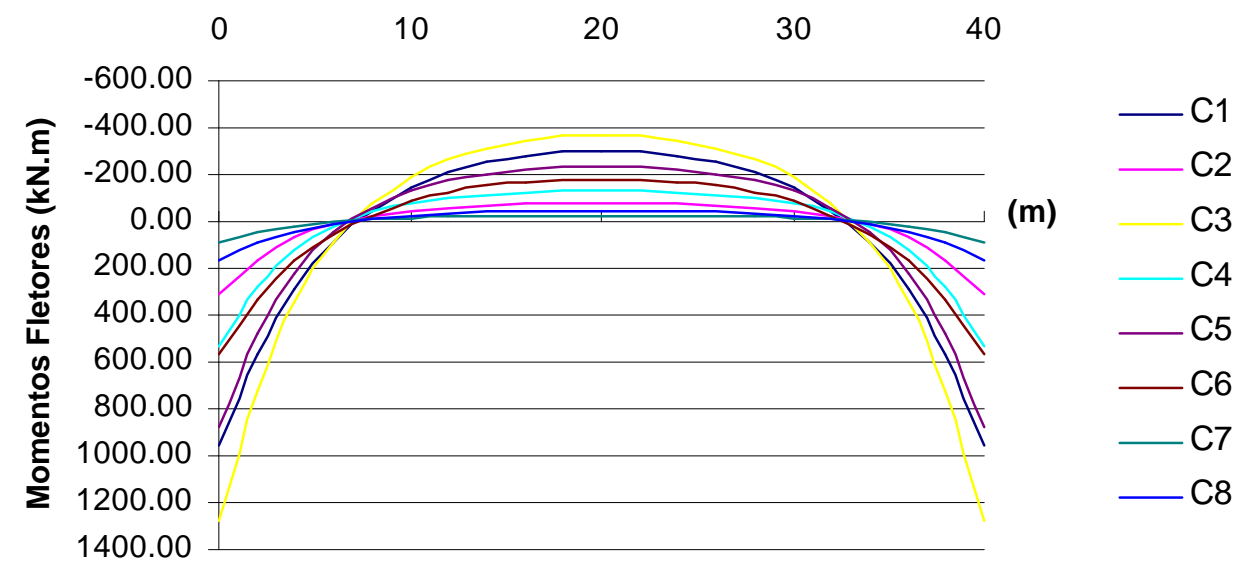

Figura 91 - Diagrama de momentos fletores.

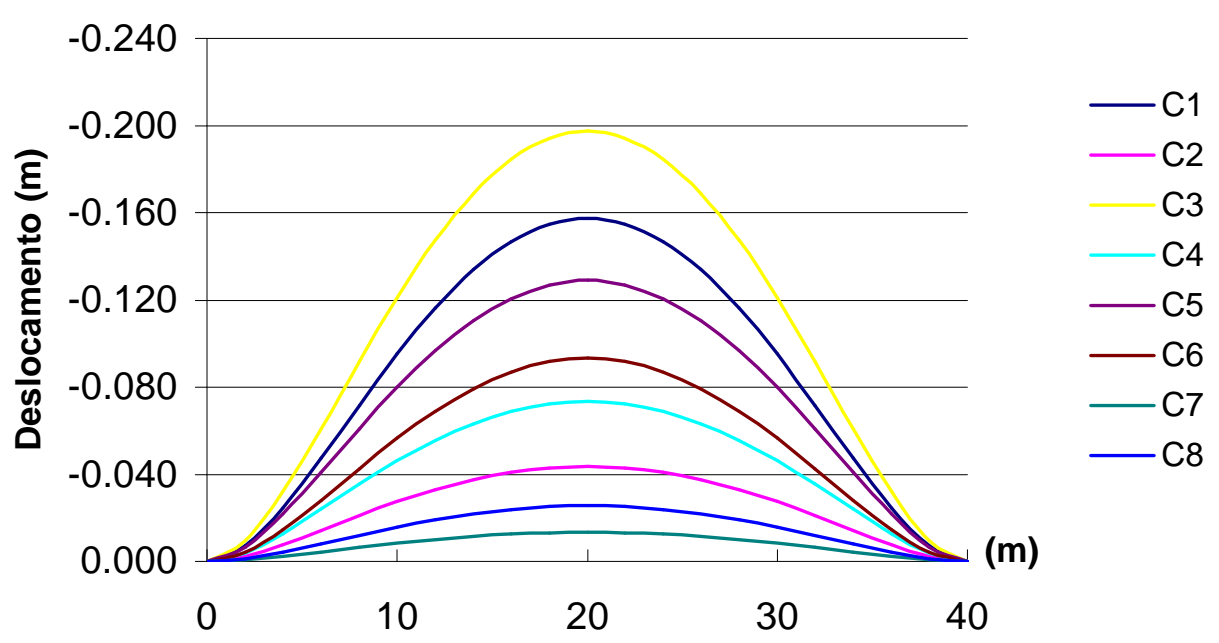

Figura 92 - Deslocamentos ao longo do vão.

\subsubsection{Estado limite último, tempo infinito}

Inicialmente, é necessário acompanhar o comportamento da estrutura sob duas situações de carregamento (tabelas 11 e 12). A partir dessas duas situações, é possível adicionar mais ações e obter as combinações de ações previstas no item 5.2.3. A combinação 1 é transitória e não tem interesse a tempo infinito.

Para a adição de outros carregamentos, deve-se fazer a atualização de geometria.

As combinações 2, 4, 5, 7 e 8, seguem a tabela 11, e a atualização de geometria é dada por:

$\mathrm{q}_{0}=\mathrm{q}_{0_{\text {ant }}}+1,4 \cdot \mathrm{q}_{\mathrm{g}}=22+7=29 \mathrm{kN} / \mathrm{m}$

$\mathrm{H}_{0}=\mathrm{H}_{0 \text { ant }}+0,9 \cdot \mathrm{P}_{0 \text { ant }}+\mathrm{h}_{\mathrm{f}}=4400+11700-7764,03=8335,97 \mathrm{kN}$ 
$P_{0}=0$

Tabela 11 - Comportamento da estrutura submetida a $q_{0}+0,9 \cdot P_{0}+1,4 \cdot q_{g}$.

\begin{tabular}{|l|l|l|l|l|l|}
\hline \multicolumn{7}{|c|}{ Combinação: $\mathrm{q}_{0}+0,9 \cdot \mathrm{P}_{0}+1,4 \cdot \mathrm{q}_{\mathrm{g}}$} \\
\hline $\mathrm{h}=$ & $-8704,65 \mathrm{kN}$ & $\Delta \mathrm{h}=$ & $940,62 \mathrm{kN}$ & $\mathrm{h}_{\mathrm{f}}=$ & $-7764,03 \mathrm{kN}$ \\
\hline $\mathrm{h}_{\mathrm{c}}=$ & $-8373,00 \mathrm{kN}$ & $\Delta \mathrm{h}_{\mathrm{c}}=$ & $2027,00 \mathrm{kN}$ & $\mathrm{h}_{\mathrm{cf}}=$ & $-6346,00 \mathrm{kN}$ \\
\hline $\mathrm{M}(0)=$ & $638,78 \mathrm{kN} \cdot \mathrm{m}$ & $\Delta \mathrm{M}(0)=$ & $32,48 \mathrm{kN} \cdot \mathrm{m}$ & $\mathrm{M}_{\mathrm{f}}(0)=$ & $671,27 \mathrm{kN} \cdot \mathrm{m}$ \\
\hline $\mathrm{M}(\mathrm{L} / 2)=$ & $-195,97 \mathrm{kN} \cdot \mathrm{m}$ & $\Delta \mathrm{M}(\mathrm{L} / 2)=$ & $115,47 \mathrm{kN} \cdot \mathrm{m}$ & $\mathrm{M}_{\mathrm{f}}(\mathrm{L} / 2)=$ & $-80,50 \mathrm{kN} \cdot \mathrm{m}$ \\
\hline $\mathrm{w}(\mathrm{L} / 2)=$ & $-0,103 \mathrm{~m}$ & $\Delta \mathrm{w}(\mathrm{L} / 2)=$ & $-0,114 \mathrm{~m}$ & $\mathrm{w}_{\mathrm{f}}(\mathrm{L} / 2)=$ & $-0,217 \mathrm{~m}$ \\
\hline
\end{tabular}

Tabela 12 - Comportamento da estrutura submetida a $q_{0}+1,2 \cdot P_{0}+0,9 \cdot q_{g}$.

\begin{tabular}{|l|l|l|l|l|l|}
\hline \multicolumn{7}{|c|}{ Combinação: $\mathrm{q}_{0}+1,2 \cdot \mathrm{P}_{0}+0,9 \cdot \mathrm{q}_{\mathrm{g}}$} \\
\hline $\mathrm{h}=$ & $-12394,63 \mathrm{kN}$ & $\Delta \mathrm{h}=$ & $1502,30 \mathrm{kN}$ & $\mathrm{h}_{\mathrm{f}}=$ & $-10892,33 \mathrm{kN}$ \\
\hline $\mathrm{h}_{\mathrm{c}}=$ & $-11922,39 \mathrm{kN}$ & $\Delta \mathrm{h}_{\mathrm{c}}=$ & $3014,39 \mathrm{kN}$ & $\mathrm{h}_{\mathrm{cf}}=$ & $-8908,00 \mathrm{kN}$ \\
\hline $\mathrm{M}(0)=$ & $914,89 \mathrm{kN} \cdot \mathrm{m}$ & $\Delta \mathrm{M}(0)=$ & $56,68 \mathrm{kN} \cdot \mathrm{m}$ & $\mathrm{M}_{\mathrm{f}}(0)=$ & $971,57 \mathrm{kN} \cdot \mathrm{m}$ \\
\hline $\mathrm{M}(\mathrm{L} / 2)=$ & $-277,77 \mathrm{kN} \cdot \mathrm{m}$ & $\Delta \mathrm{M}(\mathrm{L} / 2)=$ & $167,68 \mathrm{kN} \cdot \mathrm{m}$ & $\mathrm{M}_{\mathrm{f}}(\mathrm{L} / 2)=$ & $-110,10 \mathrm{kN} \cdot \mathrm{m}$ \\
\hline $\mathrm{w}(\mathrm{L} / 2)=$ & $-0,146 \mathrm{~m}$ & $\Delta \mathrm{w}(\mathrm{L} / 2)=$ & $-0,157 \mathrm{~m}$ & $\mathrm{w}_{\mathrm{f}}(\mathrm{L} / 2)=$ & $-0,303 \mathrm{~m}$ \\
\hline
\end{tabular}

Para as combinações 3 e 6, deve-se seguir a tabela 12. A atualização de geometria fornece:

$$
\begin{aligned}
& \mathrm{q}_{0}=\mathrm{q}_{0 \text { ant }}+0,9 \cdot \mathrm{q}_{\mathrm{g}}=22+4,5=26,5 \mathrm{kN} / \mathrm{m} \\
& \mathrm{H}_{0}=\mathrm{H}_{0 \text { ant }}+1,2 \cdot \mathrm{P}_{0 \text { ant }}+\mathrm{h}_{\mathrm{f}}=4400+15600-10892,33=9107,67 \mathrm{kN} \\
& \mathrm{P}_{0}=0
\end{aligned}
$$

O resultado do acréscimo de carregamento está na tabela 13 e o resultado final é mostrado na tabela 14 .

\subsection{ANÁLISE DOS ESFORÇOS SOLICITANTES}

Neste item serão feitas algumas considerações quanto aos esforços solicitantes obtidos no item anterior e sua influência no arranjo final da estrutura, inclusive no que diz respeito às armaduras necessárias. No entanto, não se pretende fornecer um detalhamento rigoroso de tais armaduras, atendo-se apenas a algumas indicações. 
Tabela 13 - Resultado do acréscimo de carregamento.

\begin{tabular}{|c|c|c|c|c|c|}
\hline \multicolumn{7}{|c|}{${\text { TEMPO } \mathrm{t}_{\infty}}^{\circ}$} \\
\hline Combinação & $\mathrm{H}$ & $\mathrm{h}_{\mathrm{c}}$ & $\mathrm{M}(0)$ & $\mathrm{M}(\mathrm{L} / 2)$ & $\mathrm{w}(\mathrm{L} / 2)$ \\
\hline & $(\mathrm{kN})$ & $(\mathrm{kN})$ & $(\mathrm{kN} . \mathrm{m})$ & $(\mathrm{kN} . \mathrm{m})$ & $(\mathrm{m})$ \\
\hline 2 & 5341,98 & 4791,58 & $-609,26$ & 144,02 & 0,083 \\
\hline 3 & 2295,68 & 2059,15 & 461,97 & $-118,76$ & $-0,066$ \\
\hline 4 & 6469,44 & 5802,87 & $-345,02$ & 78,50 & 0,046 \\
\hline 5 & 4067,92 & 3648,79 & 198,03 & $-49,00$ & $-0,028$ \\
\hline 6 & $-1941,08$ & $-1741,08$ & $-456,78$ & 141,75 & 0,074 \\
\hline 7 & 4292,35 & 3850,10 & $-870,90$ & 213,73 & 0,121 \\
\hline 8 & 661,43 & 593,28 & $-668,37$ & 190,08 & 0,102 \\
\hline
\end{tabular}

Tabela 14 - Resultados finais.

\begin{tabular}{|c|c|c|c|c|c|}
\hline \multicolumn{7}{|c|}{ TEMPO $\mathrm{t}_{\infty}$} \\
\hline Combinação & $\mathrm{h}_{\mathrm{f}}$ & $\mathrm{h}_{\mathrm{cf}}$ & $\mathrm{M}_{\mathrm{f}}(0)$ & $\mathrm{M}_{\mathrm{f}}(\mathrm{L} / 2)$ & $\mathrm{w}_{\mathrm{f}}(\mathrm{L} / 2)$ \\
\hline & $(\mathrm{kN})$ & $(\mathrm{kN})$ & $(\mathrm{kN} . \mathrm{m})$ & $(\mathrm{kN} . \mathrm{m})$ & $(\mathrm{m})$ \\
\hline 2 & $-2422,05$ & $-1554,42$ & 62,01 & 63,52 & $-0,134$ \\
\hline 3 & $-8596,65$ & $-6848,85$ & 1433,54 & $-228,86$ & $-0,369$ \\
\hline 4 & $-1294,59$ & $-543,13$ & 326,25 & $-2,00$ & $-0,171$ \\
\hline 5 & $-3696,11$ & $-2697,21$ & 869,30 & $-129,50$ & $-0,245$ \\
\hline 6 & $-12833,41$ & $-10649,08$ & 514,79 & 31,65 & $-0,229$ \\
\hline 7 & $-3471,68$ & $-2495,90$ & $-199,63$ & 133,23 & $-0,096$ \\
\hline 8 & $-7102,60$ & $-5752,72$ & 2,90 & 109,58 & $-0,115$ \\
\hline
\end{tabular}

\subsubsection{Região dos apoios}

Conforme esperado, é na região dos apoios que aparecem os maiores esforços e portanto tal região merece atenção especial no projeto. Em geral, adota-se um ligeiro engrossamento da seção transversal nessa região. Devido à armação necessária, recorrese a concreto moldado no local, que pode inclusive ser protendido. Dependendo da magnitude dos esforços, é possível ainda a utilização de elementos pré-moldados especiais, providos de furos por onde são colocadas barras de aço e que posteriormente são injetados com concreto. Também pode-se usar elementos pré-moldados de seção parcial, com posterior lançamento de concreto moldado no local.

Neste exemplo, é adotada uma seção retangular de dimensões $400 \mathrm{~cm} \times 30 \mathrm{~cm}$ nos 
trechos distantes 4 metros dos apoios. Esse trecho, portanto, irá possuir maior área e maior inércia que o restante do vão. Vale lembrar que para a obtenção dos esforços foi usada área e inércia constantes. Esse é certamente um dos limitantes da formulação desenvolvida. Uma possível aproximação seria obter novamente os esforços, agora com a área e a inércia da região dos apoios, como se o vão inteiro possuísse essas características. Outra opção, com certeza bem mais confiável, seria utilizar processos que permitam que a estrutura modelada esteja mais próxima da real, como por exemplo o método dos elementos finitos. No entanto, a programação computacional foge aos objetivos dessa dissertação.

A armadura obtida para a região dos apoios, calculando-se como flexão normal composta e desprezando-se a existência dos cabos de sustentação e protensão (que como poderá ser visto no item seguinte, estão próximos do centro de gravidade da seção de concreto), é um total de 40 barras $\phi 20 \mathrm{~mm}$, dispostas 20 na face superior e 20 na face inferior.

\subsubsection{Meio do vão}

Os esforços que ocorrem no restante do vão, extraída a região dos apoios, não são significativos e praticamente não requerem armadura. A fim de previnir a ocorrência de fissuras e também promover uma maior solidarização entre os elementos pré-moldados, adota-se uma armadura contínua a ser disposta na região dos cabos de sustentação pouco antes da concretagem das juntas. Essa armação poderá ser vista no item seguinte, na figura 100.

\subsection{ELEMENTOS PRÉ-MOLDADOS}

A respeito dos elementos pré-moldados, são diversas as formas possíveis. Abaixo, na figura 93, são mostradas três delas:

a)

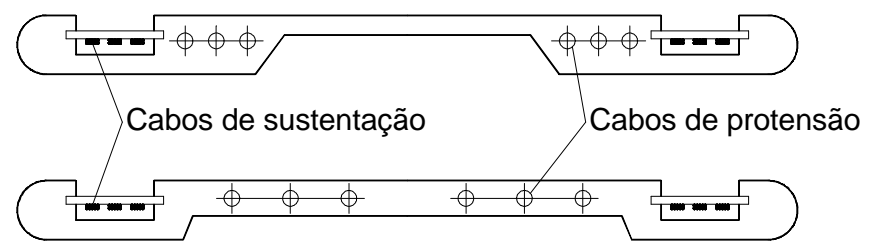

b)

Cabos de sustentação

Cabos de protensão

c)

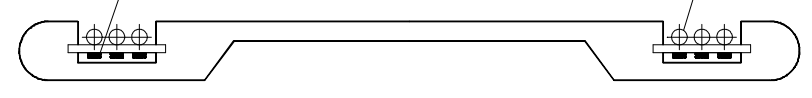

Figura 93 - Formas possíveis para o elemento pré-moldado. 
O elemento do item b da figura 93 é semelhante ao utilizado em STRASKY \& PIRNER (1986). Seu emprego seria mais interessante se fosse utilizado um maior número de cabos. Quanto ao item c, esse elemento requer uma altura total ligeiramente maior, a fim de garantir um cobrimento adequado. Além disso, sua área é menor que a adotada no prédimensionamento. Portanto, para sua utilização seria coerente um novo cálculo dos esforços. Nesse exemplo, adota-se o elemento do item a, cujas dimensões estão na figura 94.

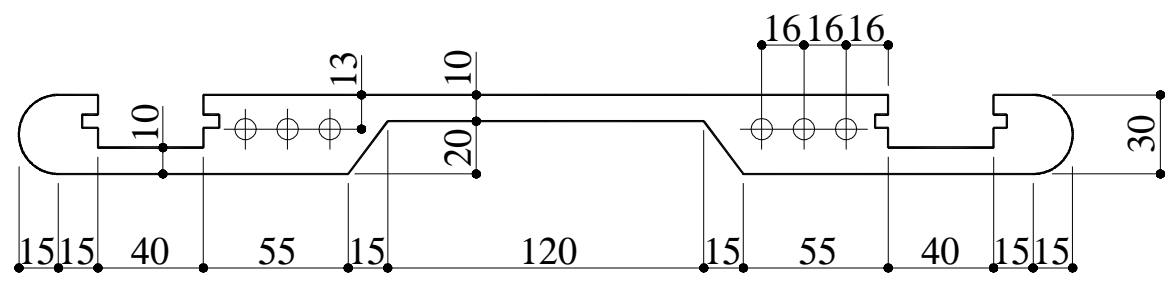

Figura 94 - Dimensões do elemento escolhido.

Excluindo-se a região de transição, adotam-se elementos pré-moldados com 3,20 metros de comprimento, num total de 10. Dessa forma, o peso total do elemento prémoldado é cerca de $58 \mathrm{kN}$.

O içamento do elemento até ser preso nos cabos de sustentação pode se dar através de: braço mecânico (v. figura 35), furo (deixado para inserção dos cabos de protensão) e tarugo de aço (v. figura 36), cintas, ou ainda por meio de laços chumbados no concreto. A utilização de laços tem o inconveniente de ser necessário seu corte após o uso. Nesse exemplo, adota-se o içamento com furo e tarugo de aço, esquematizado na figura 95.

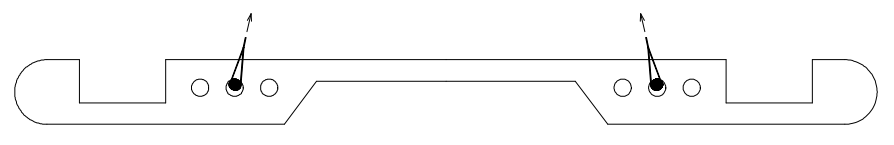

Figura 95 - Esquema para içamento.

A fixação dos elementos aos cabos de sustentação se dá através de dispositivos mostrados nas figuras 22 e 36 . Ao todo, são 4 dispositivos.

Para a verificação da segurança estrutural dos elementos pré-moldados devem ser levadas em consideração as diversas situações transitórias às quais estão sujeitos. São elas:
a) Desmoldagem;
b) Transporte interno;
c) Armazenamento;
d) Transporte externo; 
e) Montagem;

f) Início de funcionamento.

Deve-se destacar que a resistência do concreto a ser utilizada é aquela correspondente a cada operação. Maiores detalhes de como proceder as verificações em situações transitórias podem ser encontrados em EL DEBS (2000).

A seguir, são mostrados arranjos das armaduras e uma ordem de grandeza das bitolas a serem utilizadas na armação dos elementos pré-moldados. Em se tratando de um projeto a ser executado, um cálculo mais preciso e refinado deve ser feito.

Na figura 96 é apresentado um corte transversal e as respectivas armações (aço CA $50)$.

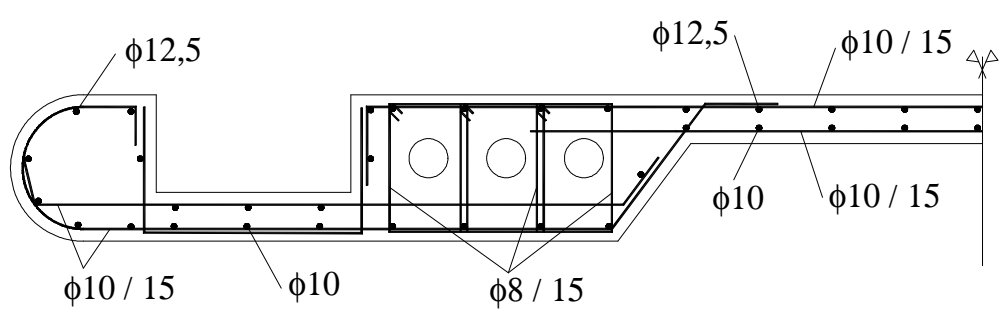

Figura 96 - Corte transversal.

A figura 97 mostra um corte longitudinal.

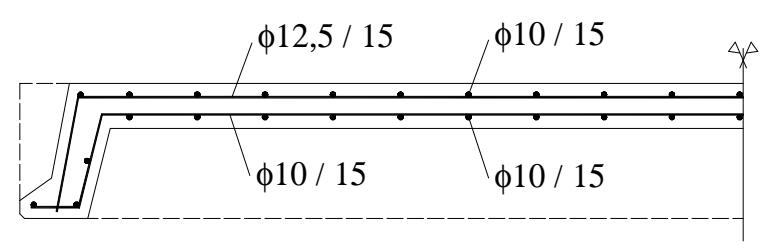

Figura 97 - Corte longitudianal.

Na região onde estão os tarugos que irão sustentar os elementos pré-moldados aos cabos de sustentação, é recomendável a utilização de um laço mergulhado no concreto e devidamente ancorado, conforme figura 98. Preferencialmente, usar aço CA 25 no laço.

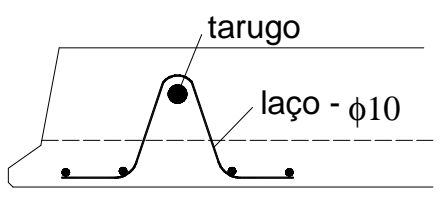

Figura 98 - Laço na região do tarugo. 
A fim de promover um maior enrijecimento e um certo monolitismo entre os elementos, são executadas nervuras nas juntas entre os elementos (v. figura 99) e é disposta uma armadura contínua passando por todos os elementos na região dos cabos de sustentação (v. figura 100). Ambas essas armações são dispostas após a colocação dos elementos sobre os cabos e antes da concretagem das juntas e da região dos cabos de sustentação.

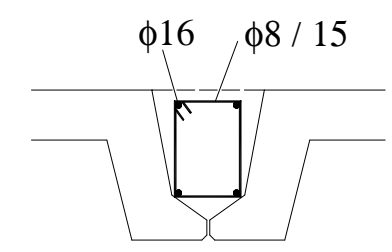

Figura 99 - Armadura nas juntas dos elementos.

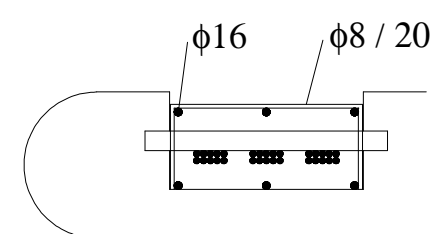

Figura 100 - Armadura contínua.

\subsection{OBTENÇÃO DAS FREQUÊNCIAS DE VIBRAÇÕES VERTICAIS}

Conforme visto no capítulo 4, as frequências verticais de modo anti-simétrico são dadas por:

$\overline{\mathrm{w}} \approx 2 \cdot \mathrm{n} \cdot \pi \cdot \frac{\gamma}{\gamma-2} \cdot \sqrt{1+\overline{\mathrm{h}}+\overline{\mathrm{P}}_{0}} \cdot \sqrt{1+\frac{4 \cdot \mathrm{n}^{2} \cdot \pi^{2}}{(\gamma-2)^{2}}}$

onde,

$\overline{\mathrm{h}}=\frac{\mathrm{h}}{\mathrm{H}_{0}}$

$\overline{P_{0}}=\frac{P_{0}}{H_{0}}$

$\gamma^{2}=\frac{1+\overline{\mathrm{h}}+\overline{\mathrm{P}}_{0}}{\alpha^{2}}$

$\alpha^{2}=\frac{E_{C} \cdot I_{C}}{H_{0} \cdot L^{2}}$ 
Utilizando-se as ações do caso 2, item 4.2.1, ou seja, $q_{0}+P_{0}+q_{g}$ a tempo zero, obtém-se:

$$
\begin{aligned}
& \alpha^{2}=\frac{33130000 \cdot 0,0068}{4400 \cdot 40^{2}}=0,032 \\
& \bar{h}=\frac{-10158,48}{4400}=-2,31 \\
& \bar{P}_{0}=\frac{13000}{4400}=2,96 \\
& \gamma^{2}=\frac{1-2,309+2,955}{0,0320}=51,44 \Rightarrow \gamma=7,17
\end{aligned}
$$

Dessa forma, a primeira frequência de vibração é:

$\overline{\mathrm{w}} \approx 2 \cdot \pi \cdot \frac{7,17}{7,17-2} \cdot \sqrt{1-2,31+2,96} \cdot \sqrt{1+\frac{4 \cdot \pi^{2}}{(7,17-2)^{2}}}=17,59$

Transformando em forma dimensional:

$\mathrm{w}=\frac{\overline{\mathrm{w}}}{\mathrm{L}} \cdot \sqrt{\frac{\mathrm{H}_{0}}{\mathrm{~m}}}=\frac{17,59}{40} \cdot \sqrt{\frac{4400}{27}}=5,61 \mathrm{rad} / \mathrm{s}=0,89 \mathrm{~Hz}$

Repetindo-se o mesmo procedimento indicado acima, a tempo infinito obtém-se $w=0,88 \mathrm{~Hz}$.

O valores obtidos estão distantes da frequência de passo mais frequente $(2 \mathrm{~Hz})$. DEL ARCO \& BENGOECHEA (1996a) afirmam que, a princípio, não parece que irá haver problemas de vibração associados aos pedestres.

Logicamente, em uma situação prática a questão dinâmica deve ser investigada detalhadamente, o que não está sendo feito aqui.

\subsection{FORÇA HORIZONTAL A SER ANCORADA NAS FUNDAÇÕES}

A força horizontal que deve ser resistida pelas fundações é a soma das forças nos cabos de sustentação, nos cabos de protensão e a reação da estrutura, ou seja:

$$
\mathrm{F}_{\mathrm{anc}}=\mathrm{H}_{0}+\mathrm{P}_{0}+\mathrm{h}
$$


Utilizando-se dos resultados obtidos nos itens 4.2.1 e 4.2.2, a tabela 15 mostra a força a ser ancorada, tanto no tempo $t_{0}$ quanto no tempo $t_{\infty}$, para diversas situações de carregamentos. Salienta-se que as ações são utilizadas com seus valores integrais.

Tabela 15 - Força a ser ancorada.

\begin{tabular}{|c|c|c|}
\hline \multicolumn{2}{|c|}{$\mathrm{F}_{\text {anc }}(\mathrm{kN})$} \\
\hline Caso & TEMPO $\mathrm{t}_{0}$ & ${\text { TEMPO } \mathrm{t}_{\infty}}^{\mathrm{N}}$ \\
\hline 1 & 6276,48 & --- \\
\hline 2 & 7241,52 & 8360,77 \\
\hline 3 & 6491,18 & 6974,12 \\
\hline 4 & 8064,39 & 9948,73 \\
\hline 5 & 10885,17 & 12353,87 \\
\hline 6 & 10015,65 & 10825,67 \\
\hline 7 & 11827,16 & 14060,52 \\
\hline
\end{tabular}

As fundações devem ser dimensionadas para o máximo valor, ou seja, uma força horizontal de 14060,52 kN (1406 tf). Conforme esperado, a máxima tração ocorre a tempo infinito. 
São diversos os aspectos a serem levados em consideração na escolha do sistema estrutural a ser empregado em pontes e passarelas. Certamente, a viabilidade técnica e econômica são questões primordiais. No entanto, devido ao grande fascínio que tais estruturas exercem sobre a população, a estética ganha especial interesse. É notável a preocupação, principalmente no exterior, com as características arquitetônicas dessas estruturas. Nesse contexto, as passarelas pênseis merecem destaque e se tornam uma opção bastante atrativa.

Embora seja crescente o uso de tais estruturas pelo mundo, no Brasil ainda elas são quase desconhecidas. Assim, a experiência de projetistas e pesquisadores estrangeiros está longe de ser alcançada e até mesmo a aquisição de material de pesquisa é um tanto complicada.

Esta dissertação buscou reunir parte do conhecimento existente sobre o assunto, tanto do ponto de vista estrutural quanto do construtivo, e fornecer subsídios para projeto, pelo menos a nível de pré-dimensionamento. De qualquer forma, tem-se consciência de que ainda é longo o caminho a ser percorrido.

\subsection{DISCUSSÃO SOBRE O COMPORTAMENTO ESTRUTURAL}

No capítulo 3, foram deduzidas equações para o cálculo de momentos fletores e deslocamentos ao longo da estrutura sob certas condições particulares. É preciso, nesse momento, fazer algumas considerações.

Primeiramente, os apoios da estrutura foram considerados nivelados. Como em geral, para passarelas, as inclinações devem ser pequenas, quase sempre os apoios estarão nivelados ou bastante próximo disso. No entanto, em pontes de correia transportadora ou pontes de tubulação desníveis acentuados podem ocorrer.

Ao se estudar os efeitos da protensão, admitiu-se que os blocos de fundação são indeslocáveis. Assim, o único efeito da protensão são forças distribuídas verticais. Em um projeto real, o movimento horizontal dos apoios, que depende das características do 
subsolo e do tipo de fundações adotado, introduz novas ações na estrutura e precisa ser melhor estudado.

Outra questão que merece destaque, é a impossibilidade de variação de área e inércia da seção transversal ao longo do vão. Dessa forma, a prática habitual de promover um engrossamento gradual na região próxima aos apoios não pode ser levada em consideração na obtenção dos esforços.

Quanto aos carregamentos impostos, diversas situações não foram contempladas, entre elas, cargas concentradas, cargas parcialmente distribuídas e a ação lateral do vento. Também não foi analisado o efeito de carregamento em apenas uma metade do tabuleiro ( $\mathrm{v}$. figura 101), causando torção na estrutura.

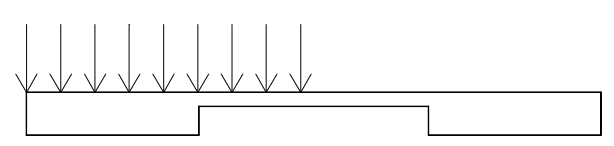

Figura 101 - Seção transversal submetida a carregamento assimétrico.

Por fim, vale lembrar que a força de protensão foi suposta constante, desprezandose a ocorrência de atrito (inclusive dentro dos blocos de fundação), foi desprezada a relaxação do aço e a retração do concreto.

\subsection{ASPECTOS A SEREM FUTURAMENTE ESTUDADOS}

São inúmeros os assuntos ligados às passarelas pênseis que merecem futuras pesquisas.

Inicialmente, podem ser citadas as variações do sistema estrutural, que aumentam sensivelmente o campo de aplicações das passarelas pênseis. Em casos de grandes vãos, quando a construção de pilares intermediários é descartada devido a razões arquitetônicas, construtivas ou de elevado custo, as estruturas suportadas por cabos adicionais aparecem como uma opção atraente. As estruturas suportadas por um arco são indicadas quando o subsolo não apresenta condições favoráveis para a ancoragem de elevadas forças horizontais, ou ainda, quando se requer inclinações muito pequenas. Ambas essas variações possuem características peculiares, tanto em termos de comportamento estrutural quanto de métodos de execução.

O uso de elementos de aço ou madeira e ainda a utilização de elementos prémoldados de seção parcial para formar o tabuleiro podem ser possibilidades interessantes de acordo com os requisitos do projeto. $O$ tabuleiro formado completamente com concreto moldado no local, apesar de aumentar o tempo de execução, também não pode ser esquecido.

A investigação do comportamento dinâmico é outro aspecto que necessita de 
atenção especial e que por se tratar de um assunto bastante complicado foi apenas brevemente comentado. Os vários casos de vibração excessiva e até de ruína em diversas estruturas servem de alerta para a seriedade do problema. Ensaios de modelos em túneis de vento, além de estudo teórico, são indispensáveis. Após a construção da passarela, ainda é recomendável testes "in loco", a fim de comprovar parâmetros utilizados em projeto. Atualmente, é sobre a análise dinâmica que se concentra a grande maioria dos estudos internacionais a respeito do sistema "stress-ribbon".

Outra questão a ser explorada são as estruturas contínuas, cuja vantagem é o valor da força horizontal correspondente apenas à do maior vão. Portanto, a economia nas fundações melhora a viabilidade econômica das passarelas pênseis.

Uma sugestão interessante é a elaboração de um programa pelo métodos dos elementos finitos, permitindo assim uma maior abrangência no que diz respeito à geometria e a carregamentos.

Finalmente, os aspectos construtivos precisam ser mais detalhados: fôrmas, detalhes de armação, o traçado dos cabos dentro dos blocos de fundação, içamento dos elementos pré-moldados, ligação dos elementos aos cabos de sustentação e posterior deslizamento até sua posição do projeto, etc. Entretanto, tais questões dependem significativamente da experiência e assim só poderão ser completamente esclarecidas se um dia vier a ser construída alguma estrutura desse tipo no Brasil.

\subsection{CONCLUSÃO DO TRABALHO}

O objetivo principal desta dissertação era a introdução do sistema estrutural de passarelas pênseis na comunidade científica brasileira, assim como no meio profissional, e também de fornecer algumas indicações ou subsídios para seu projeto. Dentro das possibilidades, espera-se que essa proposta tenha sido alcançada.

Para que se pudesse afirmar muitas conclusões, sem dúvida seria necessário o cálculo de um maior número de exemplos e a elaboração de comparações. De qualquer forma, algumas lições podem ser tiradas.

No que se refere ao comportamento estrutural, as regiões próximas aos apoios são aquelas que merecem maior atenção por parte do projetista. $O$ uso de selas ou engastamento nos blocos de fundação são alternativas a se definir caso a caso. Atualmente, nota-se uma tendência para o uso do engastamento.

Outra consideração de projeto é quanto ao grau de compressão que se deve deixar no meio do vão sob a pior combinação de ações a tempo infinito, ligado diretamente ao valor da força de protensão a ser adotada. Pode-se utilizar, para essa região, protensão completa ou mesmo protensão limitada, com as respectivas combinações de ações. Na região dos apoios, adota-se protensão parcial, limitando-se a abertura de fissuras.

Quanto à escolha da flecha, ficou claro no exemplo do capítulo anterior que uma 
relação flecha/vão muito pequena pode se tornar inviável. Relações flecha/vão inicial da ordem 1/40 são valores que conciliam o conforto dos pedestres e eficácia estrutural, haja visto que com o desenvolvimento da fluência do concreto a estrutura se torna mais abatida. O uso de relações flecha/vão inferiores a $1 / 50$ implica em uma força de protensão muito elevada, tornando a estrutura mais onerosa e menos eficiente.

Por todas as características apresentadas, espera-se que as passarelas pênseis formadas por elementos pré-moldados de concreto, juntamente com outras estruturas compostas por cabos, alcance um situação de maior destaque. 


\section{Referências bibliográficas}

ARAI, H.; OTA, Y. (1997). Kikko Bridge: Un Ponte Pedonale Tridirezionale in C.A.P. L'Industria Italiana del Cemento, v.67, n.3, p.259-261.

ASSOCIAÇÃO BRASILEIRA DE NORMAS TÉCNICAS (1984). NBR 7188 - Carga móvel em ponte rodoviária e passarela de pedestre. Rio de Janeiro.

ASSOCIAÇÃO BRASILEIRA DE NORMAS TÉCNICAS (1984). NBR 8681 - Ações e segurança nas estruturas. Rio de Janeiro.

ASSOCIAÇÃO BRASILEIRA DE NORMAS TÉCNICAS (2000). Projeto de Revisão da NBR 6118.

BARBATO, R.L.A. (1975). Contribuição ao estudo das coberturas pênseis em casca protendida de revolução. São Carlos. 143p. Tese (Doutorado) - Escola de Engenharia de São Carlos, Universidade de São Paulo.

BARBATO, R.L.A. (1991). Introdução ao cálculo de coberturas pênseis. São Carlos, Departamento de Engenharia de Estruturas, EESC-USP. (Notas de aula).

BUTLER, A.A.W. (1974). A Viaduct for the Environment. Concrete, p.34-35, sep.

BUTLER, A.A.W. (1977). Stressed Ribbon Footbridge in the Peak District. The Highway Engineer, v.24, n.3, p.12-15, mar.

COMITE EURO-INTERNATIONAL DU BETON (1990). Bulletin D'Information. Lausanne, n. 203.

DAWE, D.J. (1971). A finite-deflection analysis of shallow arches by the discrete element method. International Journal for Numerical Methods in Engineering, v.3, p.529-552.

DEL ARCO, D.C. (2001a). La banda tesa de hormigón pretensado. Personal e-mail.

DEL ARCO, D.C. (2001b). La banda tesa de hormigón pretensado. Personal e-mail.

DEL ARCO, D.C.; BENGOECHEA, A.C.A. (1994). Analytical and Numerical Static Analysis of Stress Ribbon Bridges. In: Procedings of the Centenary Year Bridge Conference, 
Cardiff, U.K., 26-30 sep.

DEL ARCO, D.C.; BENGOECHEA, A.C.A. (1996a). La banda tesa de hormigón pretensado. Un esquema estructural para pasarelas. Hormigón y Acero, n.201, p.43-62.

DEL ARCO, D.C.; BENGOECHEA, A.C.A. (1996b). Una aproximación al estudio de los puentes colgantes. Hormigón y Acero, n.199, p.9-35.

DETAIL (1999a). Bridges in Himalaia. Serie 1999 - 8, dec.

DETAIL (1999b). Bercy-Tolbiac Pedestrian Bridge, Paris. Serie 1999 - 8, p. 1445, dec.

EL DEBS, M.K. (2000). Concreto Pré-Moldado: fundamentos e aplicações. São Carlos, Projeto Reenge.

ELSGOLTZ, L. (1969). Ecuaciones diferenciales y cálculo variacional. Moscu, Editorial Mir.

FINSTERWALDER, U. (1965a). Pretressed Concrete Bridge Construction. Journal of the American Concrete Institute, p.1037-1046, sep.

KADLCAK, J. (1995). Statics of suspension cable roofs. Rotterdam/Brookfield, A. A. Balkema.

KETCHUM, M.A.; DROUILLARD, F.; SCHELD, J. (1999). Pipeline Bridge across the Arroyo Cangrejillo, Argentina. Structural Engineering International, p.6-8.

MATSUSHITA, H.; SATO, M. (1979). The Hayahi-No-Mine Pretressed Bridge. PCl JOURNAL, v.24, n.2, p.91-109, mar,apr.

PFEIL, W. (1980). Concreto Protendido. Rio de Janeiro, Livros técnicos e científicos.

PIRNER, M.; FISCHER, O. (1998). Wind-induced vibrations of concrete stress-ribbon footbridges. Journal of Wind Engineering and Industrial Aerodynamics, v.74-6, p.871881 , apr., aug.

PUGSLEY, A. (1968). The Theory of Suspension Bridges. 2.ed. London, Edward Arnold Ltd.

REDFIELD, C.; KOMPFNER, T.; STRASKY, J. (1992). Stressed Ribbon Pedestrian Bridge Across the Sacramento River in Redding, California, USA. L'Industria Italiana del 
Cemento, v.62, n.2, p.82-99.

STEINMAN, D. B. (1929). A practical treatise on suspension bridges. John Wiley and Sons.

STRASKY, J. (1987). Precast Stress-Ribbon Pedestrian Bridges in Czechoslovakia. PCl JOURNAL, v.32, n.3, p.52-73, may, june.

STRASKY, J. (1990). Precast Stress Ribbon Pedestrian Bridges. In: Esthetics in concrete bridge design. ACI Symposium.

STRASKY, J. (1997). Design-construction of Vranov lake pedestrian bridge, Czech Republic. PCI JOURNAL, v.42, n.6, p.60-75, nov., dec.

STRASKY, J. (1999). Stress-Ribbon Pedestrian Bridges. In: International Bridge Conference, Pittsburgh.

STRASKY, J.; PIRNER, M. (1986). DS-L Stress-Ribbon Footbridges. Dopravni stavby, Brno, Czechoslovakia.

STRASKY, J.; HUSTY, I. (1998). The pedestrian bridge suspended over Vranov Lake, in the Czech Republic. L'Industria Italiana del Cemento, v.68, n.10, p.758-775.

TANG, M.C. (1976). Stress Ribbon Bridge in Freiburg, Germany Features Prestressed. Civil Engineering, ASCE, v.46, n.5, p.75-76.

TECHNIQUES ET ARCHITECTURE (1999). La passerelle Bercy-Tolbiac, Paris. n. 445, p.34-35, oct, nov.

TILLY, G.P.; CULLINGTON, D.W.; EYRE, R. (1984). Dynamic Behaviour of Footbridges. IABSE Surveys, S-26, p.13-24.

WALTHER, R. (1971) Stressed Ribbon Bridges. International Civil Engineering Monthly, v.II, n.1, p.1-7.

WHEELER, J.E. (1982). Prediction and Control of Pedestrian-Induced Vibration in Footbridges. Journal of the Structural Division, ASCE, p.2045-2065, sep.

WHEEN, R.J.; WILSON, A.J. (1977). The stress-ribbon bridge concept in steel. The Structural Engineer, v.55, n.5, p.223-229, may. 
WITTFOHT, H. (1975). Puentes Ejemplos Internacionales. Barcelona, Ed. Gustavo Gili.

YOSHIMURA, T.; MIZUTA, Y.; SAVAGE, M.G.; LIU, G. (1997). Half-circular and half-elliptic edge modifications for increasing aerodynamic stability of stress-ribbon pedestrian bridges. Journal of Wind Engineering and Industrial Aerodynamics, v.71, p.861-870, jul., oct. 


\section{Bibliografia complementar}

ABRIL SIERRA, G. (2000). Proyecto de una pasarela en banda tensa de hormigón pretensado. Tesina-UPC. Escola Tècnica Superior d'Enginyers de Camins, Canals i Ports de Barcelona.

ASSOCIAÇÃO BRASILEIRA DE NORMAS TÉCNICAS (1982). NBR 6118 - Projeto e execução de obras de concreto armado. Rio de Janeiro.

ASSOCIAÇÃO BRASILEIRA DE NORMAS TÉCNICAS (1985). NBR 9062 - Projeto e execução de estruturas de concreto pré-moldado. Rio de Janeiro.

ASSOCIAÇÃO BRASILEIRA DE NORMAS TÉCNICAS (1987). NBR 7187 - Projeto e execução de pontes de concreto armado e protendido. Rio de Janeiro.

BARBATO, R.L.A. (1972). Sobre o comportamento estático dos cabos de coberturas pênseis. São Carlos. 87p. Dissertação (Mestrado) - Escola de Engenharia de São Carlos, Universidade de São Paulo.

CONZETT, J. (2000). Punt da Suransuns Pedestrian Bridge, Switzerland. Structural Engineering International, v.10, n.2.

DETAIL (1999c). Transversina Footbridge, Viamala Switzerland. Serie 1999 - 8, p. 14831486, dec.

FERNANDEZ CASADO, C. (1965). Puentes de hormigon armado pretensado. Madri, Editorial Dossat. Vol.2, Cap.7, p.701-717, p.774-777: Arcos y tramos colgados.

FINSTERWALDER, U. (1965b). Modern Designs for Prestressed Concrete Bridges. Concrete and Constructional Engineering, v.60, n.3, p.99-104, mar.

GALLEGOS, H. Los puentes colgantes en el Perú precolombino. El Ingeniero Civil.

HAYWARD, A.C.G. (1977). Stressed Ribbon Footbridge /Letter/. Highway Engineer, v.24, n.5, p.8-8.

HIGHWAY INNOVATIVE TECHNOLOGY EVALUATION CENTER (1996). Evaluation findings: The segmental concrete channel bridge system. 
IRVINE, H.M. (1981). Cable structures. Cambridge, Ma./London, The MIT Press.

KOLLBRUNNER, C.F.; HAJDIN, N.; STIPANIC, B. (1980). Contribution to the Analysis of Cable-Stayed Bridges. Institute for Engineering Research. Verlag Schulthess AG, Zurich.

KOLOUSEK, V.; PIRNER, M.; FISCHER, O.; NAPRSTEK, J. (1983). Wind Effects on Civil Engineering Structures. Academia Elsevier.

KULHAVY, T. (1998). Stress ribbon bridges stiffened by arches or cables. $2^{\text {nd }}$ International Ph.D. Symposium in Civil Engineering, Budapest, Hungary, aug. 26-28.

LIN, T.Y.; KULKA, F. (1973). Construction of Rio Colorado Bridge. PCI JOURNAL, v., n.6, p.92-101, nov, dec.

MATSUMOTO, Y.; NISHIOKA, T.; SHIOJIRI, H.; MATSZUZAKY, K. (1978). Dynamic design of footbridges. IABSE Proceedings $\mathrm{P}-17 / 78$.

OTTO, F. (1967). Tensile Structures. v.2. Cambridge, The M.I.T. Press.

PIRNER, M.; FISCHER, O. (1997). Dynamics and Aerodynamics of Stress-Ribbon Footbridges. International EXPERTCENTRUM Conference on Concrete Bridges, Bratislava.

PIRNER, M.; FISCHER, O. (1998). Influence of Torsional Rigidity on Aeroelastic Stability of Stress-Ribbon Footbridges. In: $2^{\text {nd }}$ East European Conference on Wind Engineering, Praha.

PIRNER, M.; FISCHER, O. (1999). Experimental analysis of aerodynamic stability of stressribbon footbridges. Wind and structures, v.2, n.2, p.95-104.

QUEIROZ, S. F. (1993). Estudo do comportamento estático do cabo livremente suspenso em cobertura pênsil. São Carlos. 76p. Dissertação (Mestrado) - Escola de Engenharia de São Carlos, Universidade de São Paulo.

SCATAZZINI, P. (1971). Vibration Tests on the Bircherweid Foot-Bridge. International Civil Engineering Monthly, v.II, n.4, p.189-192.

SCHLAICH, J.; ENGELSMANN, S. (1996). Stress Ribbon Concrete Bridges. Structural 
Engineering International, v.6, n.4, p.271-274.

STRASKY, J. (1987). The stress ribbon bridge across the river Vltava in Prague. L'industria italiana del cemento, n.615.

STRASKY, J.; RAYOR, G. (1998). Positively not pedestrian. Civil Engineering, ASCE, v.68, n.3, p.68-69.

WHEEN, R.J. (1976). Steel Stress Ribbon Concept - Will It Save Money?. Civil Engineering, ASCE, v.46, n.5, p.74-75.

YOSHIMURA, T. (2001). Static and Aerodynamic Characteristics of Proposed Hybrid StressRibbon Bridges. IABSE Conference, Seoul, Korea, jun. 12-14.

YOSHIMURA, T.; MIZUTA, Y.; KANG, W.; JO, H.; OKADO, M.; MIYAKE, A. (1998). Steel and Hybrid Stress-Ribbon Pedestrian Bridges. IABSE Symposium, Kobe, Japan, sep. 24. 